\title{
Cross-Cultural Product Design
}

\author{
by
}

Chen Zhang

A thesis submitted to the Faculty of Graduate and Postdoctoral Affairs in partial fulfillment of the requirements for the degree of

Master of Design

in

Industrial Design

Carleton University

Ottawa, Ontario

(C) 2019

Chen Zhang 


\begin{abstract}
The research talks about cross-cultural product design which combines cultural tradition and user's behavior and perception. It provides an example of a tea product design, demonstrating the process of how to include Chinese's tea culture and perception about tea drinking from people who live in North America in a cross-cultural product. To understand what are Chinese cultural elements and the users' perceptions about tea, this study first investigated current Chinese cultural products and conducted 100 interviews about drinking tea. In conclusion, Chinese cultural elements mainly used in current cultural products are pattern, form, material, function, historical or literal figures in cute mascot, story/anecdote, and metaphor. The participants mostly regarded drinking tea as a relaxation, social activity, and keeping health. Some of them also related tea with ceremonial, cultural tradition, emotional attachment and atmosphere. In addition, convenience of making tea is a consideration as well. The final tea set design considered the Chinese cultural elements including pattern, form and material and the users' conceptions of relaxation, social relationship, cultural tradition, ceremonial and convenience. This study suggested a method of designing a cross-cultural product, which consists of two main parts. One is to investigate the traditional design elements of one's culture and the other is to learn the users' perceptions. The final design will take both considerations into account.
\end{abstract}

Keywords: cross-cultural design, tea product, Chinses and Canadian. 


\section{Acknowledgments}

I would first like to thank my thesis advisor professor WonJoon Chung of the School of Industrial Design at Carleton University. He consistently allowed this paper to be my work but steered me in the right the direction whenever he thought I needed it.

I would also like to thank all the interviewees who were involved in the interviews for this research project.

I would also like to acknowledge Professor Birgit Hopfener of the Art History department at Carleton University as the second advisor of this thesis, and I am gratefully indebted to her for her very valuable comments on this thesis.

Finally, I must express my very profound gratitude to my parents for providing me with unfailing support and continuous encouragement throughout my years of study and through the process of researching and writing this thesis. This accomplishment would not have been possible without them. Thank you. 


\section{Table of Contents}

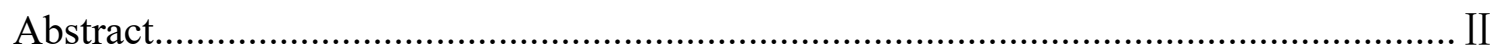

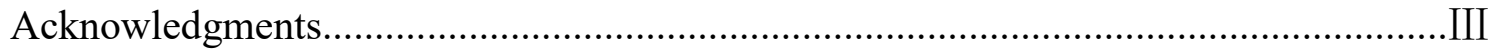

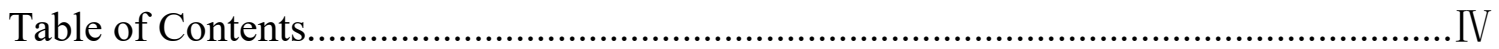

List of Tables

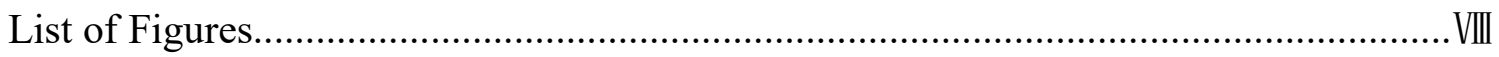

List of Appendices........................................................................................... XI

\section{CHAPTER}

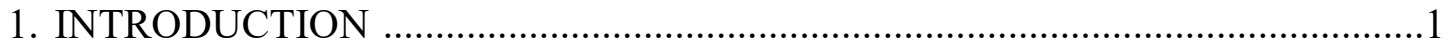

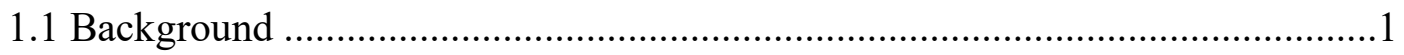

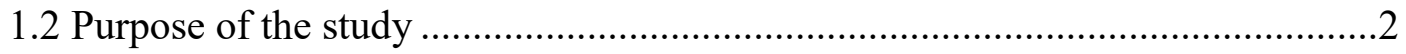

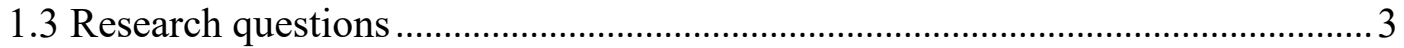

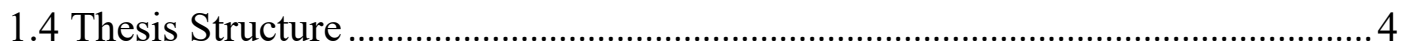

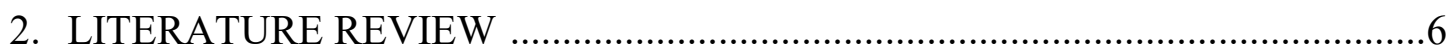

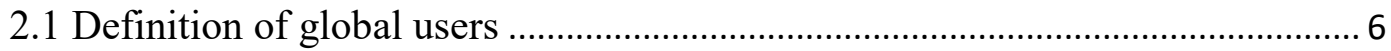

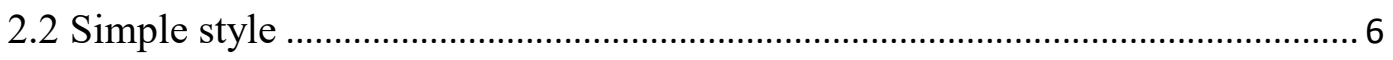

2.3 Cross-cultural design vs. cultural design ........................................................ 7

2.3.1 What is a cross-cultural design? ...................................................... 7

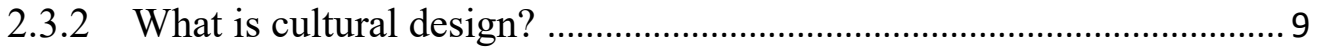


2.3.3 How culture influences human-product interaction and user

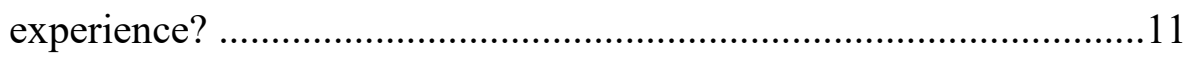

2.3.4 Culture and Emotion----Nostalgia ……………...............................12

2.3.5 Chinese culture in North America and Tea drinking ..........................13

2.3.6 Tea consumption in North America.....................................................16

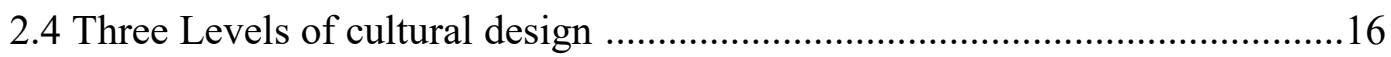

2.4.1 Outer level: Unique style ……………………………………………... 17

2.4.2 Middle level: Different functions ...................................................... 19

2.4.3 Inner level: emotions----nostalgia ....................................................20

2.5 Various Tea Cultures in different countries ...............................................23

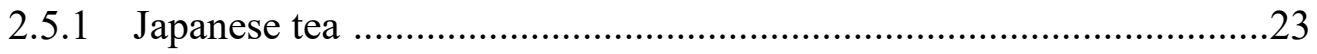

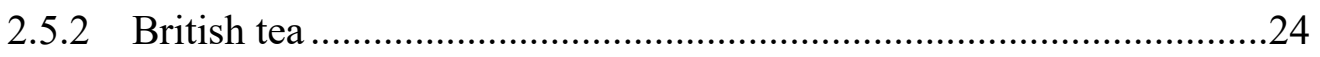

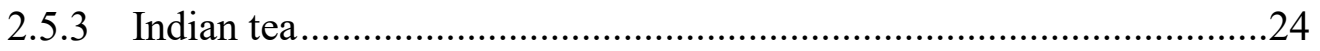

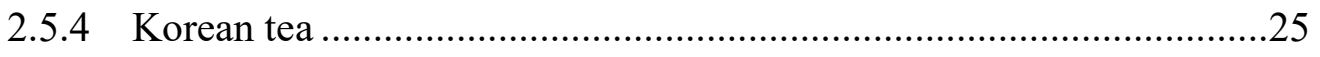

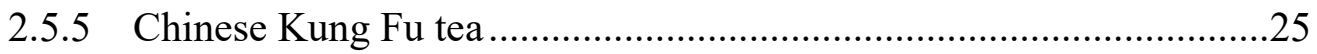

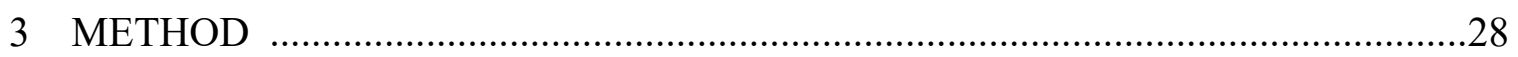

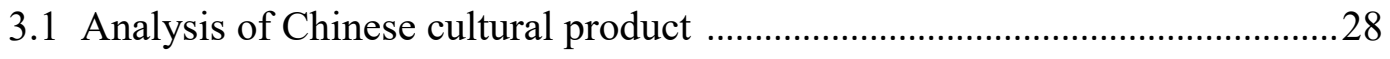

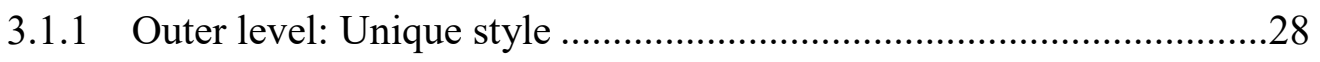

3.1.2 Mid-level: Functions based on different lifestyle ................................38

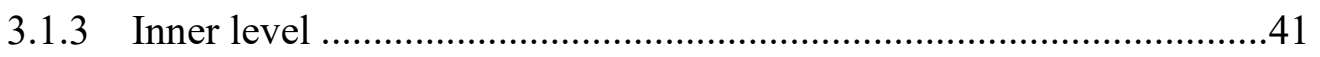

3.2 Understand User's (i.e. tea drinkers) perception ..........................................49

3.2.1 Semi-structured Interviews Sampling ……………...........................50

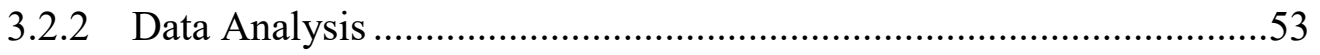


3.3 Design of cross-cultural tea set

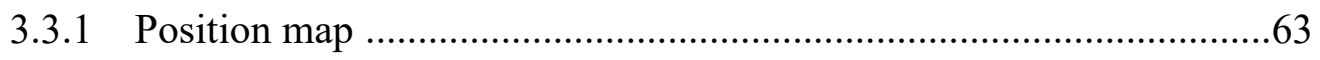

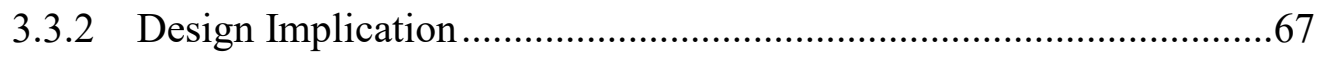

3.4 How does the tea set appeal to global market as a cross-cultural product? ......72

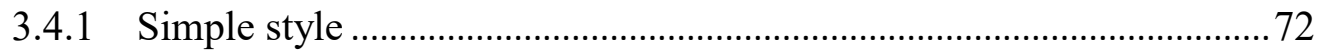

3.4.2 Traditional elements ...........................................................................

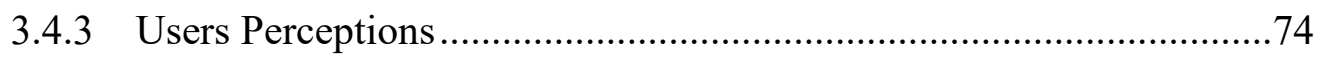

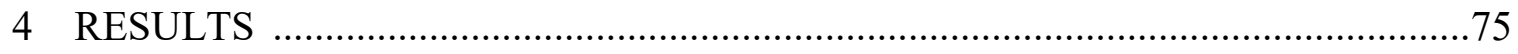

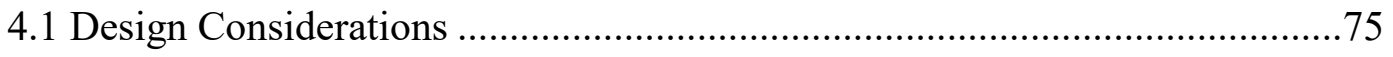

5 CONCLUSION

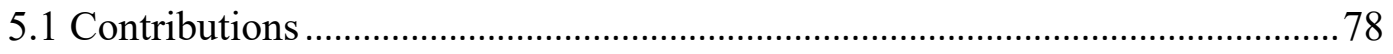

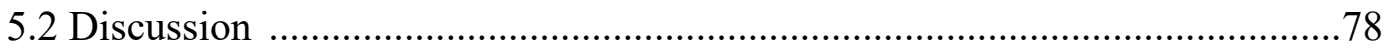

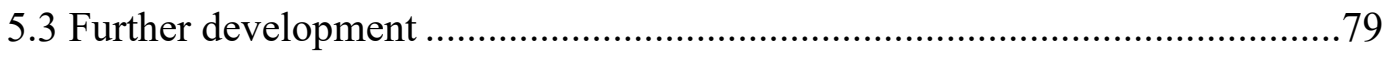

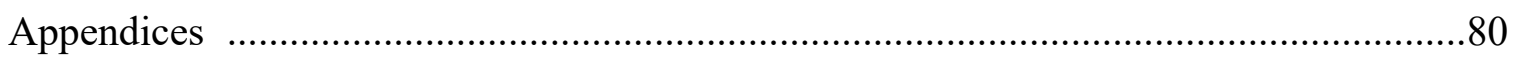

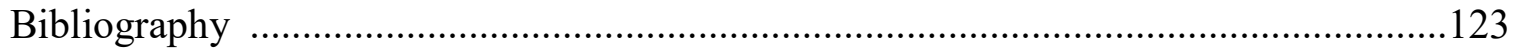




\section{List of Tables}

Table

Pages

1 Table 1 The Chinese population in the Canadian regions ..................................13

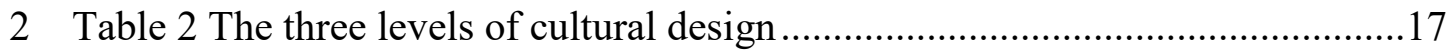

3 Table 3 Summary of current cross-cultural products.........................................22

4 Table 4 Summary of tea ceremonial aspects in different tea cultures ..................27

5 Table 5 Different Vocations of Interviewees....................................................... 51

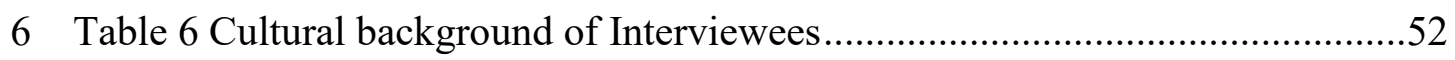

7 Table 7 Code list: Themes of drinking tea ....................................................62 
Cultural Product Design

\section{List of Figures}

Figure

Pages

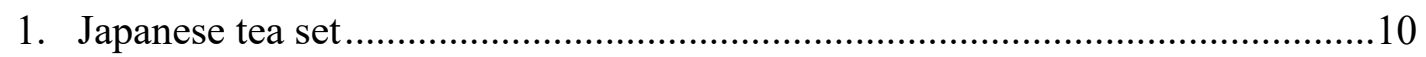

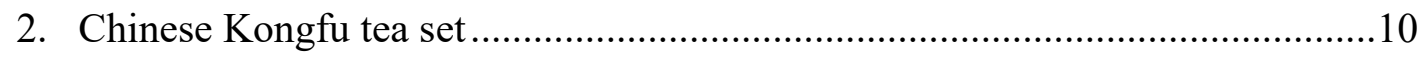

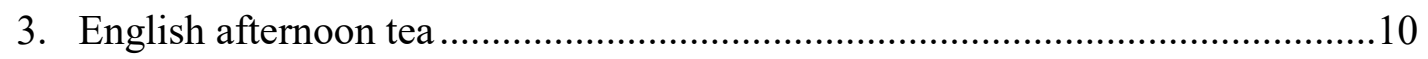

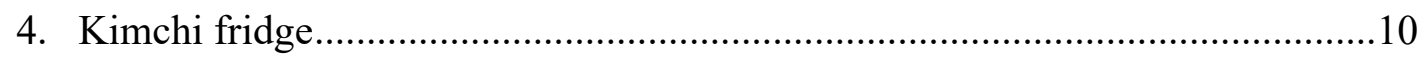

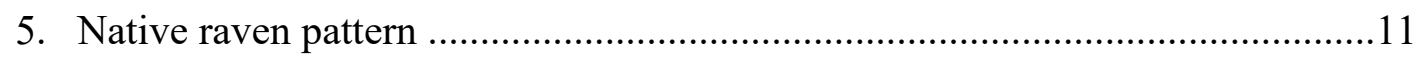

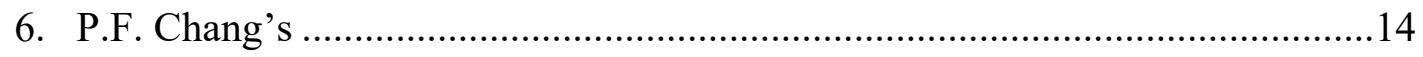

7. Starbucks design in different cultural environments .....................................19

8. Muslim Pro, Developed By Muslim Pro Limited ...........................................20

9. The Chinese restaurant----Charm of Anhui....................................................21

10. Black tiles and white walls in He yang ancient village ................................21

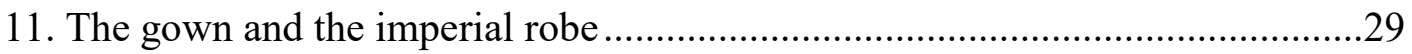

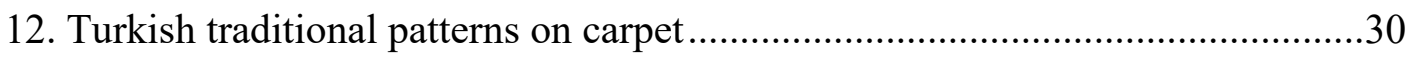

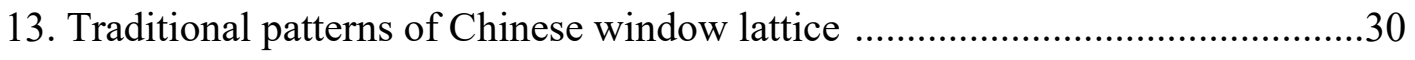

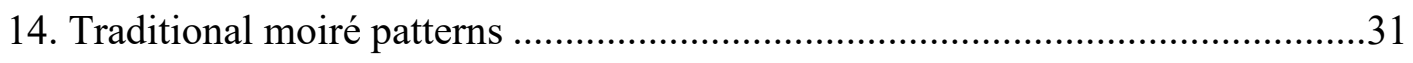

15. Blue and White porcelain, Qing Dynasty, from Nanjing Museum ..................33

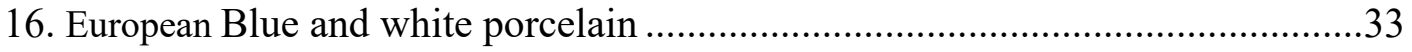

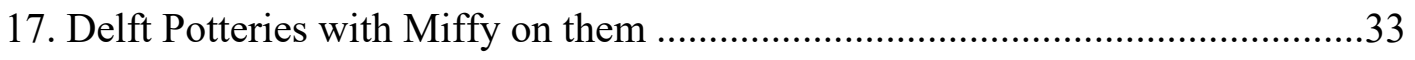

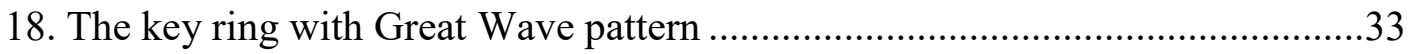

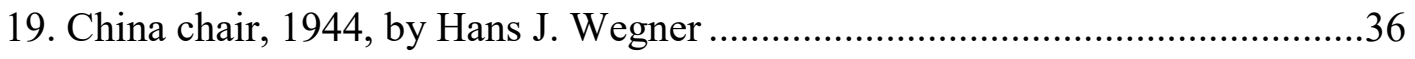

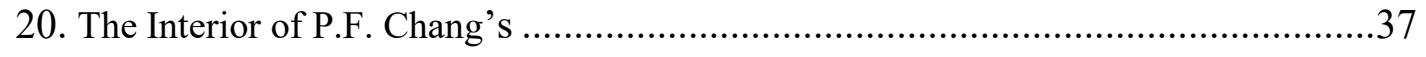

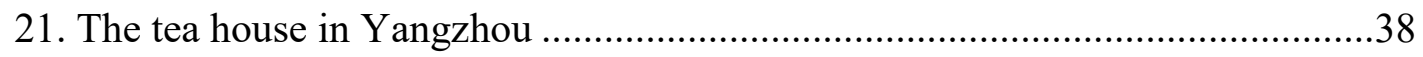




\section{Cultural Product Design}

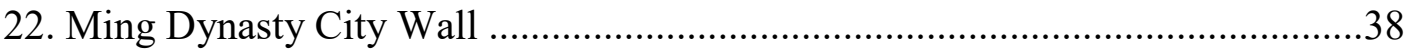

23. “Ding” Steamer, by Office for Product Design ..............................................39

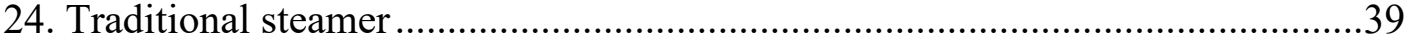

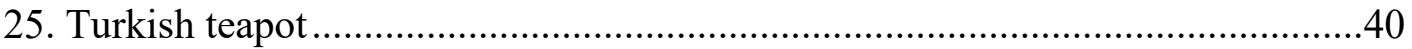

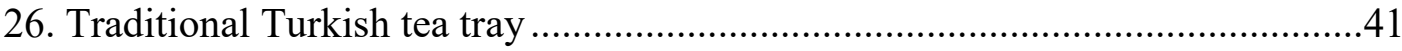

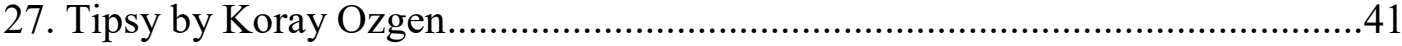

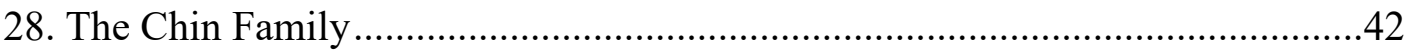

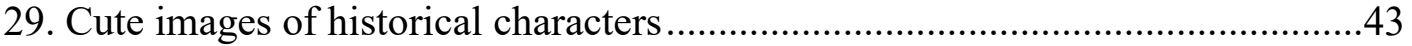

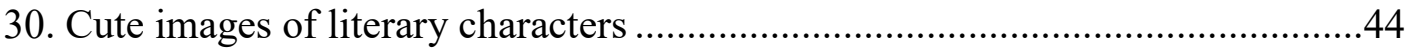

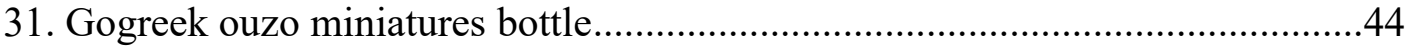

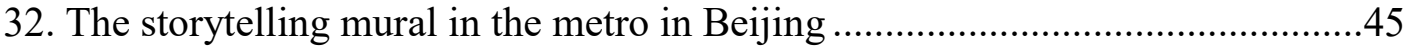

33. Traditional patterns on the Dun Huang Murals .............................................45

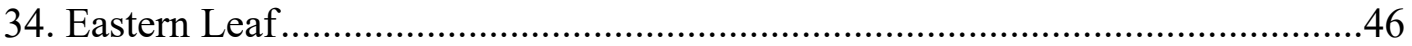

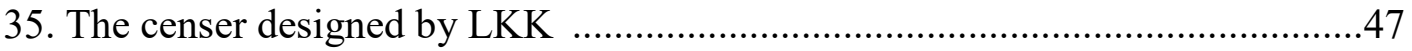

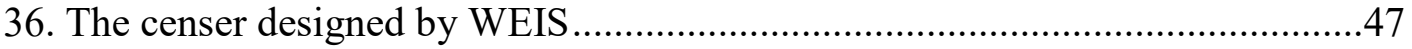

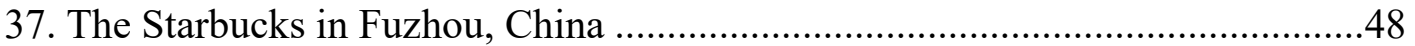

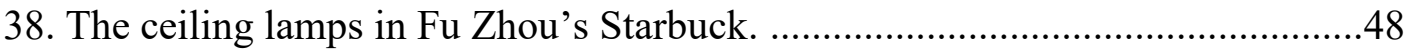

39. Geographical Distribution of the interviewees ..........................................48

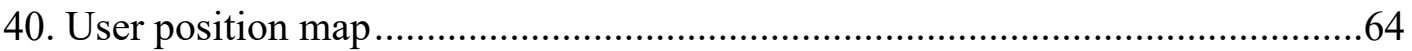

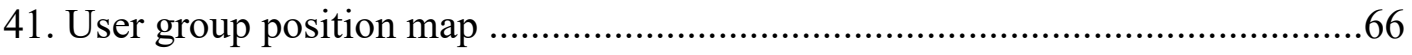

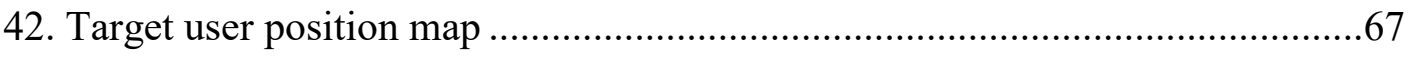

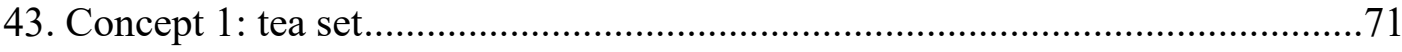

44. The complete process of tea making ceremony ...........................................72 


\section{Cultural Product Design}

45. The cultural elements used in the design concept .........................................73

46. Two considerations in a cross-cultural product design ...................................77 
Cultural Product Design

\section{List of Appendices}

\section{Appendix Name}

Table 3 Summary of current cross-cultural products.......................................................8

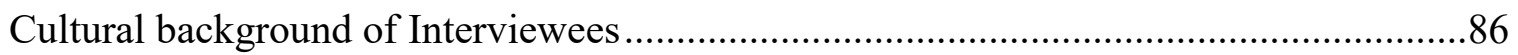

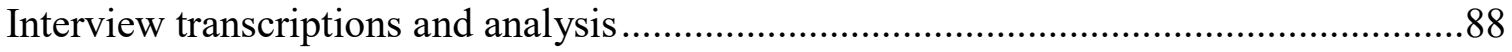




\section{Chapter 1. Introduction}

\subsection{Background}

A culture-oriented design is associated with the footprint of a particular social context including social norm, history, values, conventions and even languages (Kesebir \& Kesebir, 2017). To develop a culturally accepted product in the competitive global market, industrial designers often employ culture as an important consideration in their design process. Due to the rapid development of information technology in telecommunications, and ease of transportation, it has become a salient phenomenon that people are globally connected and easily interact with each other (Lieber \& Weisberg, 2002) which has also led to a cross-pollination of product in a global market (Perner, 2009). Currently, some products from one country are being sold in other countries around the world and designers developing the product for a global market need to consider multiple cultural aspects for the diverse customers. Based on this phenomenon, a research question has been raised in this study, "how to design a cross-cultural product for a global users?"

Globalization often caused standardization among many products, and it left nearly no place for cultural diversity. Don Norman discussed this notion in his article saying:

"Once upon a time, when I visited other countries, I would head to the department stores so I could experience the wide cultural variations in such things as cookware, cutlery, and tools for crafts and gardening. Today, I seldom do this anymore because all the stores look the same. Rice cookers and woks may have originated in Japan and China, but today they can be found in kitchen appliance stores all over the world." (Norman, D. A., 2012)

As globalization is developing actively, some local cultural features are often disappearing gradually to some extent (Chang \& Tung, 2013). However, beyond the 
functional appropriateness, there are some reasons why people pursuing a personal identity and individuality turn to the uniqueness in local cultures (Lucan, 2006).

First of all, they believe culture is a way for people to create a distinctive identity for themselves, starting from childhood (Lucan, 2006). Choe (2003, p. 670) notes that "culture is the collective programming of the mind that distinguishes the members of one group or category of people from another." That is to say, every community has their unique culture that influences their ways of thinking, beliefs, behaviors, and aesthetics. The second reason is that culture contributes to define personal identity in terms of collective values, behaviors, history, which are derived from his or her social and cultural background (Tajfel, 1978; Ashmore, Deaux, \& McLaughlin-Volpe, 2004). Thus, many of those who pursue their personal identity often utilize the uniqueness in local cultures. Sometimes, however, it becomes a dilemma when people wish to keep their local features, and they also want to be part of the global world as well (Celikoglu, O. M., 2010). In this respect, it is strongly required for designers to harmonize the taste of local culture and that of global context to keep both tastes at the same time (Celikoglu, O. M., 2010).

\subsection{Purpose of the study}

Based on the notion discussed above, the main objective of this study is to develop a way to design a cross-cultural product design that satisfies the local as well as global users' tastes. Particularly, this thesis attempts to investigate the combination between Chinese culture and various users' perceptions as a way to design a cross-cultural product, a tea set design as an example. Even though many designers are aware that culture is an important notion which plays a critical role for global market success, only a few have 
discussed how designers blend cultural aspects with one's perception of an object or behavior when develop a cross-cultural product. For this matter, this study investigates some key cultural design elements by analyzing some current Chinese cultural designs. Then, it identifies people's understanding and perceptions of tea drinking behavior in different cultures through in-depth interviews. Finally, the design of a tea set is proposed as an example to demonstrate how a culture is blended with user's perceptions.

\subsection{Research questions}

Based on the notions of combining two different cultural aspects, this study asks the following questions:

\section{Question 1 What are the cultural design elements used in current Chinese cultural products?}

\section{Question 2 How do designers blend cultural design elements with users' perceptions to design a cross-cultural product?}

For the first question, since many Chinese cultural products found on current markets are mainly counterfeits of some traditional forms or patterns, it is likely to find out what cultural elements are popularly used in current cultural products. Regarding the notion of user-centered design, the second question is asked to identify a way of integrating the cultural elements and user's understandings of a particular culture, tea culture, in a tea set design. 
Cultural Product Design

\subsection{Thesis Structure}

This thesis consists of five chapters. Firstly, the research will be introduced by discussing cultural products and cross-cultural products; the importance of cultural influence on cross-cultural products; explaining the purpose of the study followed by the research questions, then indicating the value that this thesis will have for cultural product design.

Secondly, the literature review defines cultural products and cross-cultural products. Besides, cultural aspects of tea from different countries will also be investigated.

Thirdly, the method chapter is broken down into two main parts. In the first section the cultural elements and characteristics are investigated through collecting and sorting a lot of existing cultural products in the markets. The second part demonstrates the data collecting procedure. Here, the methods utilized to conduct the primary research are explained. It discussed the setting in which the study took place; the participant profile that participated in the interviews; the questionnaire that was prepared to conduct the interviews; and the procedures followed for collecting and analyzing the data. Then, the qualitative findings which are about people's understanding of their tea drinking culture from the data analysis are presented. Also, the major themes and patterns that had emerged from interviews would be described. These results would be discussed how the findings and cultural design elements are applied to the final tea set design.

In the results section, the research questions are reviewed and answered clearly. It suggested a way to design a cross-cultural product which has two main steps. First one is to look into what are the cultural elements, and then the users' perceptions would be 
investigated. Finally, the design concept will demonstrate combining the cultural elements and the considerations of users' concepts.

Lastly, the conclusion chapter is where the key findings from the research are clearly defined, and the major contributions to the field of cultural product design are discussed. This chapter also includes a discussion revolving around the limitations of this study and suggestions for future research initiatives. These suggestions will allow researchers to improve the methodology and to deepen the understanding of how cultural products may satisfy users with a range of cultural characteristics based on different situations. 


\section{Chapter 2. Literature Review}

\subsection{Definition of global users}

Global users are consumers from all over the world. In the article "How Does Cultural Diversity in Global Innovation Teams Affect the Innovation Process?’ Winkler A. and Bouncken B. (2011) note that global teams consist of people from diverse nations and cultural backgrounds who usually work at dispersed locations (cited in Harvey and Grifth, 2007). Referring to this notion, global users can be defined as those from different countries and cultural backgrounds where they were born or live for a long time.

A product for global users should meet their general needs and special situations which are influenced by their culture at the same time. For example, a mobile phone's hardware and technology appeal to all users in all over the world, but the languages and icons on the interface of a cellphone in different countries are different (Schumacher, R., 2009). In other words, a product designed for global users should introduce certain differences and derive a range of choices for different needs.

\subsection{Simple style}

From the historical perspective, modern design is the result of acceleration in the division of labor and the introduction of mechanized production during the nineteenth century. This emerging style was developed into an international style that embodied "form follows function" (Raizman, D., 2003). To adapt to mass manufacturing, this style was concerned as plain and functional (Dormer, P., 1990). In addition, as the development of material technology, the emergency of new materials also brought new 
styles such as user-friendliness, lightness, sense of safety, and narrative content (Dormer, P., 1990).

In this study, the design refers to the simple style which means plain and simple shapes such as geometric shapes without unnecessary decoration. In addition, in terms of materials and colors, they would be used as simple as possible.

\subsection{Cross-cultural design vs. cultural design}

\subsubsection{What is a cross-cultural design?}

Culture is a way of life shared by a group of people (Swidler, 1986). Since people from different cultural backgrounds have different ways of living, cultural products should have the corresponding unique functions for the particular group of people and reflect their unique cultural behaviors (Kesebir and Kesebir, 2017, p.259).

Although some electronic products such as computers and cell phones have relatively little cultural influence, for some other products, culture plays a critical role that links with traditions and social norms, helping to create a new market. In the article "The Washing Machine That Ate My Sari-Mistakes in Cross-Cultural Design” (Chavan et al., 2009), the author discusses how some products failed in other international markets due to the neglect of the different cultural requirements. The Whirlpool Corporation, for example, designed a single, stripped-down washing machine in Brazil, Mexico, China, and India, with slight modifications for each market to appeal to local tastes. In India, "Delicate" was relabeled "Sari Cycle" on the Indian model, but the traditional South Indian clothing such as saris and lungis are six to nine yards long and they were getting caught and entangled in the millimeter-wide gap between the machine's agitator and 
drum. Another example is Kellogg's cornflakes as a breakfast food in India. The American agribusiness Kellogg's set up a branch in India and started producing cornflakes. They ignored one of the important Indians lifestyle which is eating or drinking something hot in the morning. Similar to Chinese people, Indians think that to start the day with cold drinks such as cold milk is not healthy. However, warm milk on Kellogg's Corn Flakes would instantly turn cornflakes into the wet paper (Bhaba, 2005, p. 64-65).

Although designers seem to respect and value cultural needs and differences, many products still fail in foreign markets due to poor marketing. Yet more often than not, a product's failure is due to a lack of cultural relevance (Rubin, Z, 2012). However, there are some successful cases when businesses adapt to local social conditions and tastes in the marketplace by making small changes. For example, Philips began to earn a profit in Japan only after it had reduced the size of its coffeemakers to fit in the smaller Japanese kitchens (Kotler, 1986). Also, Coca-Cola, withdrew its 2-liter bottle in Spain after discovering that few local refrigerators had large enough compartments (Kotler, 1986). Furthermore, Crest initially failed in Mexico with the U.S. campaign using a scientific appeal since Mexicans do not put great importance on the decay prevention benefit of toothpaste (Kotler, 1986).

In this regard, a cross-cultural design is designing products for an expanding customer base across national and cultural boundaries, ensuring both usability and user experience on which user-centered design focuses. In this context, usability refers to well-functioning and user experience which mainly lies in the interaction between users and products and the emotions the product can stimulate, regardless of user experience is 
quite a subjective concept. Most importantly, both usability and user experiences are often influenced by culture (Walsh T \& Helkiö L, 2009). It would be crucial for a designer to understand the distinctive aspects of a local culture regarding people's way of perceiving and behaving their unique lifestyles.

At the same time, a product needs to be internationalized to ensure that products are designed and developed free of any culture-specific attributes. In this case, usability is a major consideration which has to be met without any special cultural attributes so that people all over the world could understand and use it in the same way such as some home appliances (e.g., washing machine, refrigerator) (Norman D., 2002). Furthermore, some changes in cultural aspects can be added so that products are culturally and functionally suited for the target culture and the transformation of products will support customers around the world regardless of their difference in language, country, or culture.

\subsubsection{What is cultural design?}

Unlike a cross-cultural design, a cultural design is associated with society and carries the footprints of the social context in which it was created (Kesebir and Kesebir, 2017 , p.259). For example, the design of tea sets in different countries is influenced by their unique and different tea drinking rituals and customs. For example, the Japanese tea set (figure 1) is designed based on the Japanese way of drinking tea (e.g., Sado) while the Chinese tea set (figure 2) design is based on the way of brewing tea in China (e.g., Kungfu tea). On another side of the world, the design of an English tea set (figure 3) is also influenced by their conventions of afternoon tea. From this observation, it could be said that acquiring the knowledge and distinctiveness of a particular culture will be critical to determine the usability and design of an exclusive and unique cultural product. 


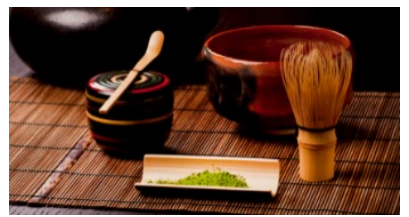

Figure 1 Japanese tea

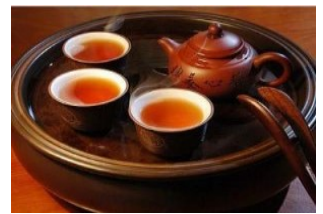

Figure 2 Chinese KungFu tea set

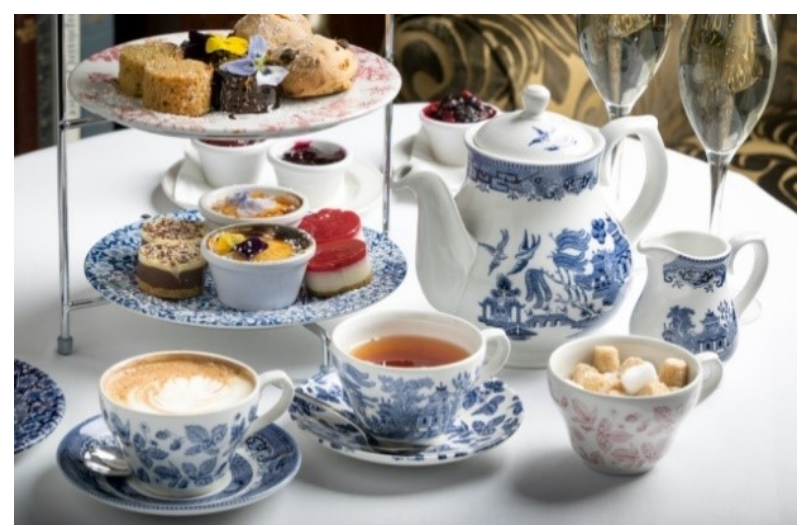

Figure 3 English afternoon tea

Since culture is a lifestyle that underlines everyday routine and behavior (Swidler, 1986), some cultural designs have embodied people's traditional behaviors, which differentiate this group of people from another. For example, since kimchi is an indispensable side dish for Korean, major home appliance companies (e.g., Samsung, LG, etc) in Korea developed Kimchi refrigerators to store kimchi with optimal conditions in their home.
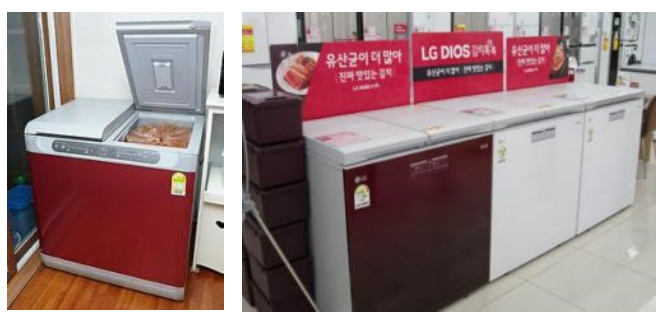

Figure 4 Kimchi fridge

Apart from machine production, according to Kumphai (2006), cultural products refer to handcrafts as well which embody local aesthetic features. In this case, cultural 
products reflect their creators' minds, which are in turn shaped by the surrounding social scene (Markus \& Kitayama, 2010). For example, a raven is one of the symbols for a Native Canadian culture that represents medicine and healing. It is believed to bring messages from the spirit world to help healers treat the injured and sick. For this reason, we can find the various designs of raven pattern or symbols on many souvenirs of indigenous culture or artworks, serving to remind people of their culture.

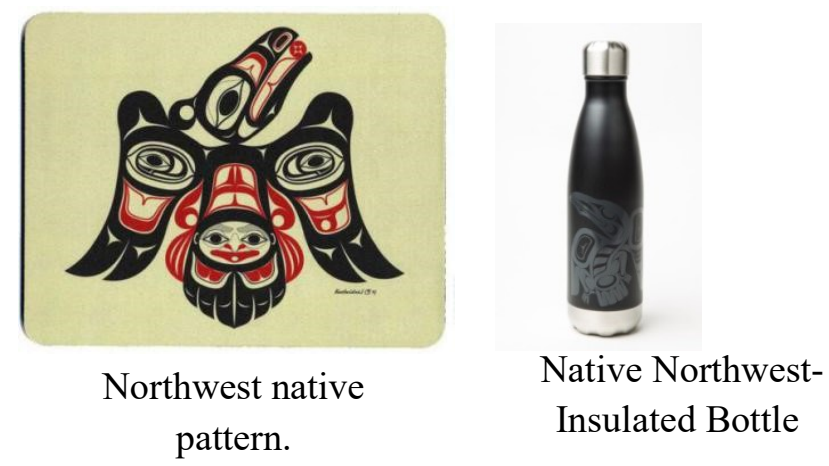

Figure 5 Native patterns of a raven

In summary, a cultural design reflects characteristics of a certain society in which they were shaped. Those characteristics can be shown as functional and aesthetic aspects in a cultural product design, which can be used to mark the boundaries and differences between different groups of people. However, a cross-cultural design is designing not only for one group of users but for multiple groups across national and cultural boundaries.

\subsubsection{How culture influences human-product interaction and user experience?}

Based on the definitions of a cultural product and examples mentioned above, it could be said that culture could provide an influence on human-product interaction and user experience in terms of functional and aesthetic acceptance. Norman (2005) 
emphasized that our reaction to a product is usually influenced by usability and also dependent on whether it awakens our nostalgia that affect consumer's emotional behaviors (Batcho 1995; Davis 1979). For example, a consumer who used to listen to a certain song in his or her youth with friends is likely to have a positive feeling when hearing the same music again. (Sierra, J. J. \& McQuitty, S., 2007). According to the research of nostalgia and consumption, furthermore, it has been discussed that nostalgic emotion plays a crucial role on a restaurant's image and customers' experiences regarding attracting customers (Chen, H. B et al., 2014). In this regard, nostalgia would be one of the attractions that influence customer's purchase choices (Sierra, J. J. \& McQuitty, S., 2007).

\subsubsection{Culture and Emotion----Nostalgia}

Nostalgia is an emotion generated by thinking about objects, persons, or experiences affiliated with a previous time (Hirsch 1992). Culture can evoke people's nostalgia which is the inheritance of shared values and beliefs, and individual identity (Kessous, 2015). In the twentieth century, sociologists note that nostalgia is used to preserve personal identity and adapt to changes in life stages during the transformation phase in someone's life (Davis, 1979) based on cultural heritage and shared memories with group members (Brown and Humphreys 2002, Cited in Sierra, J. J., \& McQuitty, S., 2007). A transformation phase in one's life could be caused by a variety of reasons such as political changes and personal choices. For example, the last generations of Canadian aboriginal people who were sent to residential schools were transported from their homes and prohibited from speaking their native languages. This caused a tough transformation of their life. Additionally, most immigrants who travel away from their homelands and 
face new living environments also face the challenges of transformation. Immigrants are likely to use nostalgia to maintain their cultural identities. Thus, it is no wonder that Chinese culture was brought into North America widely as an increasing number of Chinese immigrants flowed in. In this aspect, cultural products would have big potential markets across countries.

\subsubsection{Chinese culture in North America and Tea drinking}

The Chinese immigration in North America has a long history. The first Chinese immigrants in North America arrived in the 19th century and mainly worked as laborers (Hooper, K. \& Batalova, J., 2015). Since then, a number of Chinese have migrated to the U.S and Canada for their work, study, and living. Particularly in Canada, the population of Chinese immigrants from Hong Kong has drastically increased from the late 1980s to the earlier 1990s, culminating in record numbers in the mid-1990s, prior to Hong Kong's return to the People's Republic of China in 1997 (Li, P. S., 2005). According to Statistics Canada in the 2011 census for the 10 Canadian provinces and three territories, $1,487,585$ Chinese Canadian Population currently lives in Canada (table1) which accounts for $4.5 \%$ population, and there is a Chinatown in almost every major city.

Table 1 shows the Chinese population in the Canadian regions (Canada census, 2011)

Table 1

\begin{tabular}{|l|l|l|}
\hline Country & Chinese population & $\%$ of Chinese \\
\hline Canada & $1,487,585$ & $4.5 \%$ \\
\hline
\end{tabular}


The influx of Chinese immigrants has been a huge influence to introduce Chinese culture to North America, such as Chinese food, arts, and language, etc. Specifically, since ethnic food is a social and symbolic representation of certain culture (Warde, 2000), food has been considered a bridge that connects people from different cultures to each other (Barbas, 2003). It may not be difficult to find at least one Chinese restaurant in any small town in North America whether it is an authentic Chinese style restaurant or a fusion style in terms of its foods as well as atmosphere. The emergence of many Chinese restaurants could be a result of Chinese immigrants' nostalgia because through preparing and serving ethnic foods immigrants have maintained their culture when they adjust to life in different countries (Sukalakamala, P. \& Boyce, J. B., 2007). For example, P.F Chang (Figure 6) is a famous and upscale Chinese-inspired casual dining restaurant in North America and has an excellent combination of different cultural aspects between Chinese and Western.
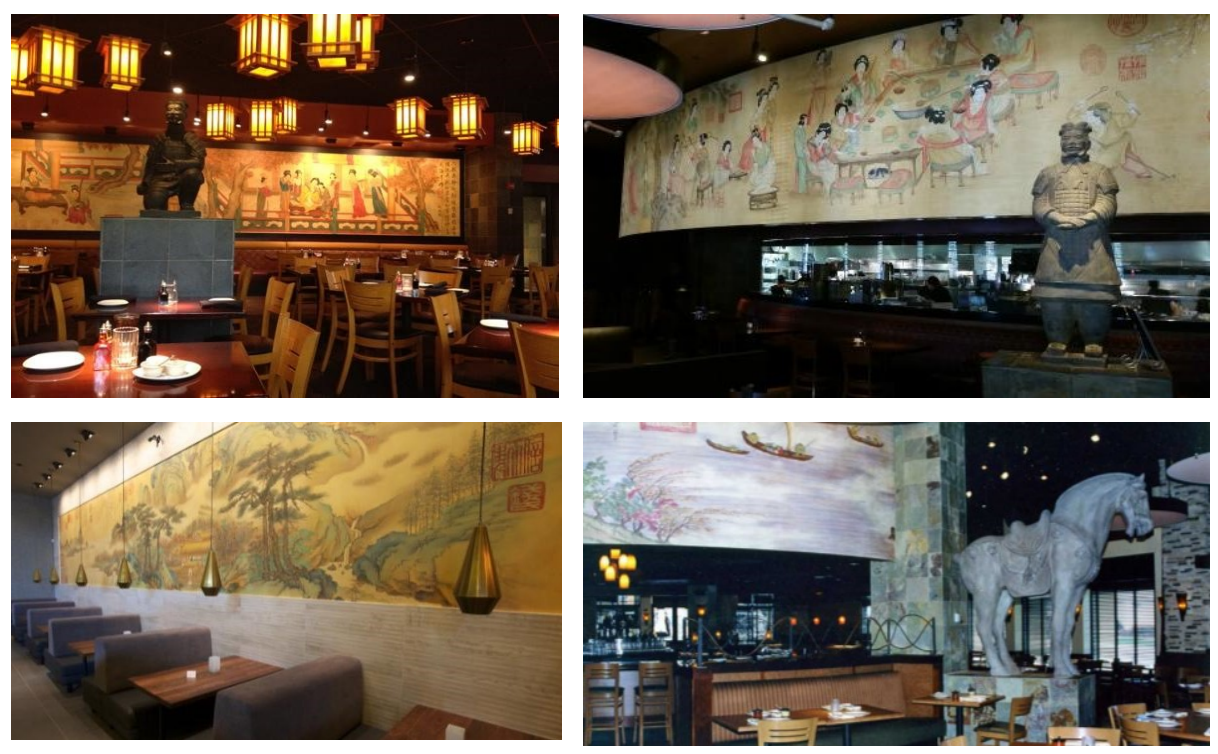

Figure 6 Interior of P.F. Chang Restaurant 
This contemporary bistro operates in 13 other countries around the world and recently launched its first branch in Laval, Quebec. Unlike other typical Chinese restaurants' interior design, P.F Chang has a unique interpretation of Chinese cultures by using a strong ensemble of iconic elements; bonsai, horses, terracotta soldiers and huge murals depicting dynastic court life. At the same time, this restaurant contains a lot of modern and western cultural mixture in their interior design which provides a nice cultural harmony, creating a unique and comfortable atmosphere for western customers as well as Eastern which is one of the critical factors that make the restaurant famous.

Besides to Chinese food, tea drinking would also be a significant concern in keeping cultural legacy for some people. Particularly, for those Chinese who immigrated to other countries, it is crucial to maintain a strong sense of an ethnic identity which requires learning about one's cultural heritage and participating in cultural customs or rituals, such as preparing and eating traditional food, and playing specific music (Phinney, 1991, cited in Mossakowski, K. N., 2003). Some researchers found that the majority of the Chinese people living overseas have not psychologically left China and tend to keep their ethnic identity (Redding, 1990). For example, many Chinese immigrants in North America still send their children to learn the Chinese language because some parents see the home language as closely related to their ethnic identity. Besides, according to the research of Zhang, D., \& Slaughter-Defoe, DT (2009), the sense of ethnic identity is very strong among Chinese immigrants. This in part has to do with the Confucian culture firstgeneration parents grew up with, which emphasizes respect for one's origin and ancestry. For those who have deep attachments to their original culture, living far away from their motherland will probably cause nostalgic emotions. 
For this reason, a tea set with the combined characteristics of tradition may relieve Chinese immigrants' nostalgia by providing a chance to learn cultural knowledge, take part in cultural practices and in the meantime, enjoy the convenience brought by industrial design. At the same time, it could also offer a chance for other groups to experience different cultures. Researchers indicate that customers in North America look for a different and exotic experience when they dine in ethnic restaurants and ethnic restaurants indeed get popular (Zelinsky, 1985). In terms of tea drinking, there might be a potential that tea drinkers from other cultures would like to try something new and special.

\subsubsection{Tea consumption in North America}

Tea is the second-most consumed beverage in the world behind only water according to the Tea Association of the USA Inc (2013), and its sales keep increasing continually. Canada has a particularly big population who have a habit of drinking tea, which Euromonitor ascribe to the immigration from countries with strong tea cultures (China, India, the Middle East and Russia). Moreover, sales of tea reached \$1.3-billion in Canada in 2015, which increased by 23 percent than the year before (Siddiqi. M., 2017).

\subsection{Three Levels of cultural design}

The cultural products described above involve the functions, symbolic aesthetics,

and nostalgic emotions. Similar to these three aspects, Lin (2009) suggests three layers of culture and three levels of cultural product design. He asserts that the three layers of culture would be Physical or Material Culture, Social Behavioral Culture, and Spiritual Ideal Culture, corresponding to the three levels of cultural product design, the outer level, 
the middle level, and the inner level. Specifically, the outer level refers to colors, texture, shape, decoration, surface pattern, materials, and details while the middle level refers to the function, operational concerns, usability, and safety of products. Lastly, the inner level represents special personal contents such as stories, memories, emotions, and cultural values.

Table 2

\begin{tabular}{|c|c|}
\hline \multicolumn{2}{|c|}{ Three levels of cultural design } \\
\hline Outer level & Color, form, texture, patterns, etc. \\
\hline Middle level & Functions, operations, usability, etc. \\
\hline Inner level & Stories, emotions, etc. \\
\hline
\end{tabular}

\subsubsection{Outer level: Unique style}

Many researchers note that cultural heritage is a vital resource of tourism markets. (Hall, Mitchell \& Keelan, 1991; Zeppel \& Hall, 1991; Craik, 1992). Due to the fact that distinctiveness of local culture is an integral part of the community's identity that cannot be imitated, it creates a core competency in the global market in which cultural diversity and local singularity are emphasized (Rowan \& Baram, 2004; Urde, 2007). As previous studies indicated, compared to the functional performance, sometimes unique cultural aspects could provide an exceptional experience. Especially in the context of cultural tourism and services such as museums, exhibitions or art collections, the presentation of the cultural product (location, internal distribution, walkways, or lighting) contributes to 
stimulating visitors' interest and desire of involvement (De Rojas, C. \& Camarero, C., 2008).

The global brand, Starbucks, has blended local cultural features with their brand identity in different countries, which is not merely for catering to local people's tastes, but also enhancing its competence in global markets through satisfying consumers' cultural expectations. For instance, on a historical street in Chengdu, China, the building design of the Starbucks is in a traditional architectural shape to merge into the local style (figure 7). In Kyoto, Japan, a Starbucks is located in a historical and well-preserved district. Instead of a big Starbucks sign, the globally recognized logo can be found on traditional "Noren" door curtains (figure 7). What's more, it is the first Starbucks to be designed in conventional tea-house style, completed with three tatami-matted rooms. Also, in South Korea, the Starbucks in the Mungyeong Saejae Provincial Park took the traditional Korean architectural appearance to fit into a local cultural tourist attraction.

In the case of Starbucks in those Asian countries, particularly, the unique design features created by the cultural aspects could satisfy local tastes as well as providing the people from other cultures who want to learn the beauty of local culture a different cultural experience. 


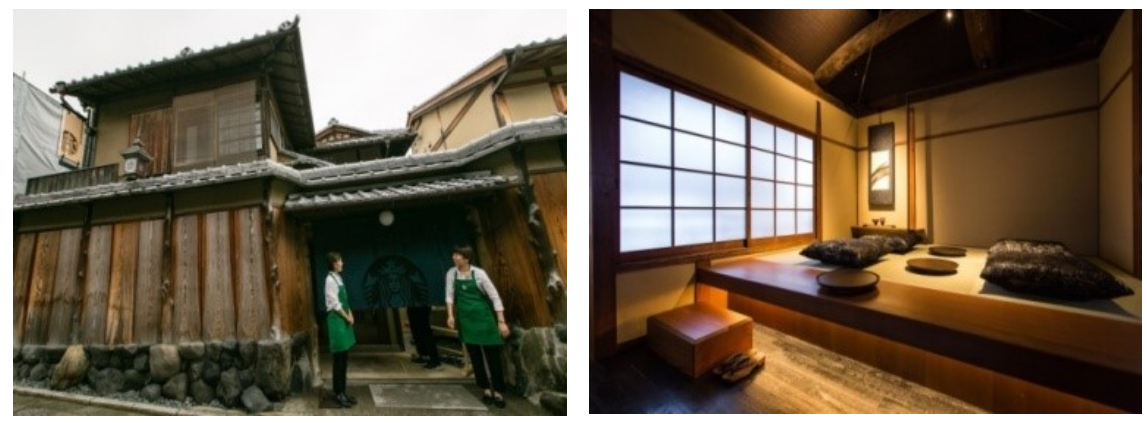

Starbucks in Kyoto, Japan.

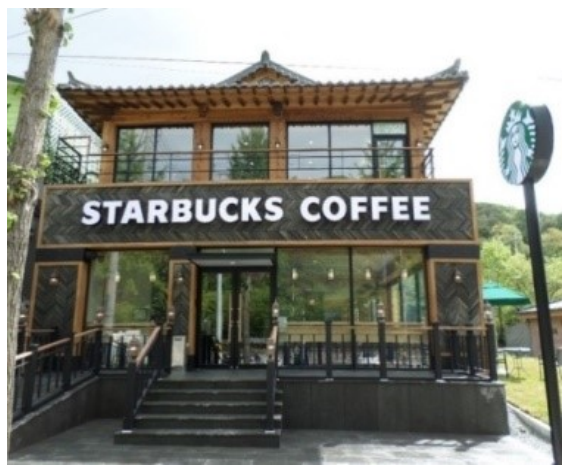

Starbucks in Korea

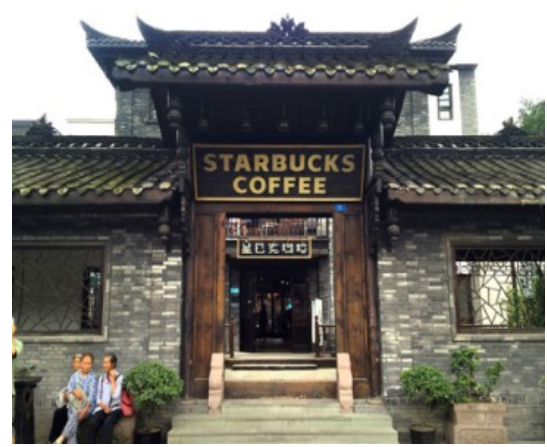

Starbucks in Chengdu, China.

Figure 7 Starbucks design in different cultural environments

\subsubsection{Middle level: Different functions}

There are many modern products that incorporate different functions as they are used in different nations where they are dominated by different cultures. Since some countries are influenced by religion in their political, social, cultural and economic system, for example, some companies attempt to develop a product that is acceptable to the religious communities, considering the authorities of the religion (Gorman, C. R, 2009). In marketing research, the cell phone manufacturer, Nokia, learned that Muslims desire a Qibla finder that can help indicate to them Mecca's direction (Corbett, 2008). 

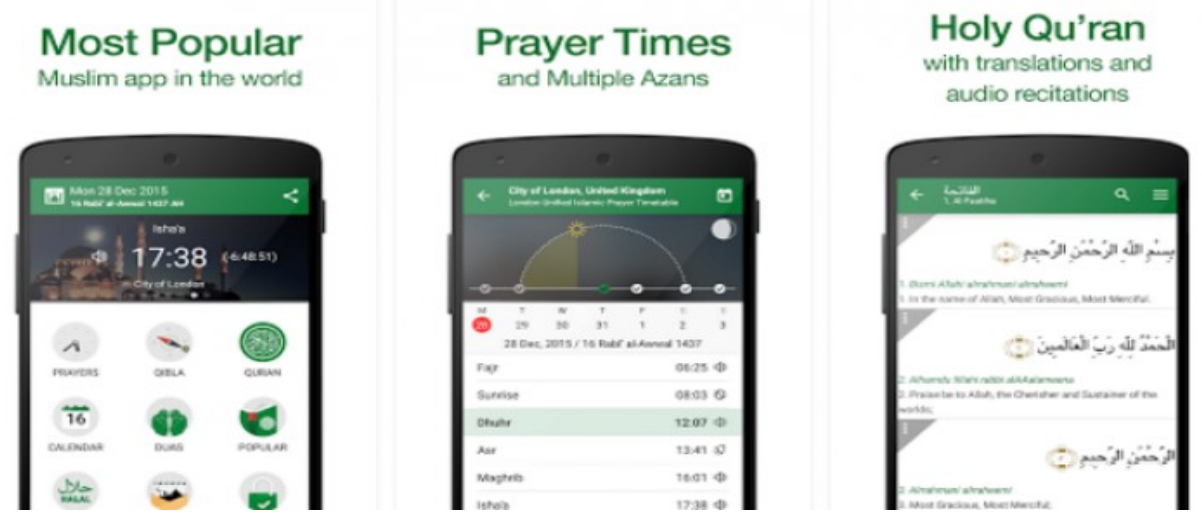

Figure 8 Muslim Pro, Developed By Muslim Pro Limited

Nowadays, there are some Muslim Quran prayer times applications that have been developed for Muslims to indicate the prayer timing, the mosques nearby, and the qibla direction wherever they are. This kind of application is mainly used in Muslim society because worship as a religious ritual is obligatory for all Muslims. More and more believers embrace these technologically advanced products because they help maintain traditional religious practices (Gorman, C. R, 2009).

\subsubsection{Inner level: emotions----nostalgia}

Products can evoke customers' associations which are generated due to their cultural background, personal experiences, and knowledge and emotional feelings (Nijkamp, M. \& Garde, J., 2010). Although different design features create different emotional associations, this study will mainly discuss the cultural design and the nostalgic emotions that highly relate to culture and how cultural design elements elicit associations and nostalgic emotions in modern products. As an emotional state, Rousseau and Kant presented nostalgia as regret for the time that has passed (Kessous, A., 2015), which is similarly defined by Cambridge Dictionary as well: "a feeling of pleasure and 
also slight sadness when people think about things that happened in the past."

The images below are examples where designers used cultural elements in a Chinese restaurant to evoke consumers' nostalgic feelings (Figure 9). For the interior design, the white wall and black tiles are used to represent typical architectural features of the traditional buildings in southern China (Figure 10). With the rapid development of urbanization, an increasing number of Chinese people are flooding into modern apartments. Meanwhile the traditional cottage is losing its usability and becoming a kind of tourist attraction. In order to recall one's nostalgic feelings, the restaurant built a cultural setting to provide customers a chance to experience their dinner in a long-lost traditional environment and provide an exquisite environment that triggers their nostalgic feelings that they are always yearning for. Also, it has modern and contemporary furniture that consumers have already become accustomed to in their current life style (e.g., sofa).
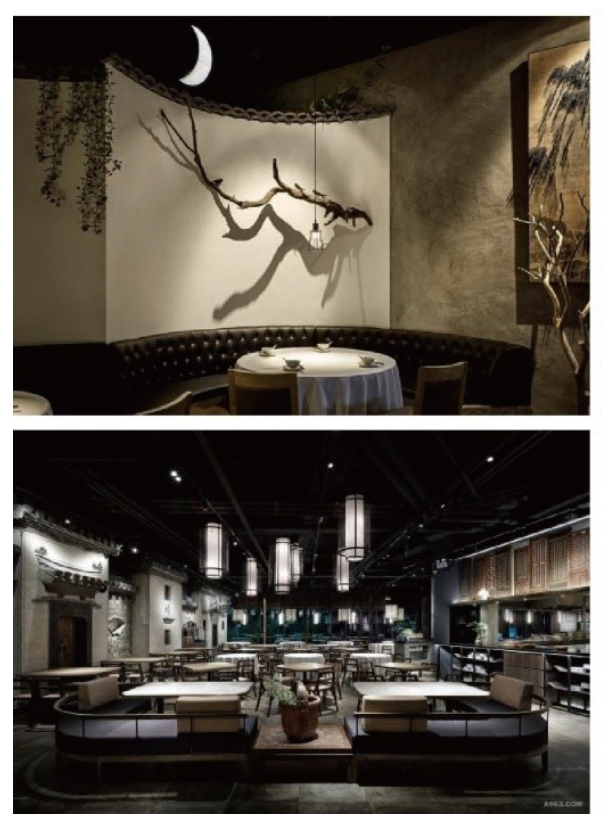

Figure 9 The Chinese restaurant---Charm of Anhui, designed by Ricky Wang
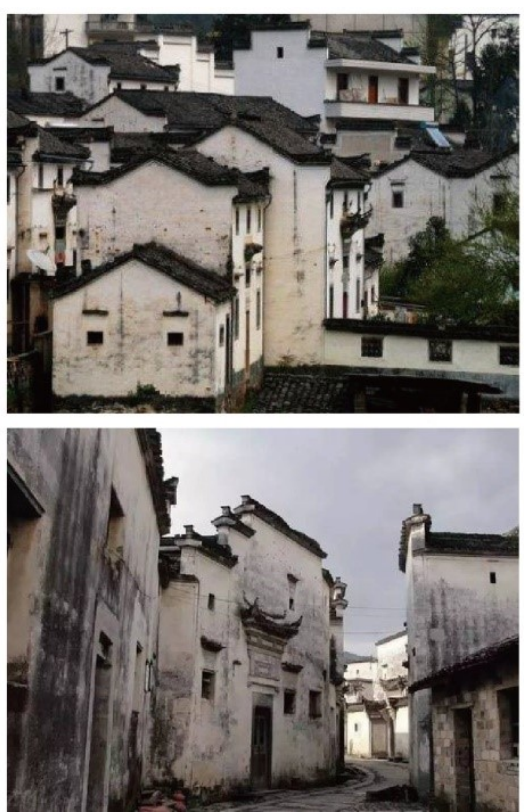

Figure 10 Black tiles and white walls in He yang ancient village in Zhejiang, China 
Cultural Product Design

All the examples above showed cultural attributes with different emphasis.

Accordingly, an overview of cultural aspects of these cross-cultural products is outlined in Table 3 based on the three cultural design levels. (Appendix A)

Table 3

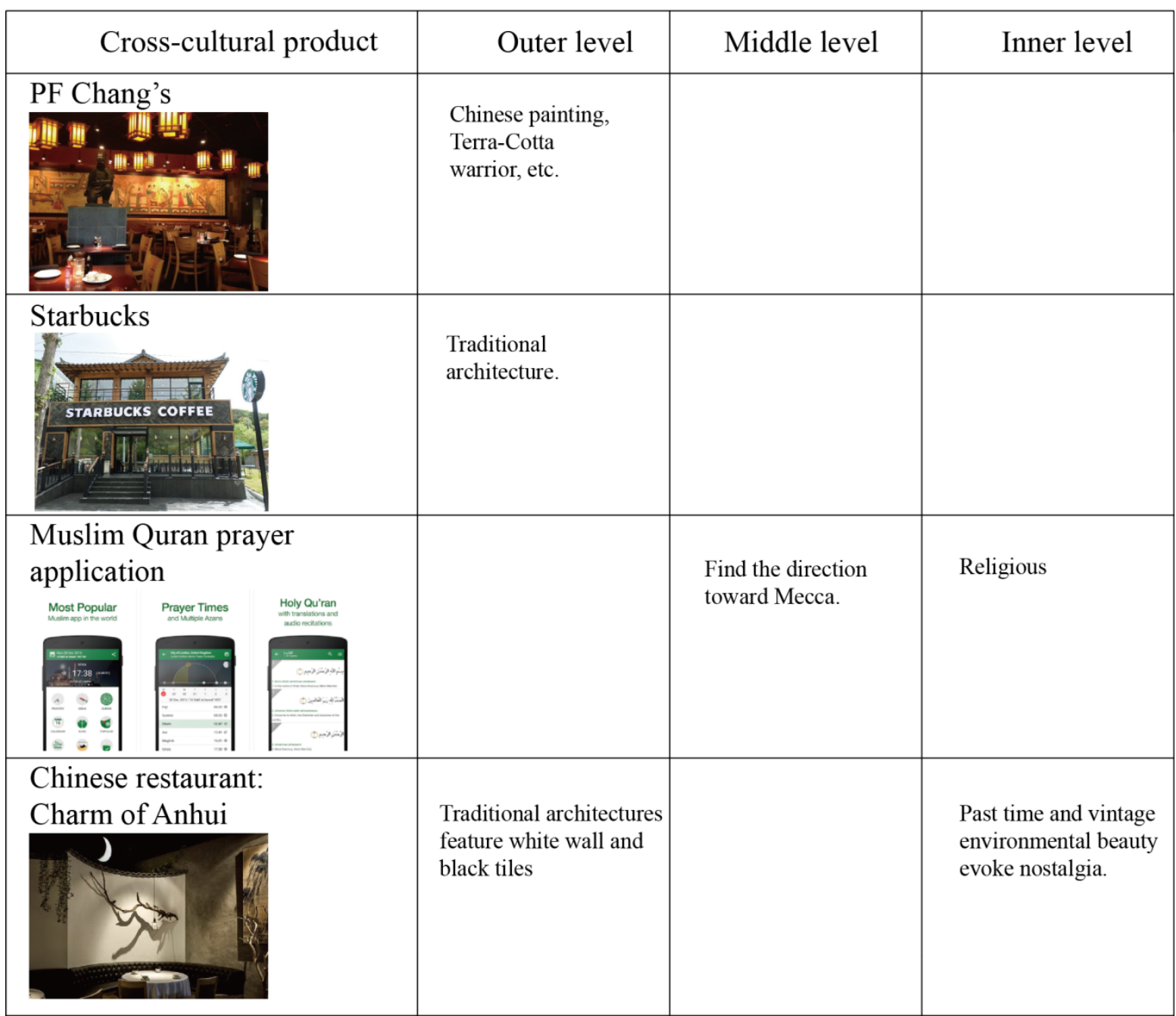




\subsection{Various Tea Cultures in different countries}

Tea culture can be defined by the way how tea is made, how people behavior in drinking tea, and the surrounding aesthetics (Magar, K., \& Kar, K., 2016). Tea drinking is an extremely commonplace act but different traditional rituals of drinking tea from different cultures have more meanings more than only drinking tea (Varley, P., \& Kumakura, I., 1989).

\subsubsection{Japanese tea}

Japanese chanoyu is an art of everyday life. The tea rules were established first in the mid-fourteenth century. The rituals include discrimination, behavior, and setting of a tea room. Discrimination means the attachment to utensils that have a particular aesthetic based on the relationship between people and things. Behavior is a social association and ethical sentiment. A tea ceremony is held to entertain people and provide them with a feast which consists of the presentation of tea and the serving of food. Tea room emerged from development in the architecture of room construction. In the setting of room, utensils and various art crafts such as painting, calligraphy, and landscape gardening are part of chanoyu (Varley, P., \& Kumakura, I., 1989).

In addition, there is a tie between chanoyu and Zen which originated from China. Tea was first brought to Japan by priests who went to T'ang China. Later the rules of matcha (powdered tea) formulated during the Song dynasty when Zen was introduced to Japan. Zen teaches that one can attempt to enter the realms of "nothingness" and “emptiness" by doing certain mediation (zazen). It is similar to seeking these realms in 
chanoyu by the tea ceremony of apportioning matcha, pouring hot water, and stirring it with a whisk (Varley, P., \& Kumakura, I., 1989).

\subsubsection{British tea}

Tea and milk is an "English" fashion. Afternoon tea or "five o'clock tea" is acquired from the Dutch and Portuguese in a mid-eighteenth century. It slowly tickled down from the upper classes to the middle and lower classes and functioned as a national identification (Irimia, M., 2011; Lutgendorf, P., 2012). Tea time was from four to seven in the afternoon (Heath E., 2012). In upper classes, it specified the consumption of pastry or biscuits with tea to please the palate. In the lower classes, it referred to bread with tea to last through the day (Irimia, M., 2011).

\subsubsection{Indian tea}

Assam is one of the world's largest tea-producing regions, where tea is quite popular and ubiquitous. It appears that tea takes a role of social beverage and hospitality offering to visitors along with biscuits and local dessert. Traditionally, tea in Assam is prepared by boiling tea in water and milk, sugar. Sometimes, spices such as ginger, black pepper, cinnamon are added according to taste. Red tea is boiled along with sugar, a bit of salt and other local spices. Unlike English afternoon tea, there seemed no specific time for people to have a tea break in Assam. Tea is consumed through all day (Magar, K., \& Kar, K., 2016). 
Cultural Product Design

\subsubsection{Korean tea}

According to Blofeld (1985), tea seed firstly was brought to Korea by a Korean envoy who returned from T'ang China. Then both local and imported teas became available. In those days, there were special tea houses where aristocrats would have tea seated around an image of the Buddha. During the Koryo Dynasty, which corresponds to the Sung and Mongol dynasties, tea was powdered in larger bowls. Tea was still confined to the upper classes and tea ceremonies would be held on important days in royal lives such as diplomatic receptions. For monks, they used tea both to serve guests and keep awake during meditation. But the ceremonial became overelaborate and complicated so its popularity declined. In the Yi period (Ming and Ch'ing dynasties in China), loose tea leaves took over from the powdered tea. However, Confucian rites took place of Buddhist ceremonies and wine became formal drink, only monks who abstained from alcohol preserves the custom of drinking tea. So the tea art was then kept in an austerely simple form. Tea drinking among Buddhist monks is regularly. A kettle, teapot and cups are used. The boiling water is first poured into a bowl and is left there. Then, put leaves into the pot. After that, the water is transferred from bowl to pot. This suggests that green tea used would yield its flavor well to water below boiling point (Blofeld J., 1985).

\subsubsection{Chinese Kung Fu tea}

In several parts of China, special ways of making tea were preserved from ancient times. In the south-west, brick tea is boiled like soup with spices such as sesame and ginger. In Yunnan province, people are fond of toasted tea especially Pu Er tea. Nomadic tribes churn it with salt and butter (Blofeld J., 1985). 
Kung Fu tea is popular Fu Jian and Guangdong province. Now Oolong tea and a few outstanding green teas are still brewed in Kung Fu manner. Firstly, the tea set only has four cups, which means there are altogether four people including the host will involve in a tea drinking ceremony. The limitation of the number of people stem from the tea drinkers of the Ming and Qing dynasties, who thought tea drinking is an intimating activity among a small group of people who shared the same or kindred values and appreciation (Wang L., 2005). The process of making a Fung Fu tea includes following steps. First, use boiling water to scald the pot before putting tea leaves in it. It is necessary because teapot is so tiny that the heat of the small amount of water disperses quickly. Second, tea leaves are now spooned to pot and fill the pot with hot water as before. The first infusion is not drunk but poured away. This is called "washing the leaves". After that, refill the pot and steep the tea for a while, during steeping time, the host scalds the cups by pouring hot water within 30 seconds. The tea then is poured from the pot with the same rotary motion so that each cup fills at the same time instead of one being filled while the others await. Then, each guest can sip the tea (Blofeld J., 1985).

The table 4 summarizes the above tea ceremonial aspects in terms of social occasions, what type of tea they drink and behaviors. 


\section{Cultural Product Design}

Table 4

\begin{tabular}{|c|c|c|c|}
\hline & Social occasions & Type of tea & Behaviors \\
\hline Japanese Tea & $\begin{array}{l}\text { A tea ceremony is held } \\
\text { to entertain people and } \\
\text { provide them with a } \\
\text { feast. The room seeting } \\
\text { includes art crafts and } \\
\text { landscape gardening. }\end{array}$ & $\begin{array}{l}\text { Matcha } \\
\text { (powdered tea) }\end{array}$ & $\begin{array}{l}\text { apportion matcha, } \\
\text { pour hot water, and } \\
\text { stir it with a whisk }\end{array}$ \\
\hline 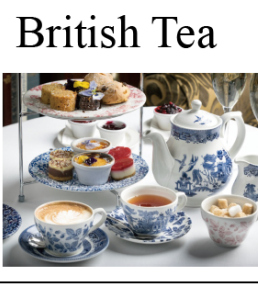 & $\begin{array}{l}\text { In the afternoon } \\
(4.00-7.00 \mathrm{pm}) \\
\text { It tickled down from } \\
\text { the upper classes to } \\
\text { the middle and lower } \\
\text { classes }\end{array}$ & & $\begin{array}{l}\text { Tea goes with milk, } \\
\text { sugar and dessert. }\end{array}$ \\
\hline Indian Tea & $\begin{array}{l}\text { Tea is a hospitality } \\
\text { offering to visitors }\end{array}$ & Red tea & $\begin{array}{l}\text { Tea goes along with } \\
\text { local dessert with } \\
\text { spices such as black } \\
\text { pepper, ginger, sugar, } \\
\text { and slat }\end{array}$ \\
\hline Korean Tea & $\begin{array}{l}\text { Important events } \\
\text { in upper calsses } \\
\text { such as diplomatic } \\
\text { receptions } \\
\text { Monks ues tea to } \\
\text { keep awake during } \\
\text { meditation }\end{array}$ & Green tea & $\begin{array}{l}\text { The boiling water is first } \\
\text { poured into a bowl and } \\
\text { is left there. Then, put } \\
\text { leaves into the pot and } \\
\text { the water is transferred } \\
\text { from bowl to pot. }\end{array}$ \\
\hline $\begin{array}{l}\text { Chinese } \\
\text { Kung Fu Tea }\end{array}$ & $\begin{array}{l}\text { Tea drinking is an } \\
\text { intimating activity } \\
\text { among a small group } \\
\text { of people who shared } \\
\text { the same or kindred } \\
\text { values and } \\
\text { appreciation. }\end{array}$ & $\begin{array}{l}\text { Oolong and } \\
\text { Green tea }\end{array}$ & $\begin{array}{l}\text { First, use boiling water to scald } \\
\text { the pot, put tea leaves in pot and } \\
\text { fill hot water. Pour away the first } \\
\text { infusion. Then, refill the pot and } \\
\text { steep the tea for a while. During } \\
\text { steeping time, the host scalds the } \\
\text { cups. The tea then is poured into } \\
\text { each cup. }\end{array}$ \\
\hline
\end{tabular}




\section{Chapter 3. Method}

Generally, cross-cultural products can carry a range of cultural elements that can reflect unique aesthetics and people's different lifestyles. The first research question in this study was "what are the most common cultural elements that are used in current cross-cultural products?" To answer this question, the author investigated different types of current cultural products that are mainly related to Chinese culture, and a few of them are about other cultures. Based on the three levels of cultural design, the author included the main Chinese cultural elements that often used in cultural products.

For the second research question, "how to blend cultural design elements with users' perceptions to design a cross-cultural product?", this study employed the semi-structured interview as a way to collect qualitative data and used a thematic analysis method to analyze the data to understand users' perceptions of drinking tea. Based on the findings of the local users' perceptions about drinking tea, the researcher proposes a tea set design that combines the cultural elements and the conceptions of drinking tea.

\subsection{Analysis of Chinese cultural product}

\subsubsection{Outer level: Unique style}

\section{Pattern}

"The national is the international" is the slogan frequently used by Chinese fashion media journalists and designers. Especially in the field of fashion design, some designers have used traditional Chinese cultural symbols such as dragons, lanterns, peonies, and ancient palaces as a core design element to design culturally distinctive and unique clothes (Tsui, 2013). 
On certain occasions such as a social display, cultural products consisting of distinctive symbols could show individual identity and self-affirmation. For example, at the closing ceremony of the 63rd Cannes Film Festival, the Chinese actress Fan Bingbing wore a gown whose design was based on an imperial robe in the Chin Dynasty. Even though the ancient styles, patterns, and decorations have been fading away in our modern life, people are likely to accept these prominent ancient aesthetics as a kind of fashion and a symbol of Chinese culture in an international occasion. These traditional symbols could not only help designers to represent their national identity but also show a nationalism nourished by patriotic education which urges Chinese designers to differentiate themselves from Western fashion designers and to gain fast recognition from the international market (Tsui, 2013).
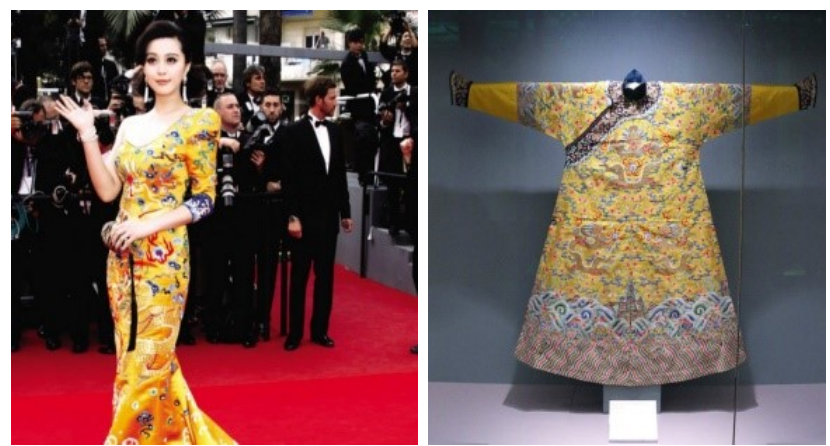

Figure 11 The gown and the imperial robe

Another example that demonstrates historic patterns in contemporary design is the design of Turkish carpets which carry traditional patterns by using the digital age's visual codes, pixels (Figure 12). 


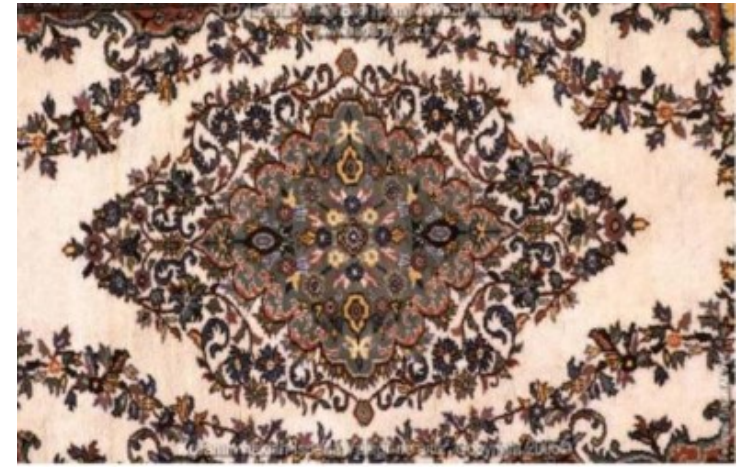

Traditional hand-made carpet

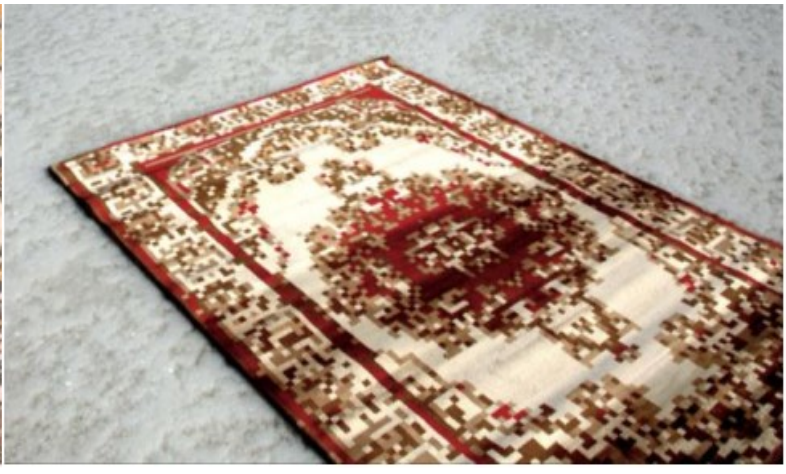

Mosaic" Carpet (Șekercioğlu, 2012)

Figure 12 Turkish traditional patterns on carpet

In addition, some souvenirs use traditional patterns as an element to represent cultural aspects. For example, bookmarks and USB sticks are decorated with the patterns of traditional Chinese gardens' window lattice to make them attractive (Figure 13).

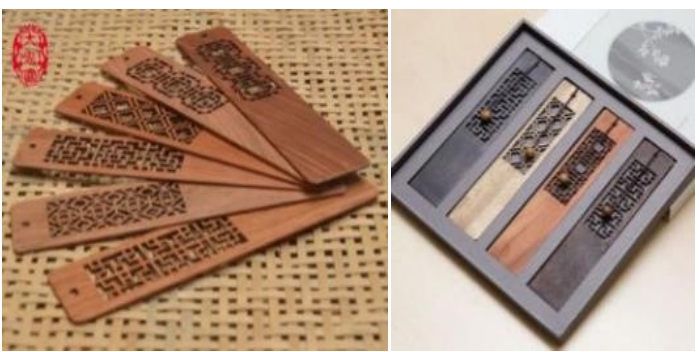

Bookmarks of Chinese style

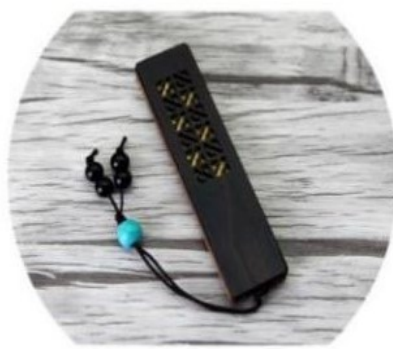

USB Sticks of Chinese Style

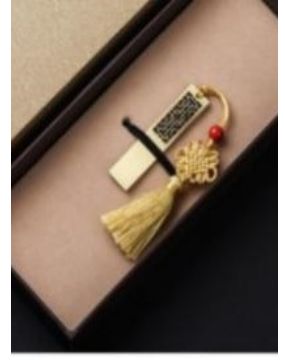

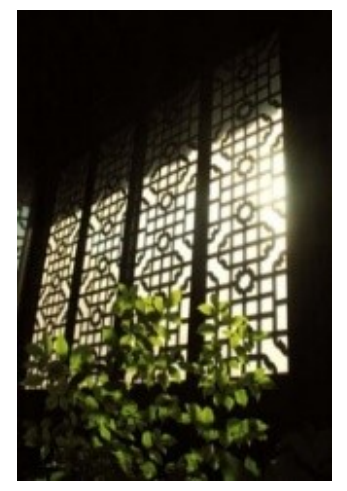

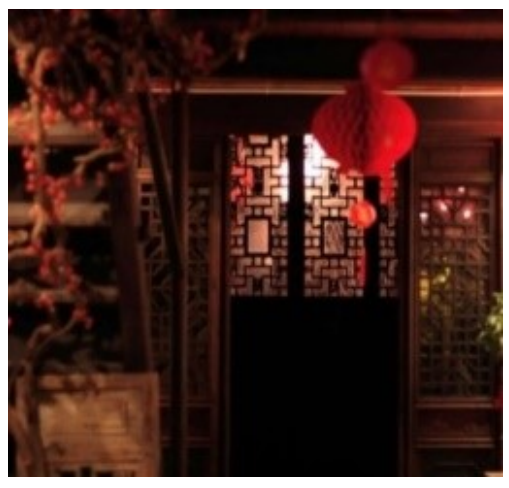

The windows of Chinese gardens

Figure 13 Traditional patterns of Chinese window lattice 
For another example of patterns, at the World Expo in Shanghai, China, 2010, the government of Shanghai opened the Expo Lines of subway especially for travelers from all over the world. Along the subway, there is a moiré droplight whose main feature is a cloud pattern which symbolizes soaring and satisfaction in the culture of the Han dynasty. This inspirational pattern could also be found in other Chinese cultural designs, such as the torch of the 2008 Beijing Olympic Games and the Lenovo laptop Tianyi F21.

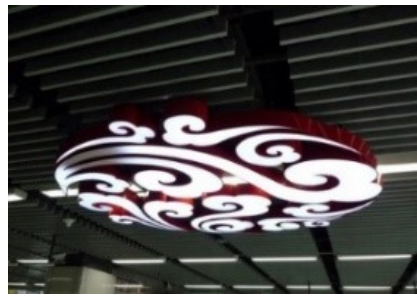

Drop light

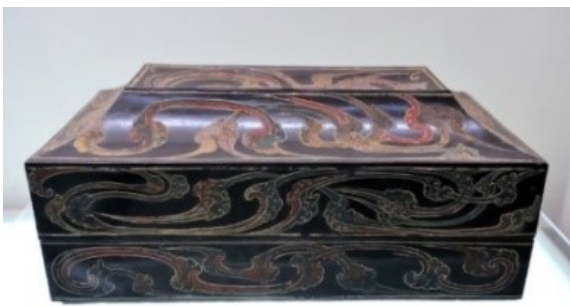

The square lacquer from the Han Dynasty, Hunan Museum

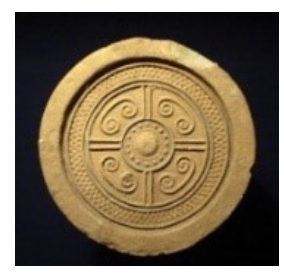

The moiré pattern

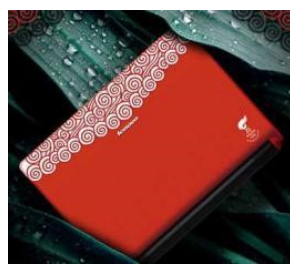

Lenovo laptop Tianyi F21

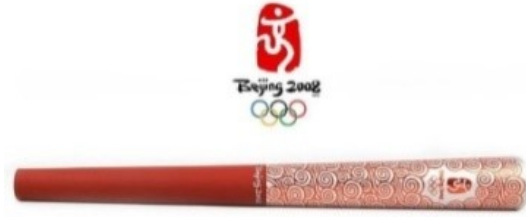

The torch of 2008 Beijing

Olympic Games

Figure 14 Traditional moiré patterns

Blue and white porcelain enjoyed its popularity globally between the sixteenth to eighteenth centuries (Batchelor, R., 2006). The patterns of flowers and animals on Chinese porcelain products had a great influence on European as well as a Western ornament on ceramic. The reason for the widespread use of Chinese patterns lay in the technical excellence of Chinese porcelain. Since Chinese porcelain remained a luxury item for Europe and the Near East, local manufactures attempted to copy the fine 
porcelain (Rawson, 1984). In this way, Chinese porcelains provided models for European pottery. Gradually, the blue and white porcelain became a tradition of many countries and the Chinese patterns were modified more or less to adapt to local culture (Rawson, 1984) (Figure 16).

Furthermore, as the only remaining earthenware factory that produces the world famous Delftware since the 17th century, Royal Delft also incorporated the 'Miffy,' a Dutch cartoon character, into their traditional porcelain production. The blue and white porcelain which merged the characteristic of Miffy into a beautifully intact product is a good example of a cross-cultural product. Chinese blue and white porcelain first reached Holland in 1604 when porcelain was taken off the captured Portuguese carrack Catharina. Later, the first caution of the porcelain in Amsterdam led to its popularity which set off an industry of imitation in Holland. At first, the blue and white wares produced by Delft factories were just literal imitations. But due to the limited skills of local potters, the domestic ceramics were superficial copies which strayed far from the Oriental design. This was not the goal of Dutch potters. They would like to make a substitute for Chinese porcelain which was not a forgery but an equivalence of their own creativity (Le Corbeiller, C., 1968). This raised the question about the transmission of design ideas across the globe, which could be regarded as early cross-cultural design. Today, Delft has already made the design which combined the Oriental blue and white style with its famous animal character Miffy. 


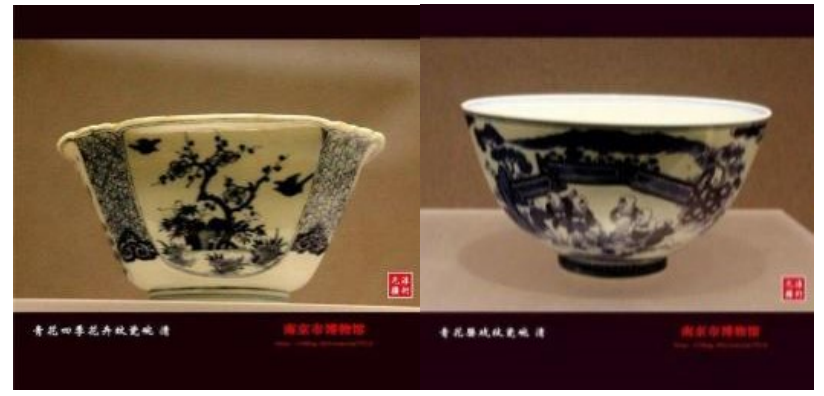

Figure 15 Blue and White porcelain,

Qing Dynasty, from Nanjing Museum

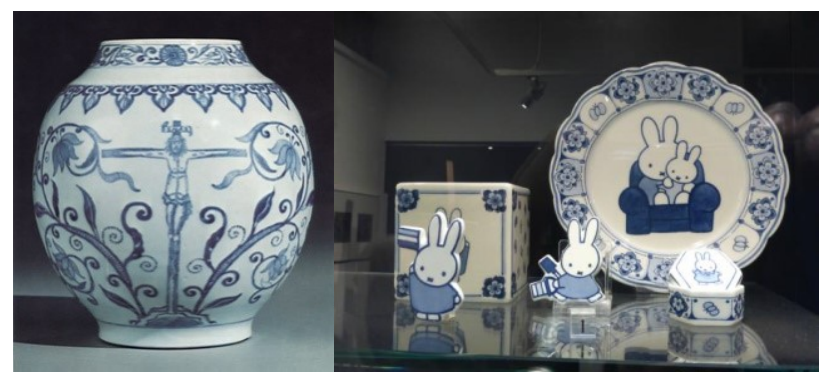

Figure 16

European

Figure 17 Delft Potteries

Blue and white

porcelain

Some special cultural products from other countries were also used as main design elements to design some cultural products (figure 18). For example, the British Museum made a key ring as a souvenir of a Japanese art exhibition. The key ring featured the pattern of The Great Wave, a Katsushika Hokusai masterpiece.

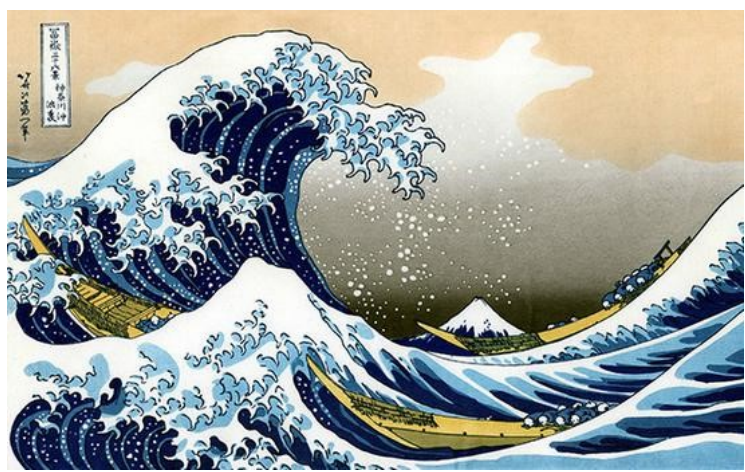

The Great Wave off Kanagawa, Katsushika

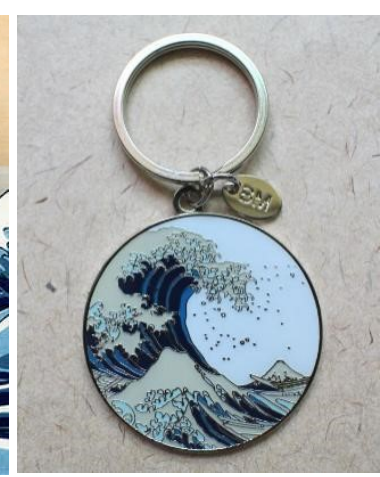

The souvenir of the British Museum, key ring.

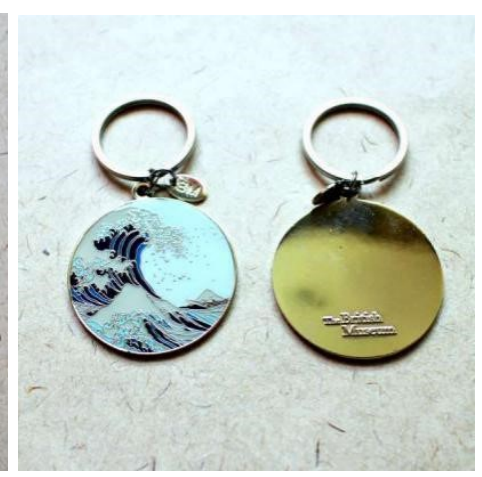

Hokusai, woodblock print, 1831.

Figure 18 the key ring with Great Wave pattern 
It seems that many souvenirs from museums were likely to use authentic patterns from the museums' collections. In this case, the souvenirs with authentic patterns have a commemorative significance for visitors who have appreciated the exhibitions and want a reminder of the visiting experience. After they have understood the backgrounds and meanings of the artworks, their consumption of the authentic souvenirs makes them feel different in form and meaning than a usual purchase (Littrell, M. A. et al., 1993). Thus, the patterns represent not only the cultural aspect but also reflect a personal experience and memories, which will make the souvenirs meaningful in different ways.

Why a traditional pattern is a popular element in cultural products and favored by many designers? Because patterns can be seen as a cultural element that provides unique and distinctive visual characteristics of a particular culture (Masuda.T et al., 2008). According to Hann (2013), patterns, no matter concrete or abstract, may possess cultural symbolism and often be deemed to fulfill a decorative function as well. These images are not only copying the reality of the real world, but are also a representative of their cultures. From the things depicted in patterns, some claims, sentiments, or ideas were also conveyed. By manipulating color usage, line drawing, and symmetrical or asymmetrical styles, which are strongly affected by the culture in which the artists live, a range of nations and countries have created a big number of images and paintings in their unique styles (Masuda.T et al., 2008).

In addition, patterns, mostly from artifacts, are never neutral. Artifacts contain values because their materials are either more or less precious and the skills of manufacturing are more or less demanding. For these reasons, patterns or artifacts can shape one's self-esteem, personality, and public identity (Powers, M. J., 2006). For 
example, porcelain was initially produced for court life. The emphasis in design was on artistic quality and exquisite craftsmanship regardless of cost.

Similarly, the porcelain tea ware with exquisite patterns represents aristocracy in Europe. But when tea became the public's beverage and tableware became inexpensive in the nineteenth century, the artistic patterns inevitably deteriorated due to large-scale production (Heskett, 1980). As a result, patterns can be viewed as important symbols in both cultural and economic aspects.

\section{Forms}

In the article, "Cultural Traditions for the Sake of Innovation: the Concept of Scandinavian Design as a Potential Tool in the Development of a Sustainable China," Skjerven (2012) suggests Scandinavian design as a tool to sustain tradition in a modern product. The Scandinavian design style is regarded as being in accordance with the regional traditions yet highly modern at the same time because the Scandinavian style is broadly understood as ergonomic, simple and modern design by using natural materials (Roncha, 2008).

For example, some Scandinavian design combined two different cultural elements in a simple and modern way. China Chair (figure 19) designed by the Danish furniture designer Hans J. Wegner, was inspired by the model of a Ming chair (Quan yi) but was simplified for bentwood production with minimum quantities of material. Its top rail and arms are a single piece but without the back forming a board so sitters can move freely on the seat (Danish Design Centre, 1994). From the simplified traditional form without changing most of the proportions or details of the Chinese chair, users can feel traditional 
style as well as modern senses. In his book "Offspring Danish Chairs with Foreign Ancestors." Per Mollerup writes that Wegner saw a reproduction of an old Chinese chair in Ole Wanscher's book "types of Furniture” (1932). The idea that taking known types of foreign furniture as subjects for renewal occurred to his mind. In this case, the traditional Chinese chair and Scandinavia regional style come across to make a cross-cultural renewal.

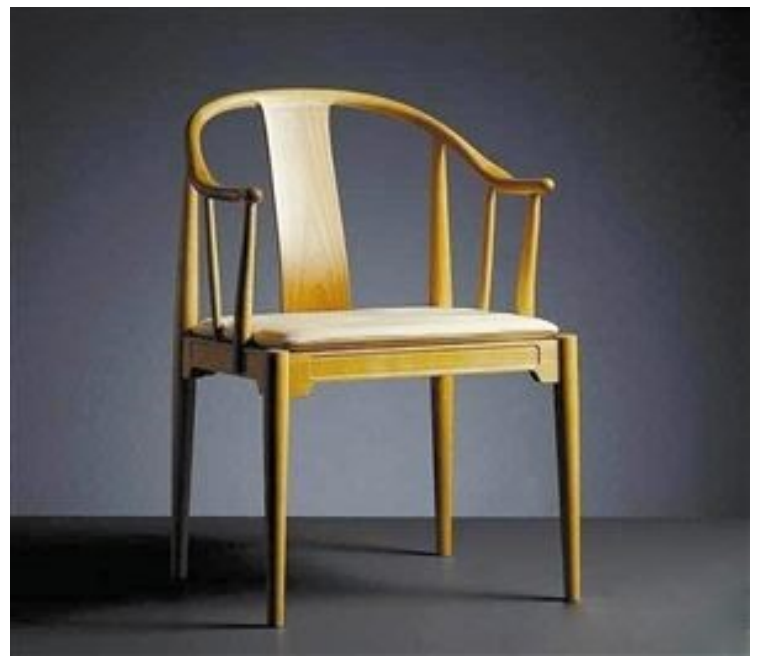

Figure 19 China chair, 1944, by Hans J. Wegner

There are some interior designs creating an authentic Chinese cultural atmosphere, which combined many authentic cultural items with modern aspects such as technology (e.g., electricity). The USA is a multicultural society where ethnic restaurants are getting increasingly popular as American customers' expectation of an exotic experience at ethnic restaurants is growing as well (Zelinsky, 1895). For example, P.F. Chang's as one of those ethnic restaurants in the USA uses plenty of authentic items as decoration including Chinese paintings and terra cotta because the authenticity allows customers to experience something new and novel to escape their ordinary lives (Ebster \& Guist, 
2005). As Taylor (1991) notes that authenticity is an important factor in an ethnic restaurant which not only refers to food but also the interior design and environment. However, the authenticity may cause customers' negative feelings because of unfamiliarity. For this reason, previous researches indicate that a combination of familiar elements with an exotic style would encourage customers to enjoy their meal comfortably (Riley, 1994; Wood \& Lego Muñoz, 2007). PF Chang's also adopted modern aspects that North Americans are familiar with such as the bistro atmosphere with dark lighting. The mixture of authenticity and modernity may contribute to the success of PF Chang's.
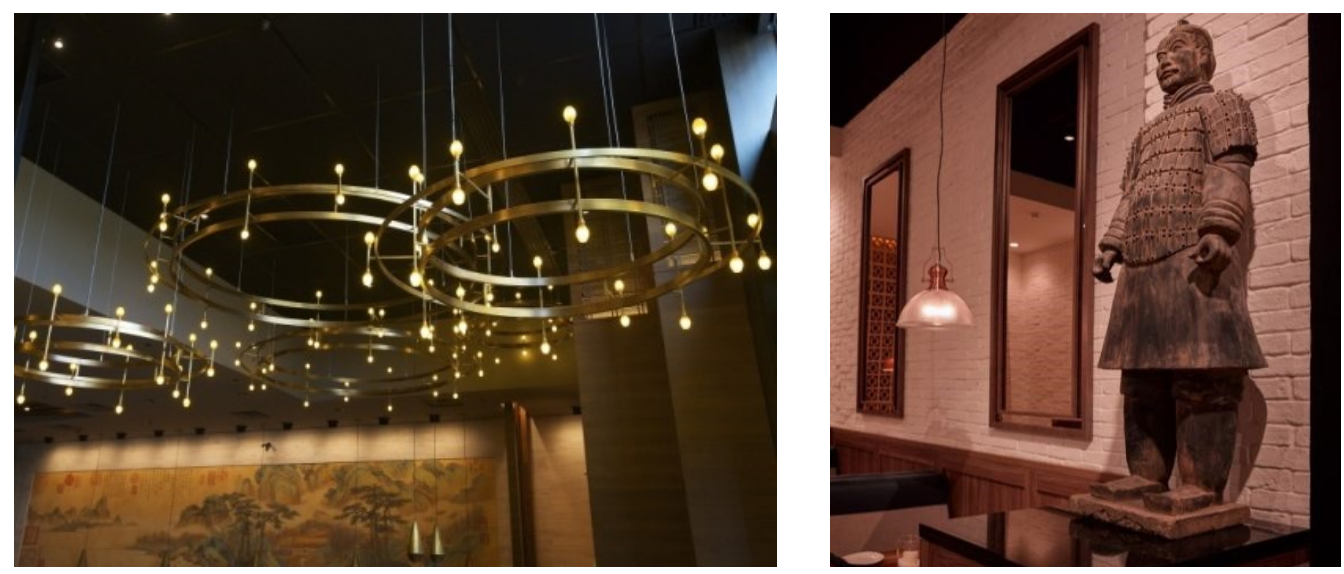

Figure 20 The Interior of P.F. Chang's

\section{Materials}

The material would be another important element in designing an attractive cultural product. In China, natural materials such as wood, stone, and bamboo have been used as materials representing Chinese culture.

Bamboo, for example, is a well-known traditional material representing Asian culture. Now in a tea house (Figure 21) in Yangzhou, China, the design also blended 
bamboo as its principle material to create an Asian aesthetic landscape. Even though the interior set-up is contemporary, using traditional materials appropriately still intensifies the cultural atmosphere.

Brick was the main material for ancient Chinese architecture especially city walls. In an architecture complex in Nanjing (Figure 22), the bricks used here simulated the ancient bricks that still exist in a historical relic the Ming Dynasty City Wall. Besides, some graffiti on pieces of bricks represented a mix of the tradition and modern.

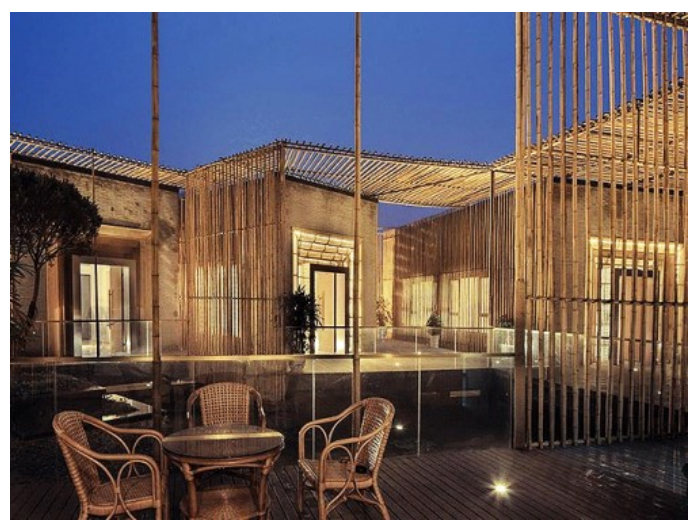

Figure 21 The tea house in Yangzhou, designed by Harmony World Consulting \& Design

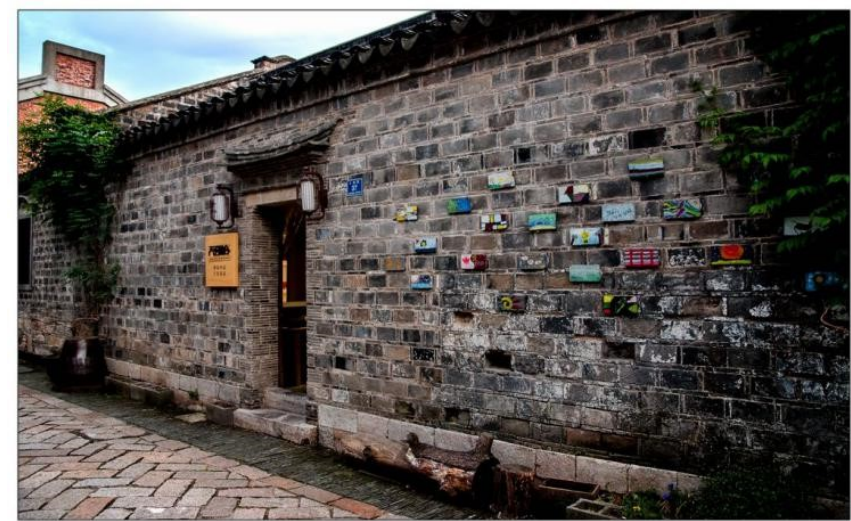

Figure 22 The architecture complex near the Ming Dynasty City Wall

\subsubsection{Mid-level: Functions based on different lifestyle}

Steaming food is a typical way of cooking meals for most Chinese people. But the size of the traditional steamer is big and usually occupied a large area, which is not suitable for home-usage in contemporary society. The "Ding" steamer (figure 23) is a modern cooker but adopted the traditional bamboo steamer as one of the design elements. This modern steamer includes matched bottom ceramic pot, and its size fits the contemporary kitchen in a household, which fixed the conflict between the traditional 
way of cooking way and a modern lifestyle. The white ceramic is in accordance with purity and simplicity of modern style. But the original bamboo part is also kept indicating a traditional sensibility (Figure 24).

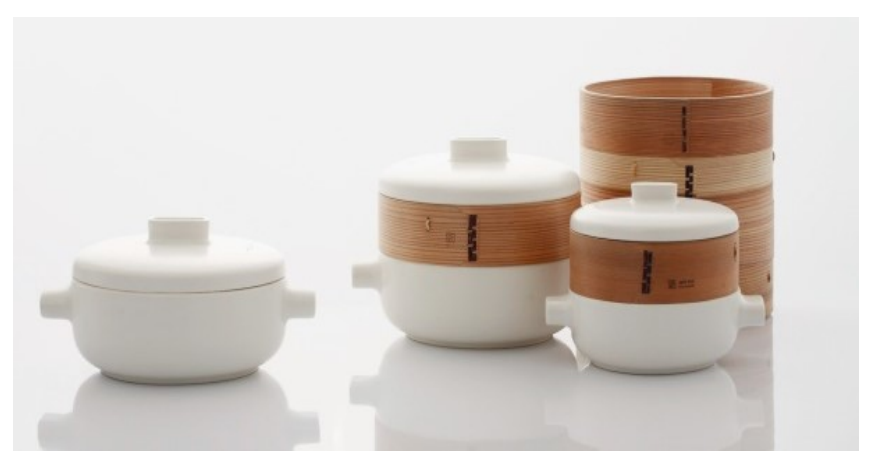

Figure 23 "Ding” Steamer, by Office for Product Design

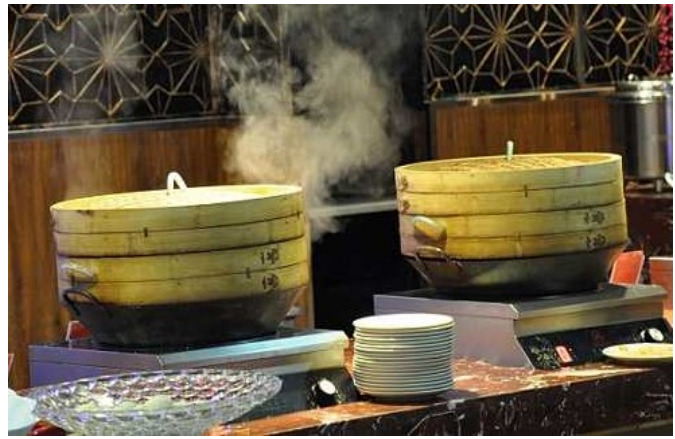

Figure 24 Traditional steamer

Products have to adjust to different needs historically and also culturally. Since people from different cultural backgrounds have different diet habits including drinking and eating, cultural products would have to make different adaptions for different regions.

As the number one consumer of tea in the world, for example, Turkey has a long history of tea drinking and has developed its own tea culture (Cayli, n.d.). Turkish tea is a black tea which is prepared in a very special manner. Using a double tea pot, the bottom pot is filled with water which is set on the flame. Meanwhile, the top pot is specifically filled with dry tea leaves, typically one small spoonful per drinker. When the water is boiling, some water will go up to the top pot, and the tea is allowed to steep for 15 minutes, but generally no longer than 30 to avoid bitterness (Cayli, n.d.). This doublelayer tea pot is especially for the Turkish way of brewing tea. Tiryaki (Addict) is a model that was launched only for the Turkish local market by Arcelik, a firm producing home appliances (Figure 25). It is basically an electric kettle, with a glass teapot placed over it and designed to brew tea with the water boiled in the kettle, to be used at home or office 
environment. It is a good example of a local product defined by a traditional habit and also as a modern response to the Turkish way of brewing tea while users' needs and living environments are changing (Öğüt, Ş. T., 2009).

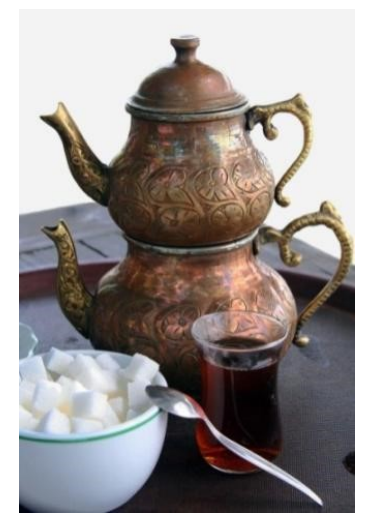

Turkish traditional teapot.

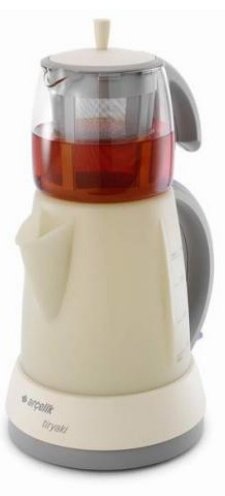

Tiryaki

Figure 25 The Turkish tea kettle

Apart from the cultural products above, which convey strong cultural characteristics, there is a kind of cultural product that avoids imitating traditional forms directly but incorporates both traditional functions and modern elements that look contemporary but still carry cultural aspects to keep its uniqueness. One example of the local products that revisit the features of "traditional cultural artifacts" is the Turkish tea/coffee tray. (Celikoglu, 2010, p. 155).

The traditional Turkish tea tray has some specific features (Figure 26): circular basis and three pipe extensions fixed on three points to form a platform. In order to translate the traditional tea tray into a modern semiology, the Turkish designer Koray Ozgen changed its shape and materials (Figure 27). To a cornered square, and its holders are made from fabric material which can be separated from the tray. This modification not saves only space when the trays are stored but also reduces the weight. Though the shape 
has been modernized and the material has been changed to add more convenience, it is still used in the traditional way, thus it keeps its traditional function and local features.

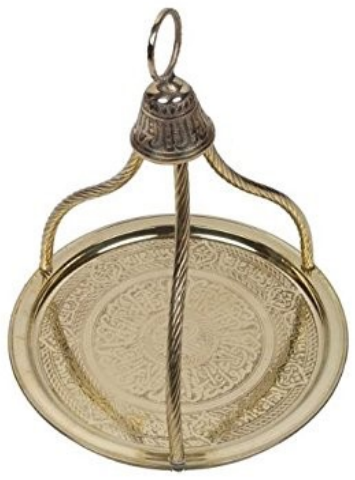

Figure 26 Traditional Turkish tea tray

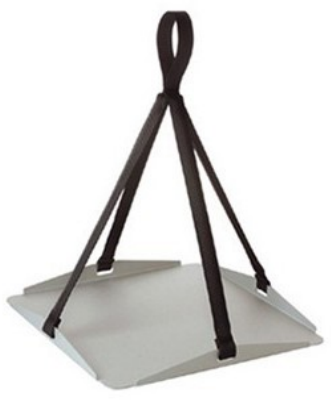

Figure 27 Tipsy by Koray Ozgen

\subsubsection{Inner level}

Japan is considered as the key origin of the culture of cuteness. Within the last 30 years, cuteness has been prevalent among lots of female teenage groups in Japan (Granot, E et al., 2014). In the late 19th and early 20th century, the obsession with cuteness transferred to the USA as well. Americans were attracted by the "cute" child who showed an innocent smile which provides us instant and unconditional 'happiness' (Newitz, 2002). As a result, the cuteness that can evoke happiness has been widely used in Japanese product design (Demirbilek, O., \& Sener, B, 2003). The Japanese word "Kawaii" means something cute, lovable, and small, which represents a Kansei (affective) value. In Japan, the cute aesthetic is used in a variety of areas including police mascots, and warning signs because cute design can reduce fear and makes dreary information more acceptable (Ohkura, M. et al., 2014). In terms of design elements, the feelings of Kawaii are caused by such features as shapes, colors, textures, and materials. According 
to the research about Kawaii rules in product design, the Kawaii rules concern shapes and colors. Round objects such as cylinders and circles are more kawaii, compared with straight lines. Colors with more brightness and saturation are likely to be regarded as kawaii (Ohkura, M., et al., 2009).

\section{Cute Mascot}

The spread of cuteness is also flourishing in China. The Italian company Alessi collaborated with the National Palace Museum in 2005 and designed a fun and playful product, "The Chin Family" (Figure 28). It is a set of adorable kitchen products that used the portraits of Emperors in the Chin Dynasty. Alessi explained that such designs cater to consumers overseas and to encourage greater awareness of Chinese history and culture in the West (Chang et al., 2013). The portrait was based on a round shape and the colors used had high saturation, which are found to be consistent with the kawaii rules of previous studies.

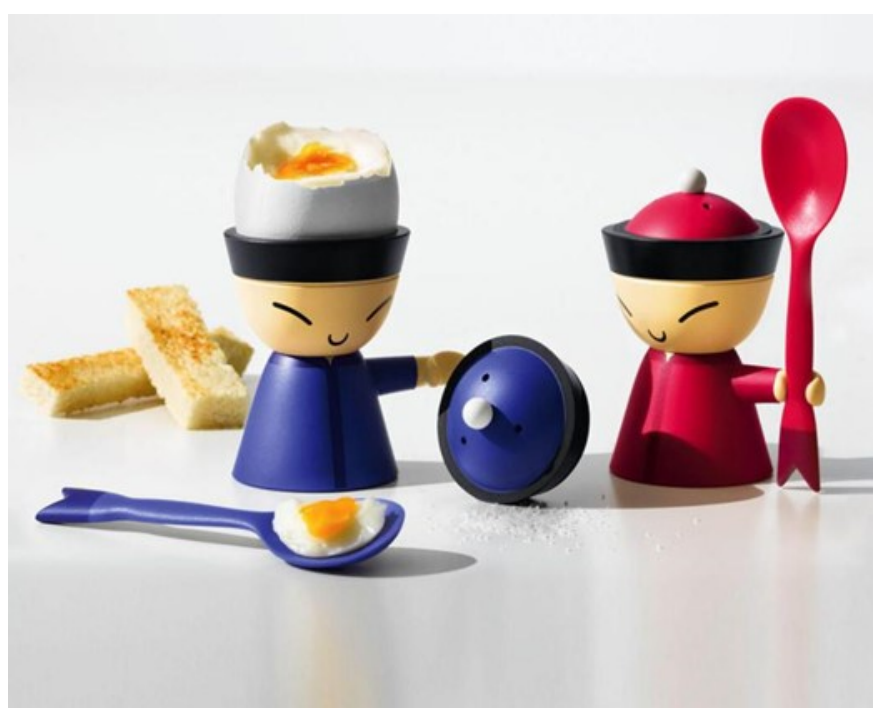

Figure 28 The Chin Family 
Inevitably, the cute portrayals of the historical emperor in the Chin Dynasty have been popular among young Chinese people. Compared to the original solemn portrait, the cute mascots are more adorable and funnier which make people feel friendly to the ancient emperors.

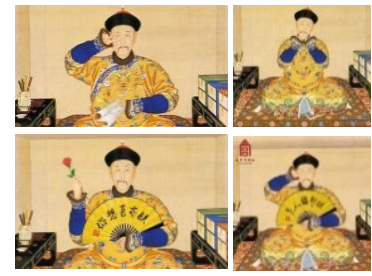

A series of portrayals of cute emperor Yong Zheng

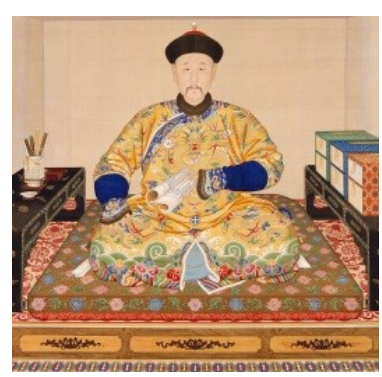

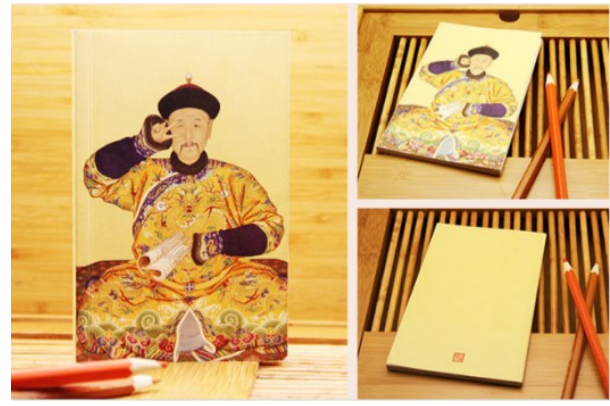

Yong Zheng's cute portrayal on the cover of the notebook

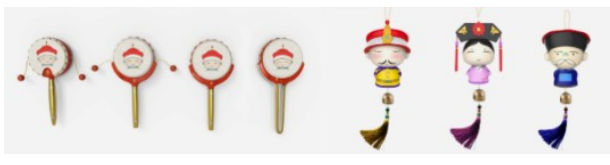

Toys of little Emperors: rattle-drum and jingle bell, by LKK Design Company

Figure 29 Cute images of historical characters

The twelve ladies, as another example, are the main characters in the novel 'A Dream in Red Mansion', which is one of the four great Chinese masterpieces of novel writing. For a long time, the images of the twelve girls have been restricted to the descriptions of the classics. In 1981, the China Post published a set of stamps depicting the twelve ladies, and their appearances looked traditional and classic. Today, the twelve ladies have been designed in round shapes with big heads and small bodies to look cute (Figure 30). 


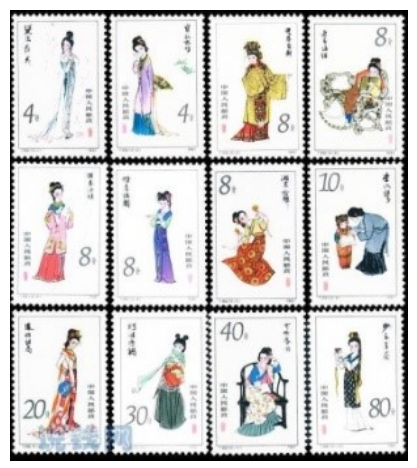

The stamps of the Twelve Ladies, China Post, 1981

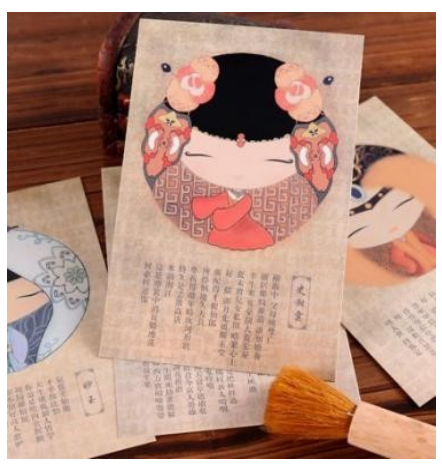

The adorable version of the Twelve Ladies

Figure 30 Cute images of literary characters

In other countries, cultural products also have adopted the idea of cuteness. For example, in Greece, Yonas Design Ltd. designed a series of miniature ouzo bottles for their tourist markets (Figure 31). The ouzo bottles were transformed into figures wearing traditional Greek folk costumes and the male and female costumes are from different regions of Greece.

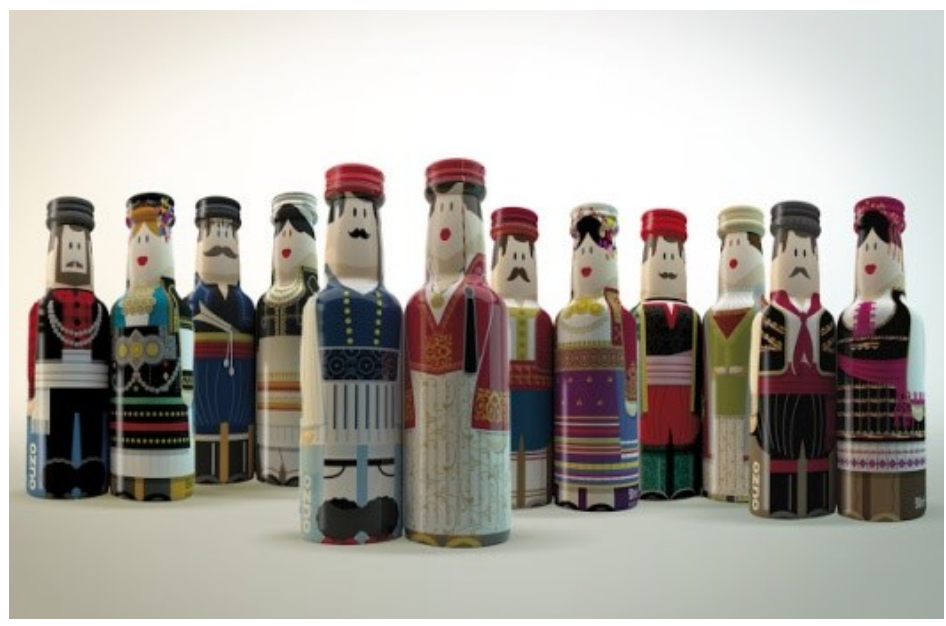

Figure 31 Gogreek ouzo miniatures bottle 


\section{Story (or Anecdote, poem)}

In China, the story conveys a sense of our history and heritage as well as celebrating how previous generations dealt with their lives. Since myths and historic legends have been passed down through countless generations, re-telling those stories would be an effective element to develop a cultural product. In Beijing's metro, a modern example, the mural arts show historic stories of the king who developed a platform of gold to recruit talented young government officials (Figure 32). Also, ancient storytelling, the religious, cultural heritages such as Dun Huang Murals present Buddhist stories on walls. Taking advantage of the thousands of murals, the souvenir industry has developed many cultural products. Being inspired by a series of the murals which tell a story about a deer emperor, LKK Company designed mugs and pencil boxes. The mugs and pencil boxes look very modern since the colors are bright, and the images are concise, the deer is the only image on the products.
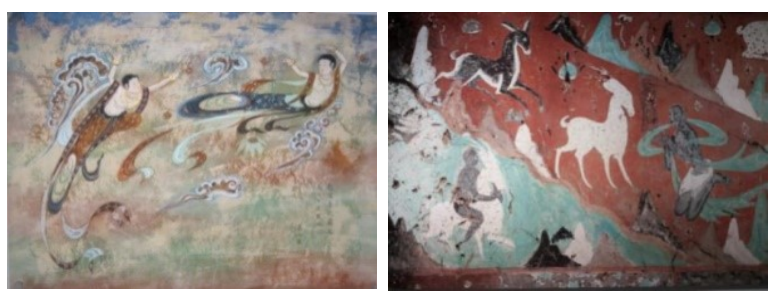

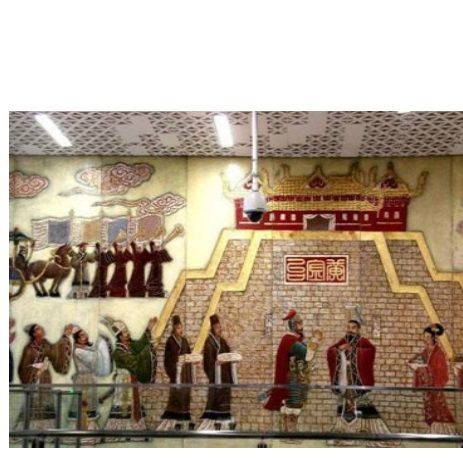

Figure 32 The storytelling mural in the metro in Beijing
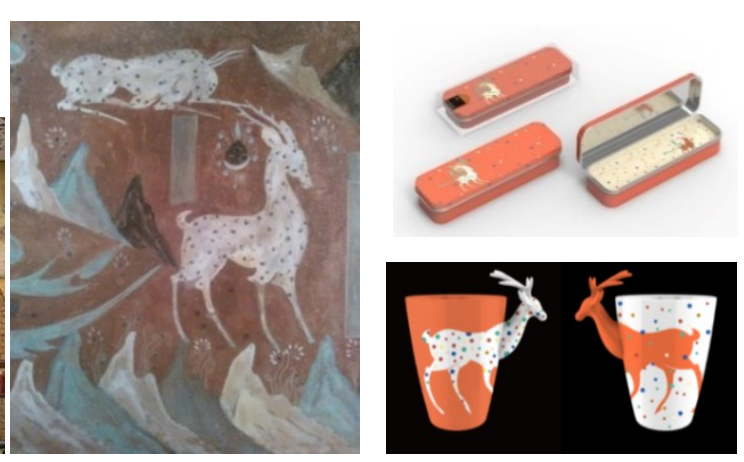

Figure 33 Traditional patterns on the Dun Huang Murals 
In addition, a series of Chinese tea beverages, Eastern Leaf was designed by the English design agency Pearlfisher, using the Chinese historic stories of tea as their design elements (Figure 34). On the package of Oolong tea, the sailing ship marks the history of the first ship that transported oolong tea to Britain, where it gradually became the English afternoon tea among the upper class. Choosing one representative image to imply the historical story not only has made the packages look concise but also distinctive due to its cultural identity.

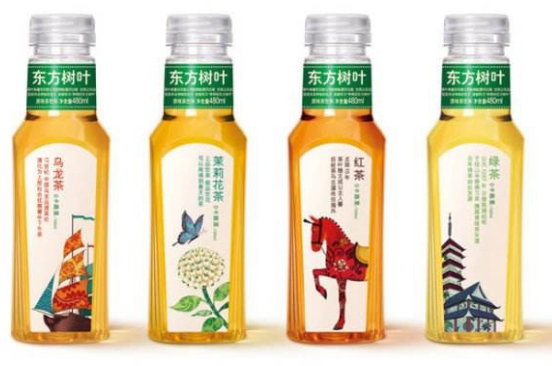

Figure 34 Eastern Leaf

Apart from ancient stories, literature is another valuable embodiment of a nation's culture. For example, the poetry of the Tang Dynasty is one of the most precious cultural heritages of China, which is the typical representation of Chinese artistic conception (Zhang, 2007, p. 103). Poets usually expressed their values and moods by depicting a scenario. One famous poem from the Tang Dynasty is called "Snow on the River". The author described a scene of an old fisherman who was fishing alone in winter when it was snowing heavily. It was a fantasy imagined by the author to express his desire of getting rid of secular worries and his insistence on his ideals (the heavy snow couldn't stop my fishing). Although the poet didn't use a word to directly express his own feelings, the 
readers could understand his unspoken implications and emotions through the scene he described.

Nowadays, like poems and painting arts, a product can also convey certain emotions and views through an artistic conception. A censer (Figure 35) designed by the LKK Company was inspired by the Poem "Snow on the River." Additionally, the Design Brand WEIS also developed a similar censer (Figure 36). The design pictures a fisherman sitting on a boat, which would remind people of the story in the old poem accompanied by the sentiment from that poem----self-affirmation and detachment.

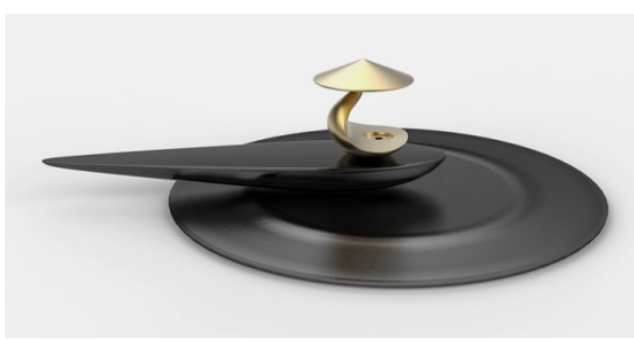

Figure 35 The censer designed by LKK

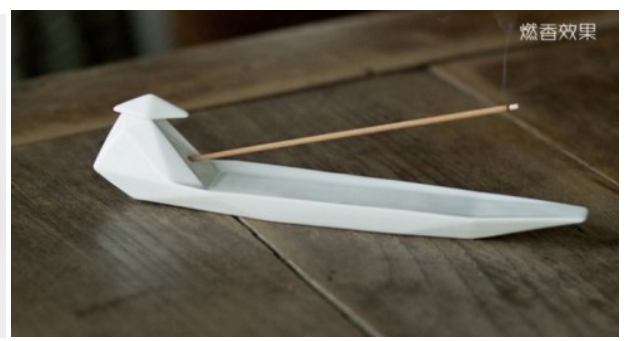

Figure 36 The censer designed by WEIS

\section{Metaphor}

Metaphor is a way to understand and experience one thing through another thing (Lakoff and Johnson, 1980). In cultural product design, the concept of metaphors often is employed as a way to represent a particular culture. The Starbucks coffee shop in Fu Zhou, China, for example, has used giant GO Stones as a metaphor to represent Chinese culture (figure 38). Also, the traditional Chinese birdcage (Figure 39) is used as another metaphor to symbolize Chinese cultures to increase the cultural aesthetics as well. 

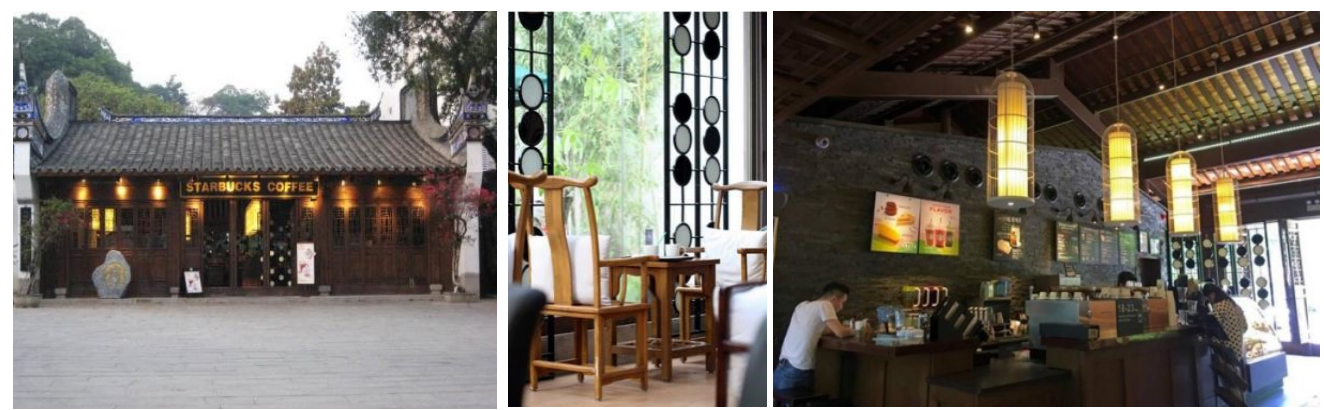

Figure 37 Starbucks in Fu Zhou, China

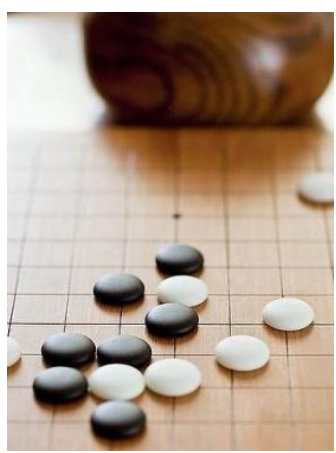

Figure 38 The game of GO

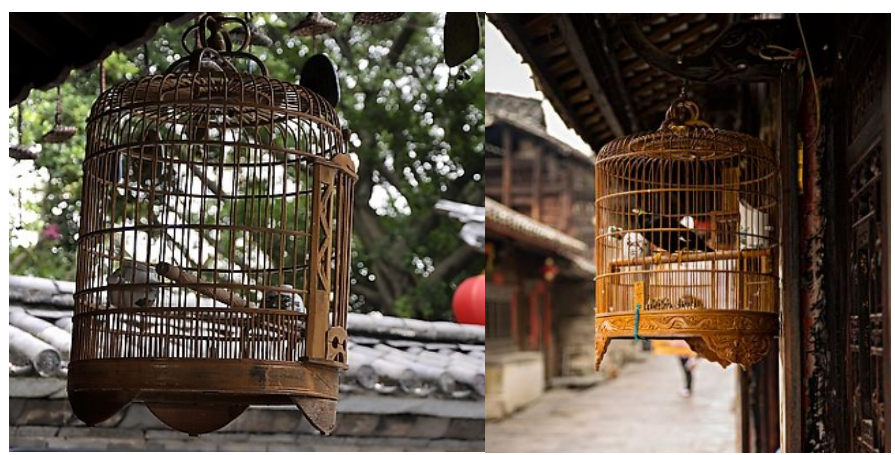

Figure 39 Traditional Chinese birdcages

\section{The Summary of Cultural design elements}

Based on investigation of the current Chinese cultural products above, the key elements of current Chinese cultural product could be analyzed as pattern, form, material, function, and emotion.

By referring to Lin's (2009) notion of the cultural layer, some categories were developed with more distinction to present a more specific classification of cultural elements in the following chart. At the Inner level, according to the examples of current cultural products, the cultural elements for designing Cute Mascots can be historical/literary figures, traditional garments, and animals. In the category of Storytelling, a lot of cultural resources can be used for design such as history, anecdotes, 
myths, and poems. In the category of Metaphor most cultural characteristics stem from traditional forms, thus, the cultural elements can be the same as those in the category of Pattern and Form in the outer level.

All the examples of current cultural products have both aspects of the old and new to different extents, such as old functions with new technology/materials, old patterns on modern items. However, as we can see from current cultural products, most cultural symbols are too apparent and strong, which brought up an issue of how to adopt cultural elements in a appropriate way to avoid making a product that looks like it came from a museum? This notion brought an attention to investigate how to make a better combination of traditional and modern aspects in a cross-cultural product, so as to make it more acceptable by global users is required.

\subsection{Understand User's (i.e. tea drinkers) perception}

According to Norman (2012), cultural differences are essential in governing social activities, types of foods and stylistic preferences. Although activities in contemporary life such as office work and transportation are dominated by technology, traditional activities are still heavily determined by culture. For example, in some countries such as China, India, Japan, Korea, and the UK, tea is a traditional beverage, and the whole process of making and drinking tea is a history-honored activity reflecting their lifestyle, custom, and philosophy. Thus, each culture has its own unique way of drinking tea and

ritual and process of making tea which influence the design of their own tea set, including a teacup, a teapot, and other items. Currently, however, the trend of the tea drinking ritual has been simplified for busy modern people. Instead of using a full tea set, they prefer to 
use a tea bag in a mug, and it seems that the intricate personal meaning of drinking tea given by culture is diminished by their outside activities (Hannam, 1997).

\subsubsection{Semi-structured Interviews}

To understand the personal perceptions about drinking tea, this study employed the semi-structured interview to gather an individual's perception of drinking tea and their intact perspectives (Hannam, 1997; Bricki \& Green, 2007). Since semi-structured interviews contain open-ended questions allowing the interviewees to express their own opinions in their own terms and tell their stories and personal experiences which may contain vital information for the topic, this study employed the semi-structured interview method for data collection by asking questions such as " 1 ) what is your experience of drinking tea? 2) what are some particular reasons to drink tea?"

The interview was conducted through face-to-face conversations as well as phone interviews. Most interviews lasted around 10 minutes, and a few of them went up to 30 minutes. 35 interviews were conducted in Chinese and 65 in English. The researcher also took notes to capture some critical concerns during the interviews.

\section{Sampling}

For the sampling, the crucial concern was defining the qualification of the target participants. All the participants do not have any traumatized reaction to tea.

The age of the interviewees is from 17 to 87 years old who drink tea regularly or occasionally. Specifically, they were customers or workers at tea stores, beverage shops and restaurant (e.g., Fleur Tea House, The Tea Party, The Vanitea, Herbal Time in SK, 
Starbucks, the Fry, Nordstrom, etc.), the owners of tea shops (e.g. The World of Tea, Nectar, The Tea Party, Tea Store, Maple Valley Tea World), other tea drinkers that the author met at busy shopping malls, Government offices, a Chinese church and some faculties at Carleton University in Ottawa, ON, Canada. The specific apportion of different vocations is shown in table 5.

Table 5 Different Vocations of Interviewees

\begin{tabular}{|l|l|}
\hline Participants & Number \\
\hline Owners of a tea store & 5 \\
\hline Workers in tea stores & 5 \\
\hline Worker or students & 83 \\
\hline Retirement & 7 \\
\hline
\end{tabular}

The first question in the interview questionnaire, "How long have you lived in Canada? Where do you come from? Can you tell me about your hometown? (What province? How long have you lived there? Is there any famous local tea product in your hometown? Etc.) ", were used to understanding the participant's different cultural backgrounds and tea culture. According to the Collins dictionary, hometown is "the town, city, etc. where a person was born or grew up or where one presently lives”. Based on this definition, in this study, a Canadian is defined as the one who was born or grew up in Canada or those who have live in Canada principally. Among the 100 participants, 40 are from China, 43 are from Canada and 17 from other countries all over the world (Appendix B). 
Table 6: Cultural Background of Interviewees

\begin{tabular}{|l|l|}
\hline Cultural background & Number \\
\hline Chinese & 40 \\
\hline Canadian & 43 \\
\hline $\begin{array}{l}\text { Other (the USA, England, France; Turkey; Africa; Kuwait; Vietnam, Lao; } \\
\text { Philippine \& Korea) }\end{array}$ & 17 \\
\hline
\end{tabular}

The second question was asking whether the tea affected their culture as well as if they are interested in their tea culture. In the interview, most participants came from places where various salient tea cultures were nourished and flourished such as Asia, Africa, and European, and they are all famous for their local produced tea.

\section{Interview questionnaires}

The interview questions were designed to help the researcher to understand how people from different cultural backgrounds perceive tea, how they drink tea, and what cultural factors influence them when they drink tea. Most of the interviews were recorded through a voice recording app in the researcher's cellphones while taking notes which were transcribed later.

Below are the five interview questions that the researcher used as a guideline during the interviews.

Q1. How long have you lived in Canada? Where do you come from? Can you tell me about your hometown? (What province? How long have you lived there? Is there any famous local product in your hometown? Etc.) 
Q2. Is drinking tea popular in your hometown? Is there any particular type of tea in your hometown?

Q3. Good! I am particularly interested in knowing more about the beverage you would like to drink such as a tea or coffee. What is your favorite drink? How often / how many cups of tea (or coffee) do you drink per day? When do you drink during a day? (E.g. Morning, as soon as you wake up in the morning, after a meal), what would you do when you drink a cup of tea?

Q4. If you prefer drinking tea rather than coffee (or vice versa), do you have any particular reason? What are the reasons to choose tea for your everyday drink? When did you start to drink tea? Why?

Q5. Where is your favorite place to drink a cup of tea or coffee? Have you been to any tea house in Ottawa? How was that? Have you ever been to a tea house that impressed you very much?

\subsubsection{Data Analysis}

\section{Thematic Analysis}

The method to analyze the interview data is a thematic analysis which is the process of identifying patterns or themes within a qualitative dataset (Braun \& Clarke, 2006; Bricki \& Green, 2007). In order to identify common issues and central themes, the researcher followed four stages of the thematic analysis; reading transcripts, identifying themes, developing a coding scheme, and coding the data (Bricki \& Green, 2007). Then, the outcomes were plotted and organized visually in a user position map.

After transcribing the recorded interview, first of all, the researcher made a careful observation of the data to look for common patterns to identify themes. Some keywords were made beside the transcriptions to note what the interviewee is referring to. For 
example, the transcript below shows how the researcher developed a theme from an interview.

"When I was in Foshan as a child, I lived by the river. In the night, people walk and drink tea outside. There are many tea houses along the street beside my home, sometimes my parents and their friends just talked with each other as they drank tea outside in the night. I think tea is a culture and a lifestyle. Tea makes people closer."

The keywords of this dialog would be 'social relationship' moreover, its unique features are from its circumstances such as natural atmosphere (i.e., Riverside) and relaxation (i.e., talking, walking, and drinking). After careful reviews, keywords were defined, and several themes were developed based on the frequency of keywords and interviewee's emotional intensity of their responses.

Once themes are identified, they were coded by a number and applied to the whole set of data. For example, a theme, "Relaxation" is coded as number 1, and the "Social relationship" is coded by 4 .

After all interviews are done, all the data are transcribed in the table to understand user's perception of tea by identifying the primary and the secondary keywords. The transcriptions were reviewed, and the keywords were developed by the researcher as well as the thesis advisor, Prof. WonJoon Chung.

As a result, the author identified 8 different perceptions of tea based on the dialogue in the interview which is presented in the next section. 


\section{RELAXATION \& MEDITATION}

The most significant perception of tea is relaxation. Along the track of history, tea has been mostly regarded as a drink for relaxation and meditation. People like a cup of tea when they feel peaceful and relaxed, for example, with some recreation like watching TV or reading. Sometimes when they face stress, tea-making and drinking is an excuse and a chance for a rest both mentally and physically. Here is the conversation from the interviews about relaxation.

"I regard brewing tea as relaxing. I work for several hours and take five minutes to make tea. Sometimes when I face some problems in my work, I would drink tea as I am thinking. (Chun pei Lin)"

"I like to drink tea at home quietly. I don't drink tea in a noisy place and I also don't like to go out for tea. I like to have tea alone and quietly, so I can concentrate and think about something. (Minjie Ma)"

"I drink tea before my performance (audition show), to calm down. (Nicholas)"

"I drink tea every day like water, but if there has to be an activity with tea, I would say copying Buddha scriptures sometimes. Tea is a way how you live, like I said, copying scriptures can make you calm down. Tea also needs time to ferment, if you want good tea, you need to wait. So tea is also an attitude to life. (Ya Zhi)"

"When I feel stressful in my work, I would prefer drinking tea since tea can make people calm down. When I drink tea, I do nothing but focus on my tea and enjoy it quietly. (Mulin)"

"I don't relax very often, so tea is a very nice way for me to take 5 minutes, doing nothing. (Susan)"

"I prefer a quiet place at home and l enjoy looking people passing by through the window. (Richard)"

"I like to sit here and I can watch people. (Catherine)"

"When I drink tea at home, I just stare blankly and empty my mind, which is relaxed and calm. (Yuchen Wang)"

"I meant that for me, it's not only about the tea but the whole experience so the place should be nice and cozy. (Marie)"

"Sometimes, as I am off the work, I would like to brew tea with my tea sets and enjoy it with reading. (Wenli Zhu)"

"I usually drink it when I am watching TV. (Charles)"

"When I need caffeine, I go for coffee but if I want hot drink I will have tea. I drink tea for enjoyment. But coffee is not for enjoyment. (Lisa)"

"I have breakfast with British tea. And have tea with something sweet after lunch and dinner. (Pinar tuncer)"

"Sometimes after a meal, I have tea with desserts with families. (Ardien)" 
Cultural Product Design

\section{HEALTH}

Similar to relaxation, health is also a common perception of tea for the participants. Many people said they consider tea as their daily drink because they believe tea has many

health benefits and has less caffeine compared to coffee.

\section{Less Caffeine}

"I prefer tea. I cannot drink coffee. It's too strong for me. Tea's caffeine is acceptable. (Shirmen)" "Coffee has too much caffeine. It makes my heart beat faster and I get nervous feeling. But if I don't drink tea I get headache. I just need a little bit caffeine. (Nathalie)"

"When I was in secondary school, I often felt sleepy, tea is better than coffee. Coffee has too much caffeine. (Yiwei Zhang)"

"I almost have one coffee every morning during weekdays, so on the weekends, I don't drink coffee, I choose tea instead since I don't want too much caffeine. (Jimmy)"

\section{Sick}

"I never drink tea only if I feel sick or I get cold, I would think about drinking tea. (Nancie")" "I also drink a lot more tea (herbal tea) when I'm sick. (Jimmy)"

\section{Health benefits}

"If I drink coffee, I must add coffee mate and sugar which I think unhealthy. Tea can refresh myself, remove fat, and green tea is anti-cancer. (Wenli Zhu)"

"Traditional Chinese tea is health which has theophylline, helping lose weight. (Guan Shan)"

\section{CEREMONIAL}

Some participants emphasize ceremonial aspects in tea drinking. Ritual drinking with a whole tea set usually happens when people have guests visiting or a formal social gathering. A few participants also use a full tea set from time to time when they have the luxury. In general, the ceremonial drinking is often linked with the social relationship. 


\section{Full Tea set}

"If I have friends visiting me, we will have tea using tea sets. When I am alone, I just use a mug. (Shenwei)"

"I must use a whole tea set for drinking tea. (Zhiya)"

"When I am in my office, I just use a mug to drink tea. But when I am at home, I use my whole tea sets, I watch TV as I am drinking tea. (Zi Xuan Wang)"

"Sometimes, as I am off the work, I would like to brew tea with my tea sets and enjoy it with reading. (Wenli $\mathrm{Zhu}$ )"

"How the tea is served (rituals) will attract people to go for the experience you won't have at home. (Lisa)"

\section{SOCIAL RELATIONSHIP}

Social relationship is another vital image of tea. In the past, people would express their friendship and cherish each other through social interactions like drinking tea which gradually became a traditional convention. The activity of tea drinking in Chinese society has always been more strongly related to interpersonal relationships and social contact (Kumakura, 2002). To date, drinking tea is a way to make friends, or meet with old acquaintances especially in Chinese community (Huang \& Deng, 2008). While in Canada, socializing with tea is more like a time of amusement. But on some momentous occasions like a family gathering or a birthday party, ceremonial tea drinking is always appropriate, and also it has become a significant way to enhance the relationships and develop closer connections within a family regardless of people's cultural background.

\section{SOCIAL RELATIONSHIP}

"Every time I go back to Chengdu, I would drink tea when I play mahjong, twice a week." (Will)

"Tea is not an everyday drink; if I have time at home with my friends or girlfriend, we would have tea. It's a social drink." (Daniel)

"I like to enjoy tea with local tea farmers. We can talk for a long time. (Jean)" 


\section{EMOTIONAL ATTACHMENT}

Tea also provides people with a sense of continuity from now to their old experience.

For instance, some traveled to a new place and learned the tea culture there. After they came back to their home country, drinking tea became a connection to their memories in that foreign country. Besides, if someone grew up in a country where tea is a traditional common drink, they would feel more familiar with tea than other beverages when they are away from home. In this case, drinking tea may strengthen one's selfidentity and relieve nostalgia especially when someone is in a transition phase, living away from their culture that raised and immersed them. Thus, tea is a bridge between experience and current situations.

\section{MEMORY}

"I started tea in my thirties. Several years ago, I went to Kenya which produces many teas, and I learned black tea there. In Morocco, I learned to drink mint tea, and in Egypt, I learned sweet tea. (Dorcas)"

"Sometimes I have green tea at home by myself. After drinking green tea a lot in China in 2007, I wanted to maintain that connection, so that's one way I do it. (Allan)"

"They serve tea with sandwiches. That's what I did with my families. (Todd)"

"Another thing about tea is when I was a child, my grandparents are from England, and they served tea with milk all the time. I got used to tea with milk and sugar. Later my wife introduced me to tea with lemon. (Allan)"

"When I was a child, my grandmother always made tea, and we drink tea. (Josh)"

"After I was 20 years old, I started tea regularly. My grandpa always had tea when I was younger. (Monty)"

"When I was young, I drank tea with my parents. (Sarah)"

\section{ATMOSPHERE}

According to some interviewees' experiences and preferences, they enjoyed drinking tea in natural environments such as beside a river, mountains and in a backyard. 
The reason is that the proximity with nature helped them plunge into a relaxing and enjoyable environment. Similar to the other side of the earth, people's attachment to nature can also be found in the traditional culture such as Chinese Garden Architecture. In Chinese gardens, besides some indispensable design features including trees, flowers, rivers, and stones, tea is always the key element to make the whole closer to the tranquility of nature, because tea is a part of nature and it goes along well with nature.

What's more, due to rapid social change, people are struggling with the hustle and bustle of modern society, and they appreciate an opportunity to have a special experience which distinguishes their daily life. Being exposed to natural surroundings is a chance for them to escape worldly trivia. Similarly, in addition to nature, some people enjoy a fancy modern atmosphere, and some seek an authentic atmosphere.

\section{Nature}

"I prefer the place that closes to nature, like a park, Rideau Canal, or the balcony of the house, which would make me quiet. I enjoy watching the sky quietly. (Shirmen)" "Just sit outside on the back deck at home. No matter sunny or raining. (Kate)" "It is the best to have tea in the desert such as Africa, Morocco, and Egypt. Especially after hiking, you drink a cup of tea at the top of the mountain. In winter they have hot tea and in summer have ice tea. That will be wonderful. (Dorcas)"

"On the hillside of Wuyi mountain, there was an outdoor tea house. There is a waterfall beside it. It's kind of like a stall. The mountain and river (waterfall) are so beautiful, the tea was brewed by the spring water, and the experience was very good. (Zi Xuan Wang)"

"The mountain and river (waterfall) are so beautiful, the tea was brewed by the spring water, and the experience was very good. (Zi Xuan Wang)"

"It better look authentic, imaging you are walking on the Himalaya, like a Tibet tea house, that would be cool in Ottawa. (Carl)"

\section{Modern}

"I like Drift, there are lots of types of drinks, the environment is cozy, and they have music, it looks modern. (Anessa)"

"1. Large selections 2. Nicely decorated (I like modern style), everything is well-maintained 3. Large rooms. Have good neighborhoods of the town. (Marie)" 


\section{CULTURAL TRADITION}

When people talked about tea, culture is an inevitable topic since there is a long history of drinking tea in both Chinese and English culture, which makes their tea drinking habits special and attractive. People mentioned cultural aspects including decorations, knowledge, anecdotes, and special experiences like how tea is served ritually. They prefer an authentic cultural experience which they cannot usually reach in their busy lives, in terms of how special tea is served, how exotic the traditional decoration is, and how intriguing the knowledge or anecdotes are.

\section{CULTURAL TRADITION}

CZ: Have you been to any tea house in Ottawa? How did you like the place?

"Tea party: not busy, quiet environment, good atmosphere, relaxing, customized flavors. I felt the culture and mental, psychological thing. It's special and fancy. (Nicholas)" "In China, there are special tea houses. The tea tastes good, it's a place for family or friends gathering, and it's very well decorated and traditional. The atmosphere is Chinese traditional, they have a small table, low bench, and good tea cups not the paper cups. It looks old. (Ida)"

"The ambiance there was Turkish traditional with Turkish music. (Sahil)"

"The traditional tea house in my imagination would be very quiet, have wood tables, the decorations would be Chinese painting, calligraphy. The background music can be Chinese music played by gu zheng. (Ziyu Wang)"

"The setting or atmosphere is traditional and cozy. They would have nice tea sets. (Lisa)"

"The furniture should be beautiful, and the colors were chosen for the décor be appealing. (Marie)"

CZ: Have you ever been to a tea house that impressed you very much?

"I haven't been to an impressive tea house. I don't think Ottawa has any traditional tea house. I think a traditional tea house should 1) offer different tea; 2) offer service, it's not like I go to the counter but the servers come to me; 3) Have traditional elements; 4) Educate more traditions. (Claudie)" "In Guang Zhou, the tea house is a pavilion. Everyone has an individual teapot and under a teapot there is a candle to keep it hot. I like the process of making tea and I enjoyed it. (Joyce) 


\section{INCONVENIENCE}

Considering making tea, most Chinese participants are fastidious about the authentic Chinese tea flavors so they do not appreciate tea bags, but also think loose tea leaves are impractical and troublesome for most of the time. Thus, they would rather drink water for convenience.

\section{INCONVENIENCE}

"I usually drink water, but I like tea. I am just so lazy to brew it. (Alicia)"

"I started to drink more tea in Africa (Tunisia) where it was very common. In Africa, I also drank tea more, but not as often as Asia because it was more widely offered in restaurants and where we were going. (Sylvain)"

"I would choose coffee because coffee is easy to get here, while tea needs to be brewed on my own. (Hui Zhang)"

"I would buy tea in Tim Hortons. I seldom brew tea myself because it's troublesome (Mulin)."

"In winter time, whenever I have access to tea I would get tea because I am too cold. Either from home in the morning, I take a cup, or whenever I stop to a coffee shop during the day, I may grab one cup of tea. In my working place, there is a kettle so that I can make tea myself. When I do volunteer work, during the day, I stop by coffee shops and get some tea. (Denise)"

"I use a tea bag, I don't make tea from tea leaves even though I brought tea leaves from China because I think it is trouble and it seems I am an elder. (Song zhe heng)"

Above all, users' perceptions of tea include relaxation \& meditation, health, ceremonial, social relationship, emotional attachment, atmosphere, cultural tradition, and inconvenience. Among these perceptions, relaxation \& meditation occupied a big portion. Besides, those conceptions are connected with each other. Even though the ceremonial tea drinking was not mentioned often, other perceptions including relaxation \& meditation, social relationship, emotional attachment, and cultural tradition are more or less related to ceremonial tea drinking. 
In addition, from the findings of the Literature Review, the cultural design elements are also connected to some of the conceptions. The design elements such as pattern, form, material, and stories would contribute to the category of cultural tradition. The design element of the mid-level which is function is related to the category of ceremonial tea drinking. And the metaphor can be used for building an atmosphere of a product. In this case, nature and modernity are considered.

The code list was completed after reviewing all transcriptions, and it shows as follows:

Table 7 Theme list: Themes of drinking tea

\begin{tabular}{|l|}
\hline Theme 1 Relaxation \& Meditation \\
\hline Theme 2 Health \\
\hline Theme 3 Ceremonial \\
\hline Theme 4 Social relationship \\
\hline Theme 5 motional attachment \\
\hline Theme 6 Atmosphere \\
\hline Theme 8 Inconvenience \\
\hline
\end{tabular}

Later, the researcher needs to look for patterns across the codes. Finally, the themes were interpreted in an analytical and logical way to guarantee the drawing of possible conclusions and hypothesis. 


\subsection{Design of cross-cultural tea set}

\subsubsection{Position map}

The user position map is a method for analyzing how users group together according to two intersecting attribute scales. Each user is plotted within the boundaries of the position map. The method helps illuminate where users fall within the defined space and their relative position to one another.

It works in five steps: First, identify entities for comparison. Second, select two attributes related to entities that would be useful for comparison. Thirdly, place the entities on the position map. Then, analyze the position map. Some entities are positioned at the extreme edges, or there may be a gap where entities do not cluster. Does the gap represent unmet needs or a potential opportunity? There is also a possibility that some entities may occupy different positions over time. What are the common characteristics of the entities that fall within the same quadrant? Last, get insights and findings (Kumar, V, 2012).

\section{Classification and Attributes associated with different user types}

Since the objective of this research is to integrate traditional culture into a crosscultural product (a tea set), whether users drink tea in a traditional or simplified way should be taken into consideration. Therefore, one aspect ought to be examined is whether people drink tea in traditional style or modern style. In this case, the traditional style refers to those who prefer a ceremonial way to drink tea such as using a whole tea set and the new style refers to those who would choose a simple and easy way to drink 
tea such as using a tea bag in a mug. On the other hand, the frequency was estimated to find the users who drink tea as often as the target population.

As the map shows (Figure 40), the participants in the right upper quadrant prefer to drink tea in an easy way as a result of their busy daily life, usually when they are working or

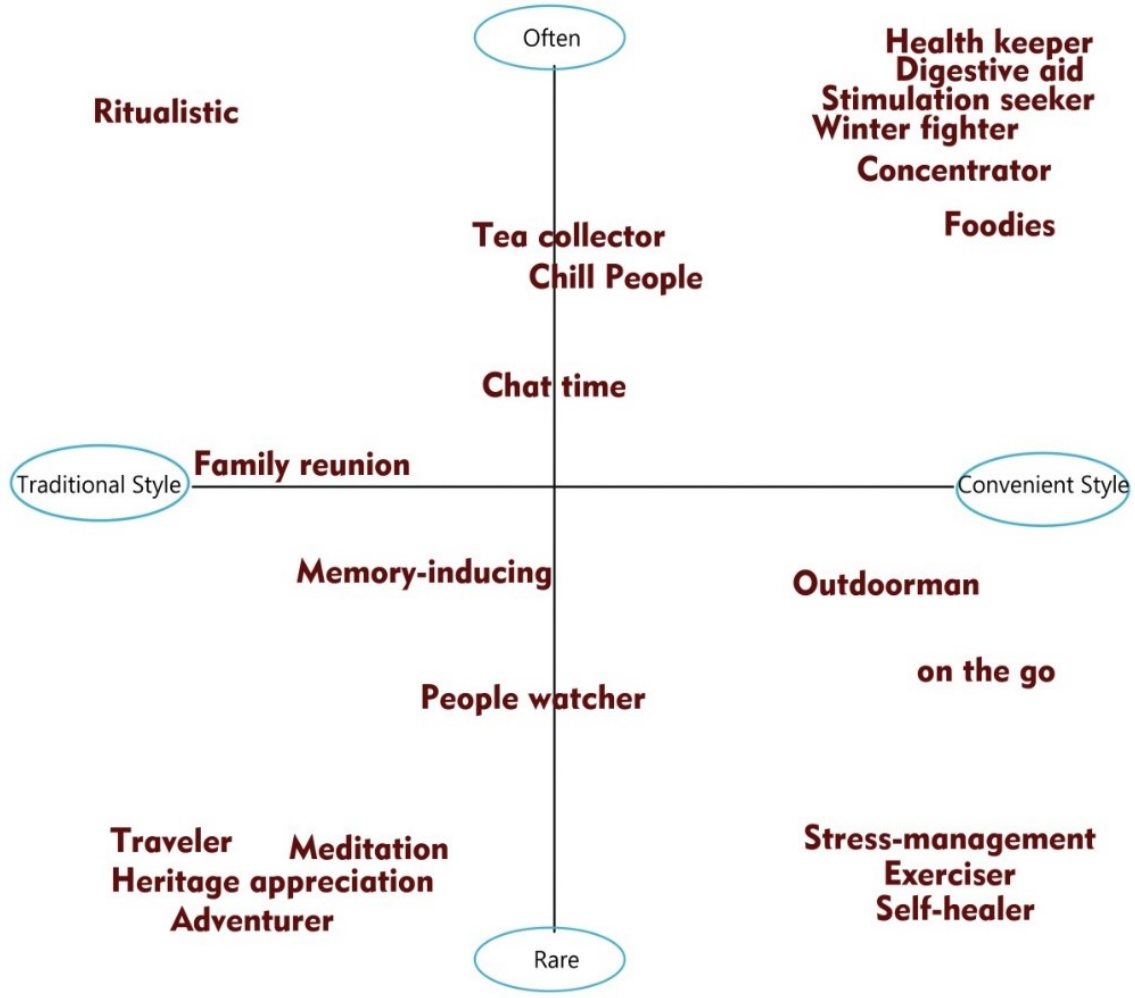

Figure 40 User position map

studying. The participants in the left upper quadrant represent those who have tea often but in a more traditional way. In this quadrant, the number of users is the smallest. Since in contemporary society, a ceremonial way to drink a cup of tea seems to be a luxury for busy modern people who live in an era of efficiency. Users in the left bottom quadrant seldom drink tea, but if they drink, they would like to do it in a traditional manner. Some of them probably will attach their personal memories or meanings to drinking tea, 
especially when they need to connect to their memories which are related to tea, they would prefer drinking tea in the same way they did in the past. In addition, some of them just appreciate relaxation through a traditional tea drinking ritual in their traveling or at certain occasional events. In the right bottom quadrant, users in the extreme edges do not take tea as their daily drink. If they drink tea, there will be some specific reasons.

Once the tea drinkers are plotted based on their frequency of drinking tea against their style to drink tea, the researcher grouped them in the four general types of users, Ceremonial, Dynamic, Contemplative, and Convenience.

\section{The target population (global users) for the tea set design}

Since this study takes tea product as an example to demonstrate to design a crosscultural product design, the global users refer to the people enjoying tea drinking in different cultural backgrounds and the cultural aspect is the traditional Chinese tea ritual and forms.

Inside of the realm of the global user, target users will be narrowed down.

According to the mind map, there are some users occupying both "convenient style" and "traditional style" because they are flexible with their way of drinking tea. They choose to have tea in leisure time, but their focus is on other activities such as socializing or watching TV instead of completely on the tea itself. 


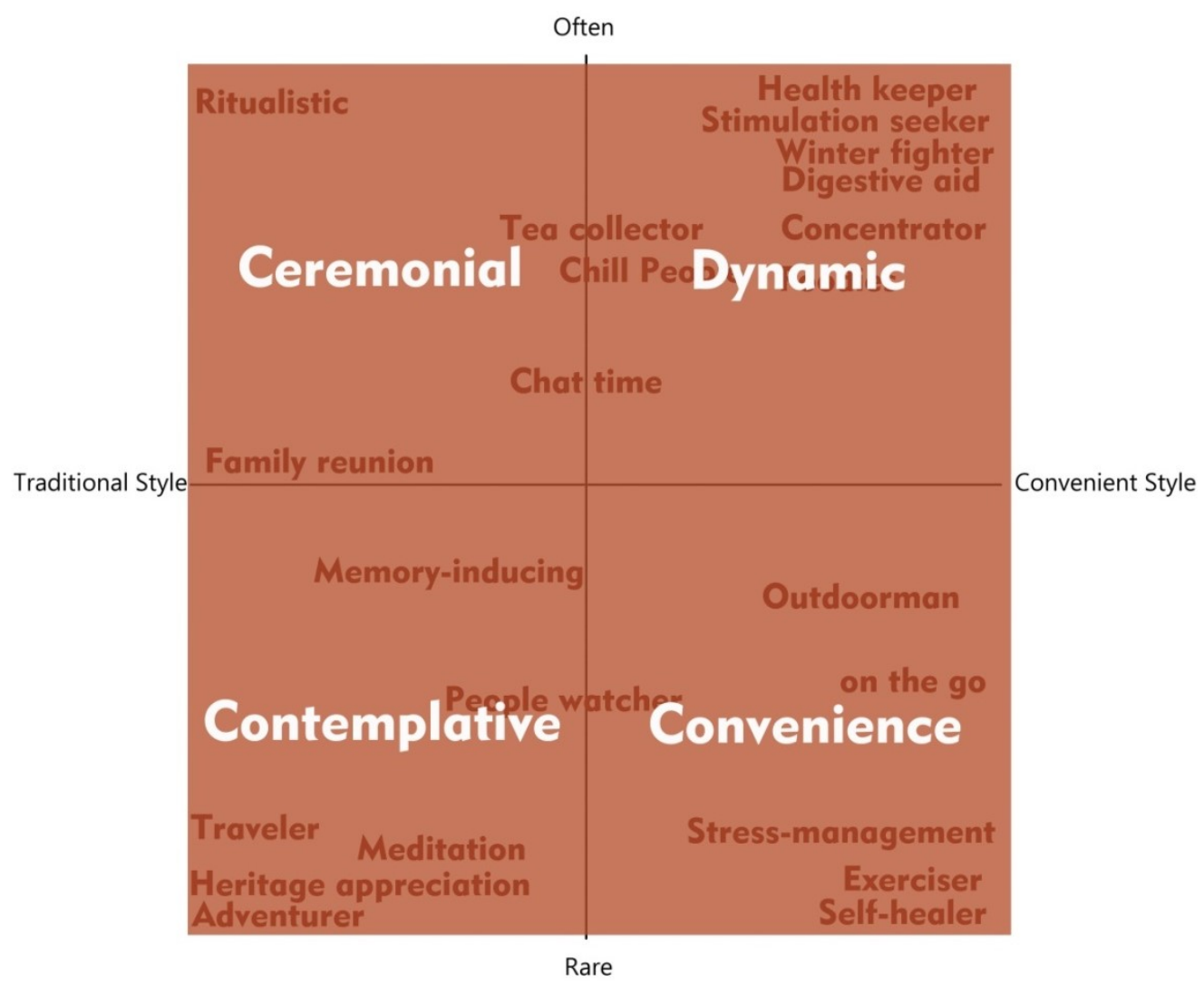

Figure 41 User group position map

In this case, a complicated ritual or a mug with a tea bag would make both work.

The researcher chose to focus this type of user group as the target population to design a tea set for the frequency of drinking tea is relatively high, and the tea sets design would require the combination of traditional cultural aspects and modern design aspects, additionally they are not the extreme users with extreme needs of a certain aspect. 


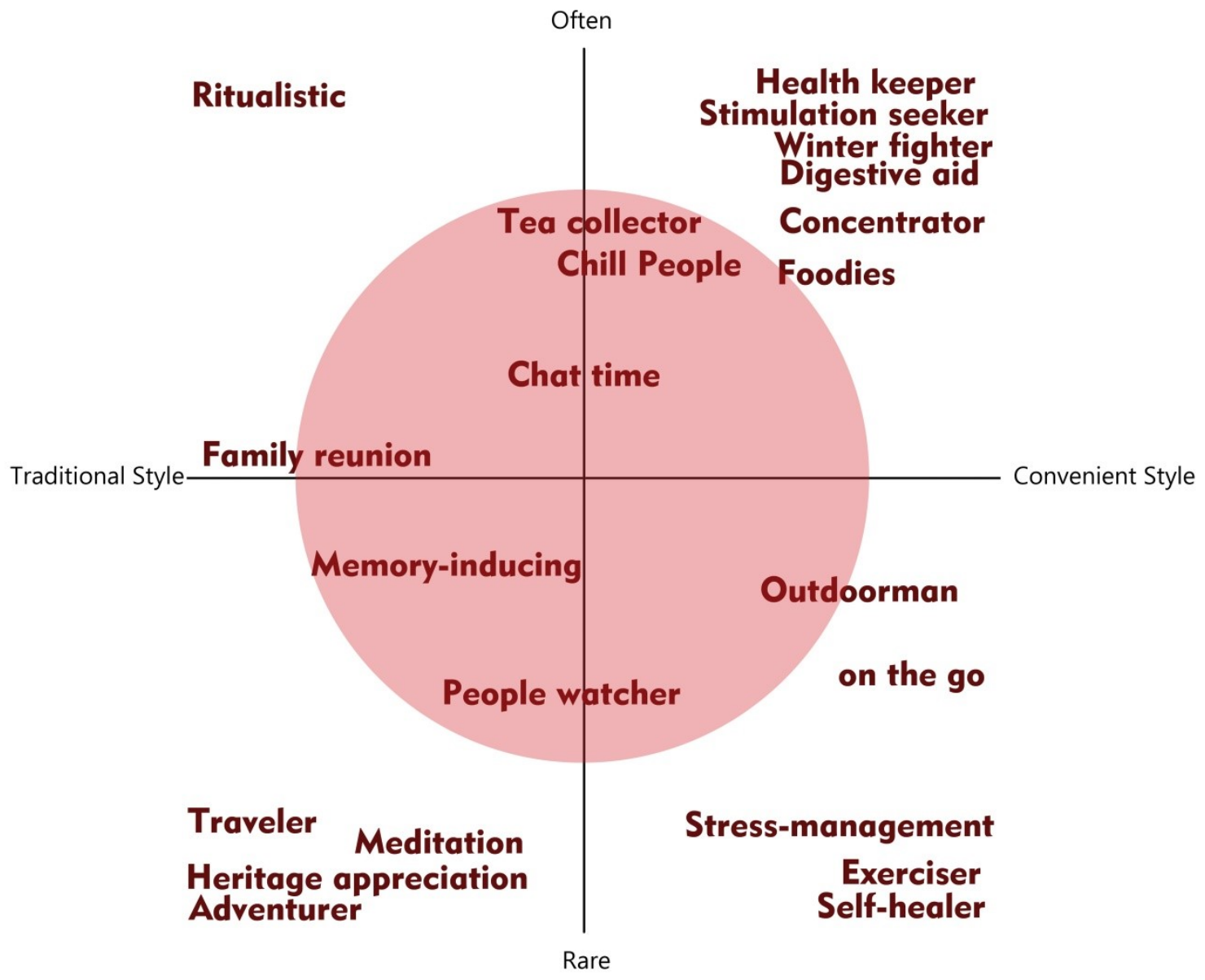

Figure 42 Target user position map

\subsubsection{Design Implication}

\section{Relaxation, Meditation \& Ceremonial}

The most common perception about tea is that people seek relaxation and relief through drinking tea. In Chinese tea art, a ritual process could help people forget about their stress for a while (Blofeld J., 1985). When they brew tea in a ceremonial way, more concentration will be on Here and Now, which could not only offer a different authentic experience distinguished from ordinary life but also turn their attention far away from worries. To be specific, in a traditional tea ceremony, users' attention would be attracted 
by usually unnoticed things like tea's color, the exquisiteness of cups, and even the sound of pouring tea. It is a way to calm down. Besides, a predefined process can reduce unsettling senses so users can feel security because they are controlling everything in the whole process. Therefore, when people want to relax or when they are free, a whole tea set can provide them with a chance to relax and meditate in a ceremonial process.

\section{Social Interactions \& Ceremonial}

The act of serving tea represents a way to express one's concern and respect for others. In a tea ceremony, serving tea is a necessary part. Especially in Asian culture, it serves as a mean for younger people to show their reverence for their elders. Here in Canada, a multicultural society, serving tea is also a way to show respect and care either for friends or senior people. From this perspective, a ceremonial tea drinking offers a chance for users to show their respect or concern for their guests.

\section{Cultural tradition \& Ceremonial}

Ritual or ceremony of brewing tea is a tradition in Asian culture. Although it is an ethnic experience of Eastern culture, global users can still benefit from the relaxation and social interaction. Thus, the tea set design will include well-equipped facilities to ensure the ceremonial process of making. Additionally, attractive and pleasurable things work better in neutral or positive situations (Norman, 2002), thus drinking tea as a positivityspreading and relaxing activity should incorporate exquisite decorations into the overall design. Considering the previous cultural design elements investigated in the second chapter, cultural aspects including pattern, form, and material, will be designed into the product's outer appearance. 
There are a host of ways of making tea in several parts of China. Kong Fu tea is popular in the southeast of China and Taiwan. Moreover, immigrants who now happen to be living in Hong Kong, Thailand, Malaysia or Singapore, remain faithful to Kong Fu manner as well (Blofeld J., 1985). In other words, Kong Fu tea is relatively more popular and familiar in an international context.

This tea making process is from the Kong Fu tea's practice. The tea making process starts from boiling water, then the boiling water is used for warming cups by rinsing cups. On one hand, this step is to clean cups. On the other hand, the higher temperature of cups is helpful to present tea's taste. After that, the host puts tea into teapot and then pours hot water into the teapot (In this design, the teapot is bigger than traditional one for containing more water. Thus, after warming cups, there is some water still left so the host doesn't need to pour hot water again). The tea made the first time is poured away. This is called "washing the leaves". One reason to do this is that the second and third infusions will be better than the first if the infusion and pouring are correctly practiced (Blofeld J., 1985). Then, the host pours hot water into the teapot for the second infusion this time the tea leaves are exposed fully and immediately send out their fragrance (Blofeld J., 1985). Afterwards, the tea would be poured into a serving cup. A serving cup is used to fill each tea cup for making every cup of tea tastes same, avoiding the situation that previously poured tea is light and latterly poured tea is strong. The last step is that the host serves tea to every guest and joins them. 
Cultural Product Design

\section{Atmosphere}

Closeness to nature is related to relieving stress as well. Since the natural environment is opposite to the busy modern life, people who are always on the go would appreciate a mental and physical gateway to turn far away from their work and stay in a different place enjoying a moment of tranquility. Therefore, a tea product that includes natural elements could offer a special experience that could reduce users' stress. In the design of the tea set, the natural elements would be incorporated metaphorically.

\section{Convenience}

In today's modern lifestyle, drinking tea might occur in a living room, a study, or an open-air garden. Hence, a portable and serviceable tea set is more appealing to the current market. Given that brewing tea requires boiling water, portable electric heating equipment would be included instead of using the stove to boil water. In addition, assembly is another consideration to add more convenience. If all parts of the tea set can be assembled together, the space can be spared and the portability is more viable.

Based on the researched cultural elements and the users' conceptions of tea, the researcher suggested a concept of tea products design (Figure 43). 

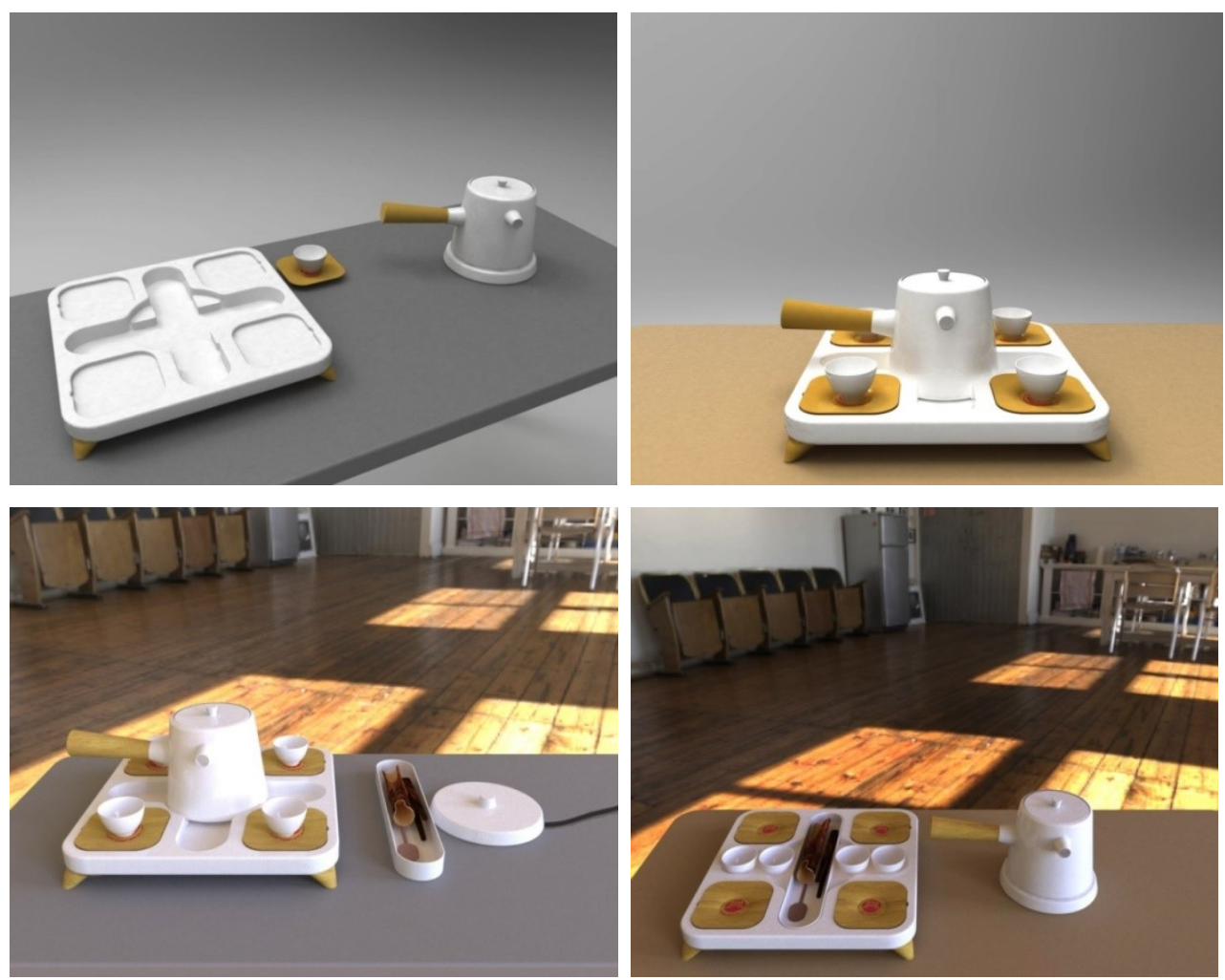

Figure 43 concept 1: tea set

In Chinese tea art, the satisfaction during drinking tea can be achieved by hearing, smelling, tasting, seeing, touching and mental consciousness. Consciousness means paying attention and concentrating on the Here and Now. Consciousness is important in enjoying tea. In today's world which is full of distractions, mindfulness needs to be cultivated, since when this is achieved by users, the relaxation and enjoyment will reveal themselves. Therefore, the whole tea set should facilitate the ritual process.

The ritual includes warming cups with hot water, washing tea leaves, filling tea with serving cups and drinking tea. Thus the tea set includes a teapot, four cups, one serving cup, other tools for taking tea leaves and a tea tray which assembles most of the functions and tools together. The tea tray also has a shallow sink where users can discard water 
after users warming cups and cleaning tea leaves. The complete process of the tea ceremony is demonstrated as followed (figure 44):

1. Boiling water

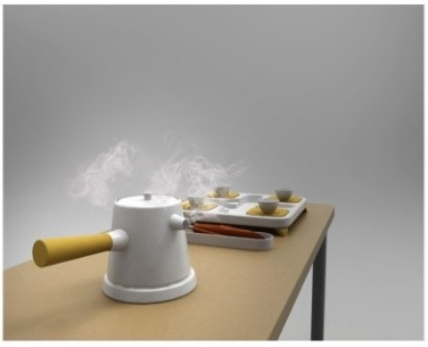

4. Put tea into tea pot

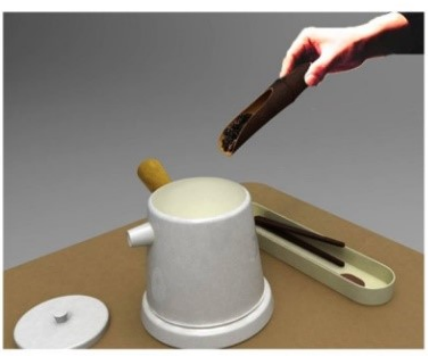

7. Pour tea in a serving cup

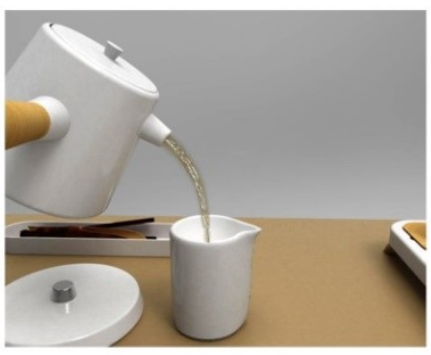

2. Rinse the tea cups

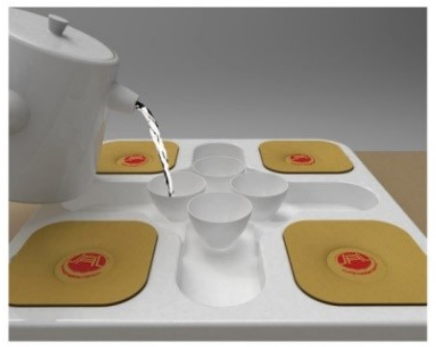

5. Clean tea leaves

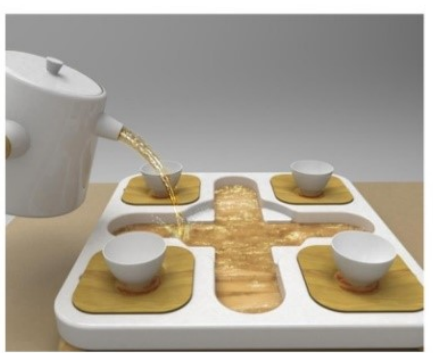

8. Fill tea cups with serving cup

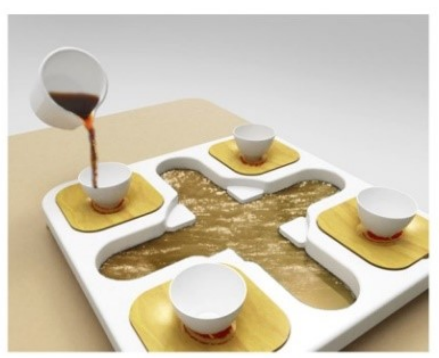

3. Discard the water

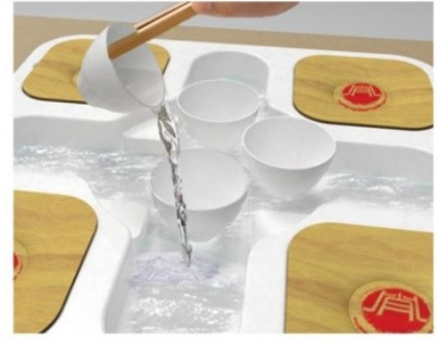

6. Refill the teapot with hot water

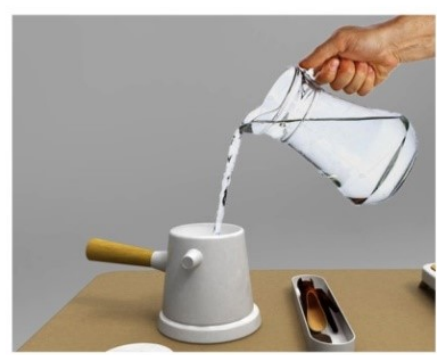

9. Keep Tea pot warm and Done

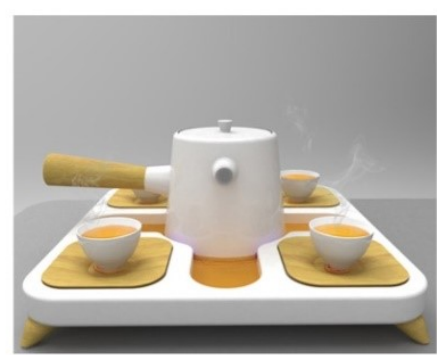

Figure 44 The complete process of tea making ceremony

\subsection{How does the tea set appeal to global market as a cross-cultural product?}

\subsubsection{Simple style}

The characteristics of the tea set design concept include the simple and minimal form, and the implicit expression of functions. The form of the tea set is not restricted to 
historically familiar shape for Chinese users but let other users feel exclusive possibly. Since this tea set design aim at cross cultural design aspects, simple and minimal form have been applied. For example, geometric shape has been applied for the design of the teapot and the tray to show a sense of implicitness and simplicity- rectangle and cylinder.

\subsubsection{Traditional elements}

Some traditional elements of Chinese culture have been employed in the tea set design which may provide nostalgic feeling to Chinese customers which provide an exotic feeling to customers from other cultures (Figure 45). For example, the shape of the tea cup and the pattern painted on the saucer are from Chinese traditions as well as the natural material, wood.

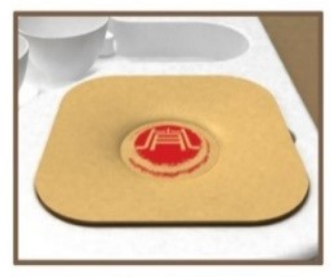

Pattern

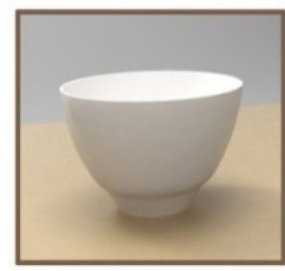

Traditioanl cup form

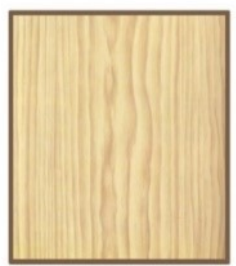

Wood material

\section{Cultural Design Elements}

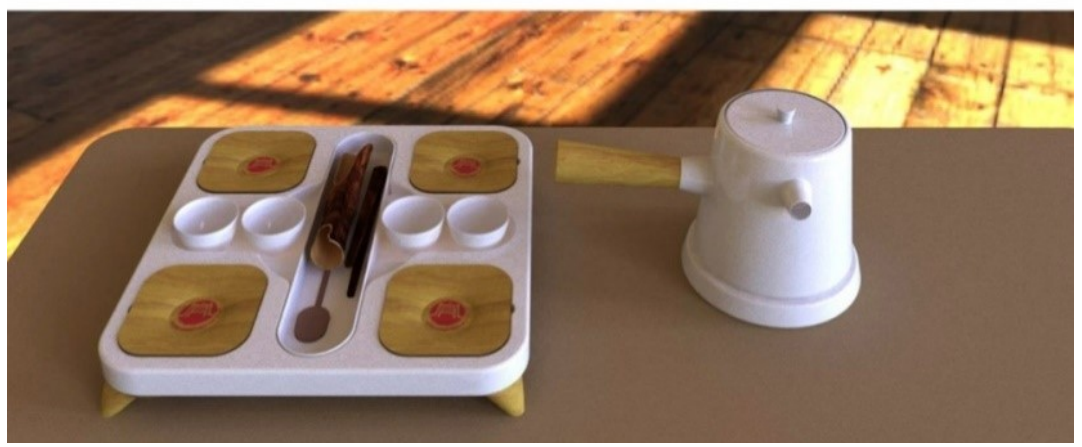

Figure 45 The cultural elements used in the design concept 


\subsubsection{Users Perceptions}

Since the tea set is designed for not Chinese customers only but also for global customer from different cultural backgrounds, the perception of drinking tea from different cultural perspectives must be identified clearly. This study found that the tea drinkers who from different cultural backgrounds considered tea drinking as a way to enhance social relationships, keep traditional culture and take a relax. In addition, they also prefer to drink a tea in natural environment. To elaborate cultural aspects, the proposed design emphasized on the ceremonial aspects to make a tea as it is highly conjunct to social activity, tradition, and relaxation. In addition, the material, wood and ceramic may help to build natural atmosphere while the convenience is embodied by the assembly, portability and the use of electricity. 


\section{Chapter 4. Results}

The purpose of this research is to develop a way to design a cross-cultural product that satisfies the local and global users' tastes. This research explored what design elements should be considered in designing a Chinese cultural product which combines traditional elements and users' perceptions. A review of previous research has defined the cultural design elements into three cultural design levels. In the outer level, the cultural elements are pattern, form, and material. The midlevel refers to the function of the product, especially the traditional usage. In the inner level, on the contrast, the emotion is the main consideration and those cultural elements that are highly linked with cultural stories, the usage of metaphor and mascot. The metaphor usually implies traditional items and the mascot is in the image of historical figures.

In order to discover the people's understandings of tea, a user-centered method, a semi-structured interview is used to explore people's conceptions of tea. First, interviews were conducted with individuals who are tea drinkers. The interviews aimed to find out what does drinking tea mean to people especially who are from China and North America. Data from the interviews and the previous studies were then used to generate implications for the final design concept.

\subsection{Design Considerations}

This study generated a set of design elements that should be considered when designing a cultural product which is suitable for global markets. These considerations can be grouped into two categories. One is the objective cultural elements that come from 
traditional heritages, and the other one is the users' conceptions of the specific culture (drinking tea).

The cultural design elements:

- The Outer level: Pattern, form, materials

- The Midlevel: Functions

- The Inner level: Emotions especially nostalgia which can be easily evoked by cultural stories, the cute mascot of historical figures, and metaphor of traditional items.

The user-centered considerations include the users' perceptions of tea drinking which needed to be kept in mind when designing tea products. These are:

- Relaxation \& Meditation

- Health

- Ceremonial

- Social relationship

- Emotional attachment

- Atmosphere

- Cultural tradition

- Inconvenience

The Figure 46 summarizes the two aspects in a cross-cultural product design. 


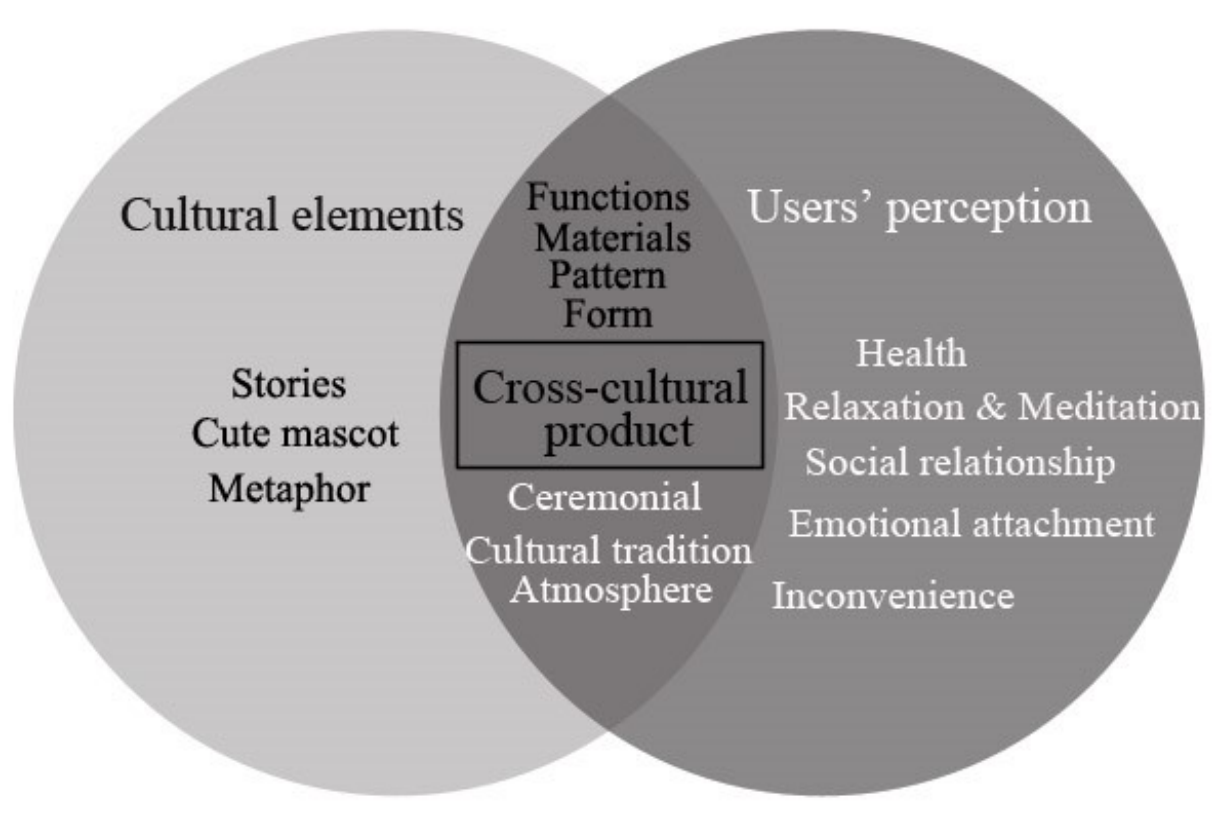

Figure 46 Two considerations in a cross-cultural product design 


\section{Chapter 5. Conclusion}

\subsection{Contributions}

The examples of cross-cultural products given by marketers mainly considered the user behaviors and functions. While in this study, the primary contribution of this research is that it proposed the combination between cultural elements and users' conceptions as a way to develop a cross-cultural product for a global market. This research was conducted from design-wise and marketing-wise views. The user-centered research was conducted to define the target market and users' conceptions. Besides, the large number of participants of this research (100) ensures that analysis can be conducted in both quantitative and qualitative ways. Therefore these cultural design elements and the process of the research can be used when developing a cross-cultural product for a multi-cultural market.

In general, this research takes initial steps in exploring designing a cross-cultural product, which can be regarded as a basic framework for future research in cultural product development.

\subsection{Discussion}

When it comes to cultural products, it's easy to think about traditional forms such as old patterns, colors, and shapes. Indeed, most cultural products on markets copy those genuine forms from many years ago. However, cultural products are not only about appearance or aesthetic but also to meet users' experiences and usability. In the research, the author found that everything has its meanings, and the qualitative research is important to dig out the meanings of the daily items. As a result, in tea product 
development, cultural aspects and users' conceptions should be both put into consideration. In addition, for a global market, the forms don't have to be too authentic or traditional which is not appealing to modern tastes and complete simulation of the old things could be too expensive in terms of time and money. Therefore, to adapt cultural products into global markets, combining traditional aspects and modern style is necessary.

In conclusion, the tastes of different generations are different in each era. Tradition is not wholly static because it can be renewed by each new generation with preserving its cultural inheritance and integrating modern style.

\subsection{Limitation and Further development}

Different cultural products focus on different cultural aspects. The cultural elements and users' conceptions of tea product in this research are more related to rituals (functions). Maybe other cultural products emphasize other cultural elements such as patterns or stories. This research only takes tea products as examples. Thus, the process of this study may not applicable for every cross-cultural product development. Tea has different cultures and histories all over the world. But some products have few connections with culture and even users' conceptions such as a key chain. For developing other cultural products, there would be further research to be conducted. 
Cultural Product Design

Appendices A

(Table 3 Summary of current cross-cultural products) 
Table 3

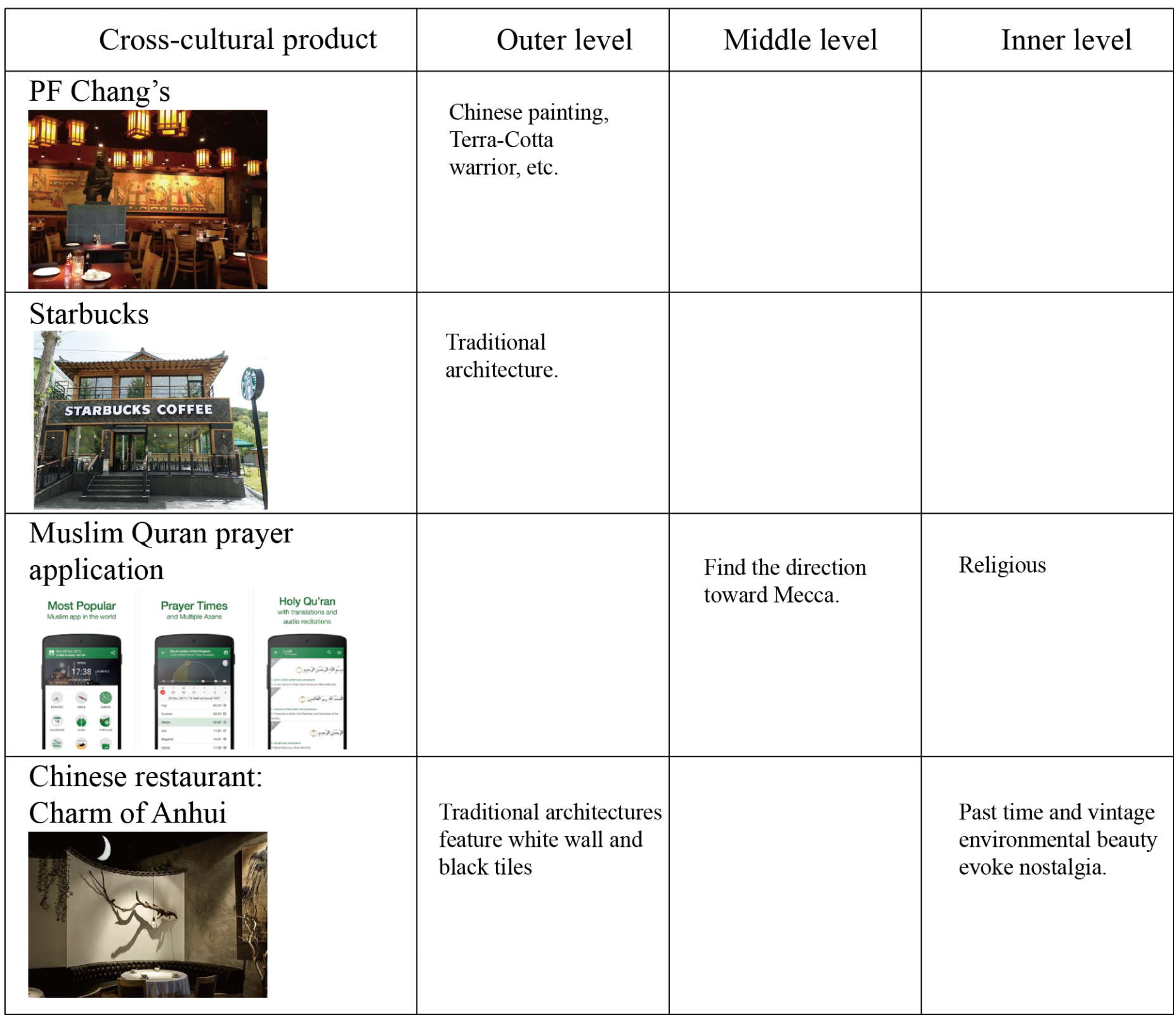


Cultural Product Design

\section{Appendices B}

(Cultural background of Interviewees) 
Cultural Product Design
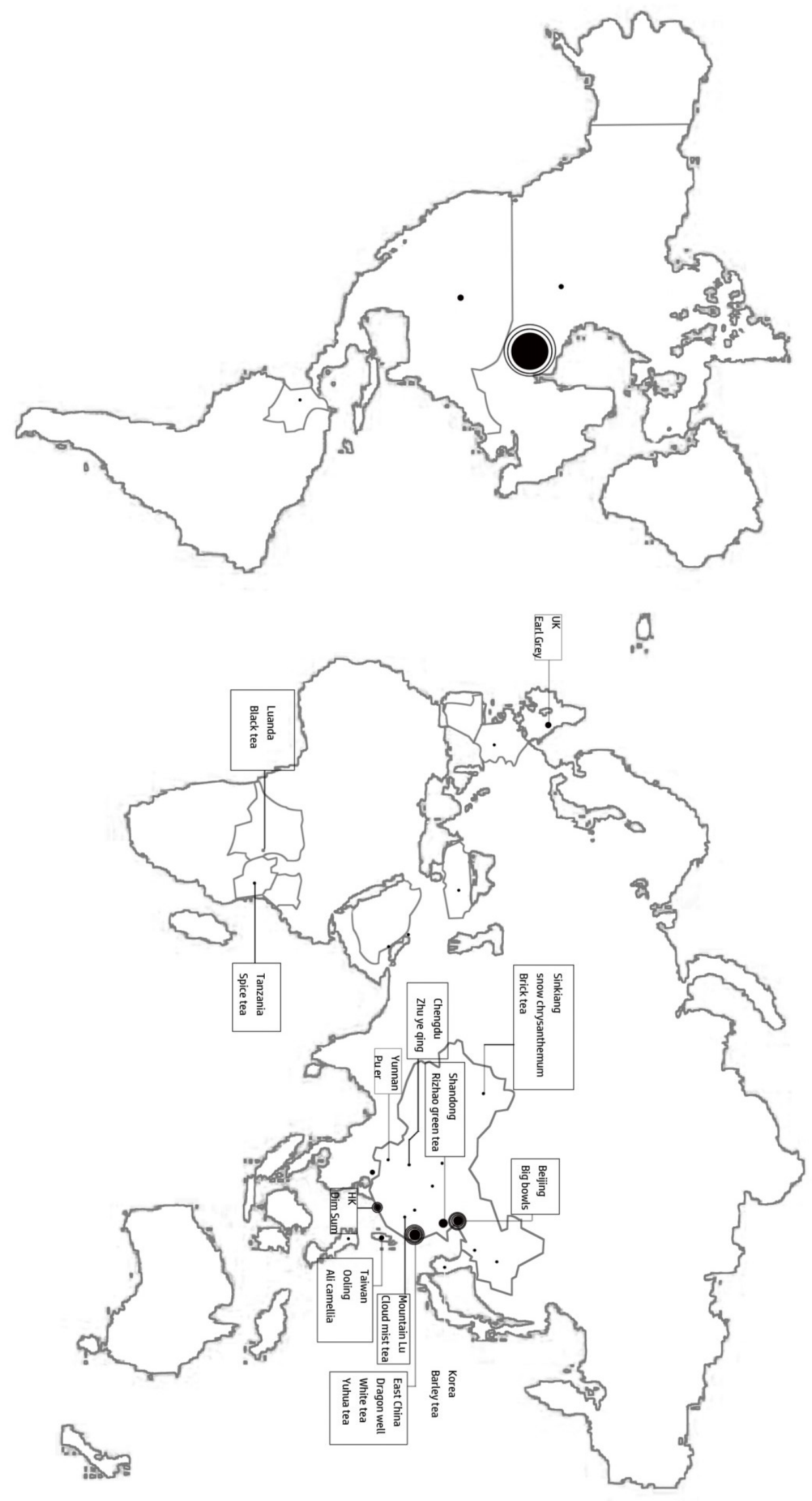
Cultural Product Design

Appendices C

(Interview transcriptions and analysis) 


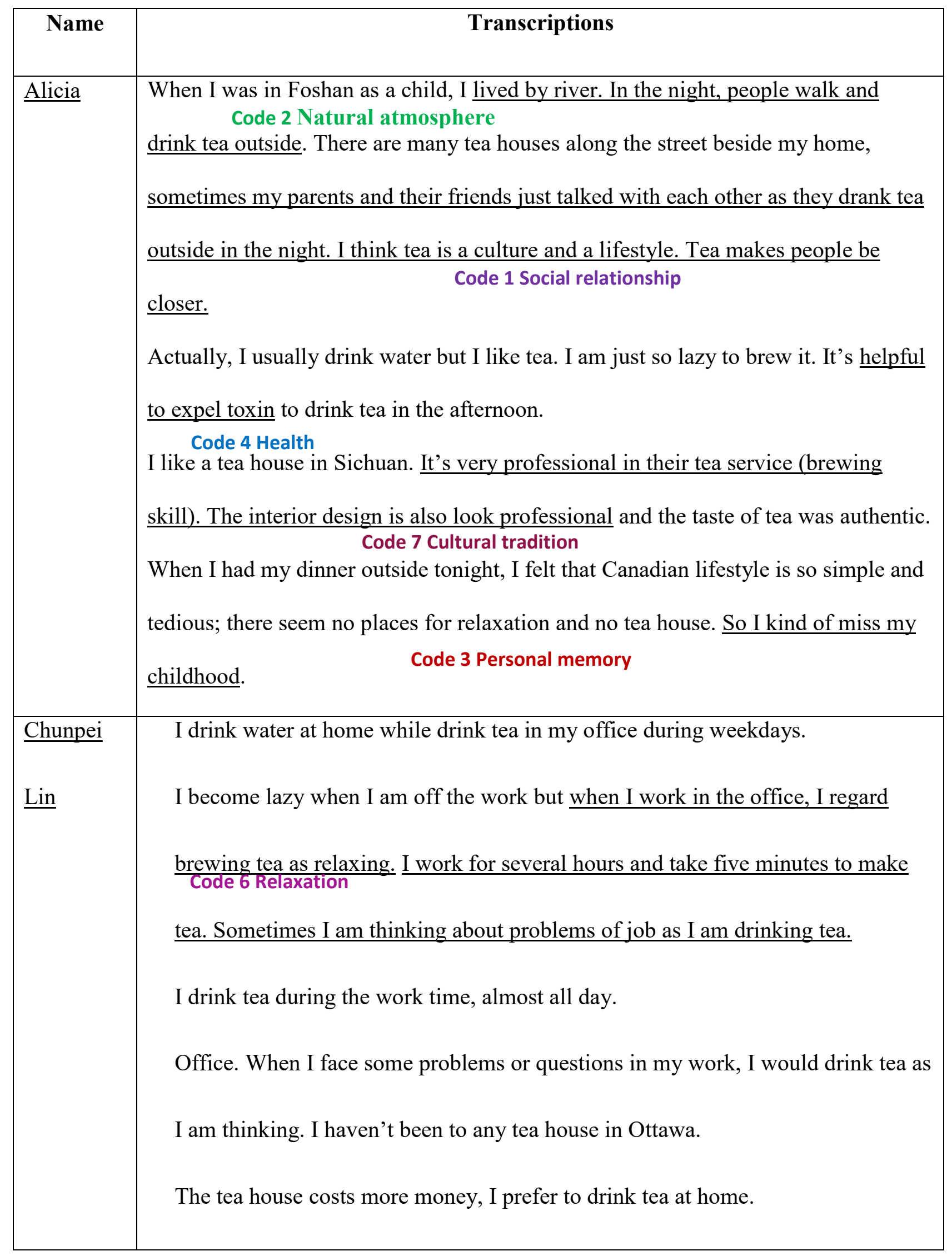




\begin{tabular}{|c|c|}
\hline & I don't like coffee. $\frac{\text { Tea is natural and healthy. Tea tastes good. }}{\text { Code } 4 \text { Health }}$ \\
\hline Meng sha & $\begin{array}{l}\text { The winter in Canada is so cold, I would like some hot beverage in winter. I also } \\
\text { drink tea but in Canada, coffee is easy to buy and the Chinese tea in Canada is } \\
\text { Code } 8 \text { Availability \& Convenience } \\
\text { not authentic. } \\
\text { Besides, I like drink cold tea in summer. I drank tea since I was a child. } \\
\text { I started drinking coffee when I came to Canada } 4 \text { years ago. I just wanted to try } \\
\text { coffee at the first since it's the popular beverage in Canada and I liked it then. } \\
\text { I have been to a tea house in St Laurent. I am not into flower tea, sour and sweet, } \\
\text { it tastes not like tea. }\end{array}$ \\
\hline Mengyuan & $\begin{array}{l}\text { Basically, I brew a bag of tea every day and keep adding water for 3-4 times till it } \\
\text { becomes tasteless. I am a traditional Chinese. I am accustomed to drinking tea. } \\
\text { Since I was a Child. When I was young, I would drink a little bit when my } \\
\text { Code } 3 \text { Personal memory } \\
\text { parents drunk tea. I have been to a tea house in An'xi in Fujian province, I like } \\
\text { the tea sets there, they are made out of bamboo and wood. } \\
\text { Code } 7 \text { Cultural sense }\end{array}$ \\
\hline Stella & $\begin{array}{l}\text { I am usually too lazy to make tea. If I eat something greasy, I want to drink tea. } \\
\text { Drinking too much Coffee is not good. } \\
\text { Drinking tea won't make me fat, but I drink coffee with milk and sugar. } \\
\text { Code } 4 \text { Health } \\
\text { I think many kinds of tea tastes good but I can only accept one flavor of coffee. } \\
\text { Generally, my everyday drink is water. When I was young. My dad loves tea so }\end{array}$ \\
\hline
\end{tabular}




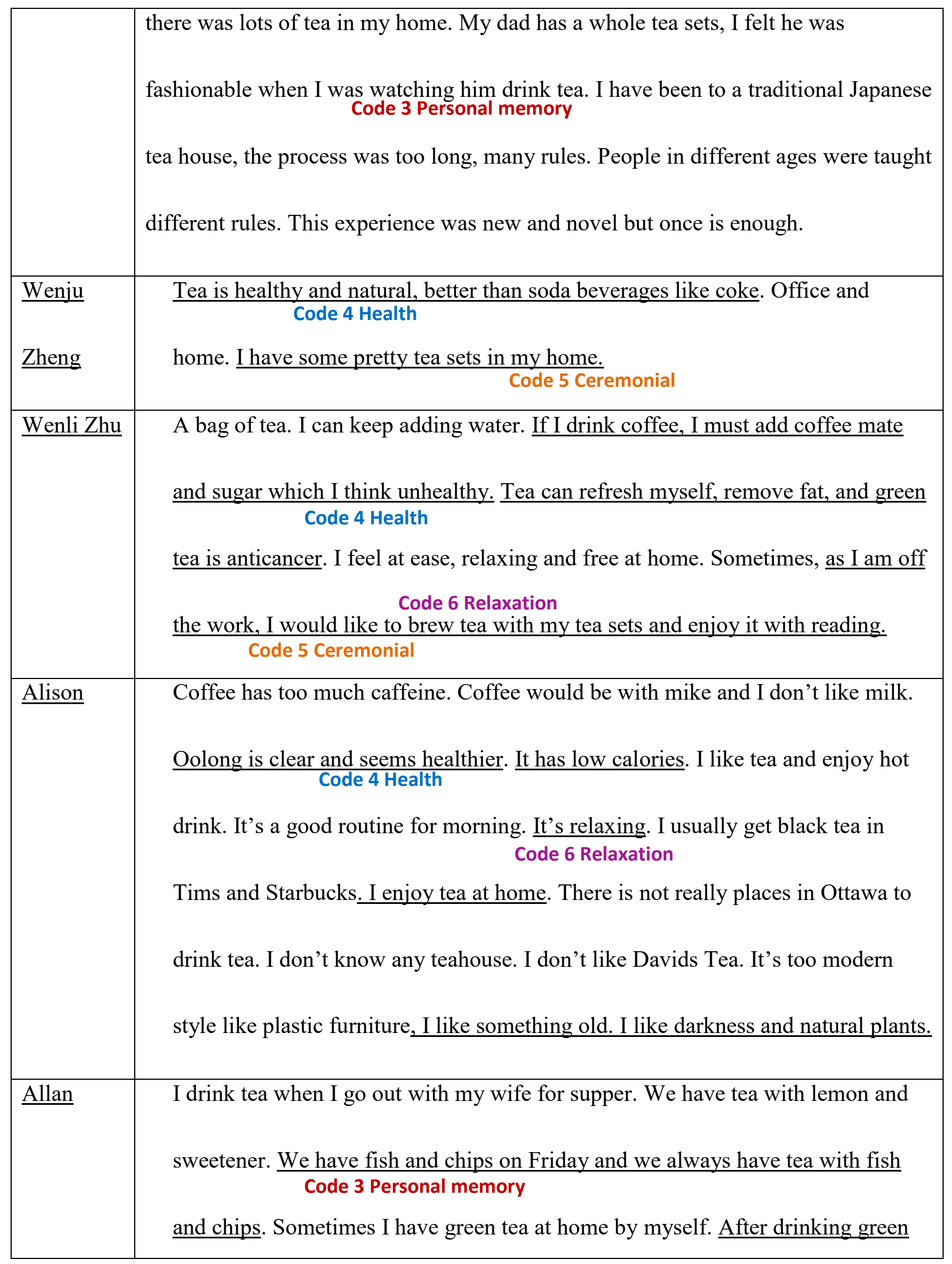




\begin{tabular}{|c|c|}
\hline & $\begin{array}{l}\text { tea a lot in china in } 2007 . \text { I wanted to maintain that connection so that's one way } \\
\text { I do it. Another thing about tea is when I was a child, my grandparents are from } \\
\text { England, they serve tea with milk all the time. I got used to tea with milk and } \\
\text { sugar. Later my wife introduced me tea with lemon. When I was } 5 \text { years old with } \\
\text { my England grandparents. After WARII, they came to Canada. They often went } \\
\text { to Yorkshire Club. Everyone there drunk tea and had fish and chips. }\end{array}$ \\
\hline Cheryl & $\begin{array}{l}\text { I usually have coffee in the morning. I drink tea in the evening after dinner, } \\
\text { Code } 3 \text { Personal memory } \\
\text { watching TV and relaxing. Code } 6 \text { Relaxation } \\
\text { Since I was young. You know, Chinese. Parents drink tea at home. } \\
\text { Bubble tea shop or Chinese restaurants (dim sum). The experience there is } \\
\text { unique. It's also enjoyable to drink at home. I get a lot of tea in David's Tea. I } \\
\text { have been to a tea house where serves English afternoon tea in prince of wales. I } \\
\text { like the whole sets, they are pretty and they provided all types of tea with dessert } \\
\text { Code } 5 \text { Ceremonial } \\
\text { (food). }\end{array}$ \\
\hline$\underline{\text { David }}$ & $\begin{array}{l}\text { I like the taste of expresso coffee. Some tea I like but some I don't. I like the tea } \\
\text { that most Chinese restaurants serve. }\end{array}$ \\
\hline Ilyas & $\begin{array}{l}\text { Usually Juice, coke. But when I feel it is cold, I would like to get tea or coffee. I } \\
\text { prefer them both at the same time, depends on what's available to me and } \\
\text { Code } 8 \text { Availability \& Convenience } \\
\text { convenience. }\end{array}$ \\
\hline
\end{tabular}




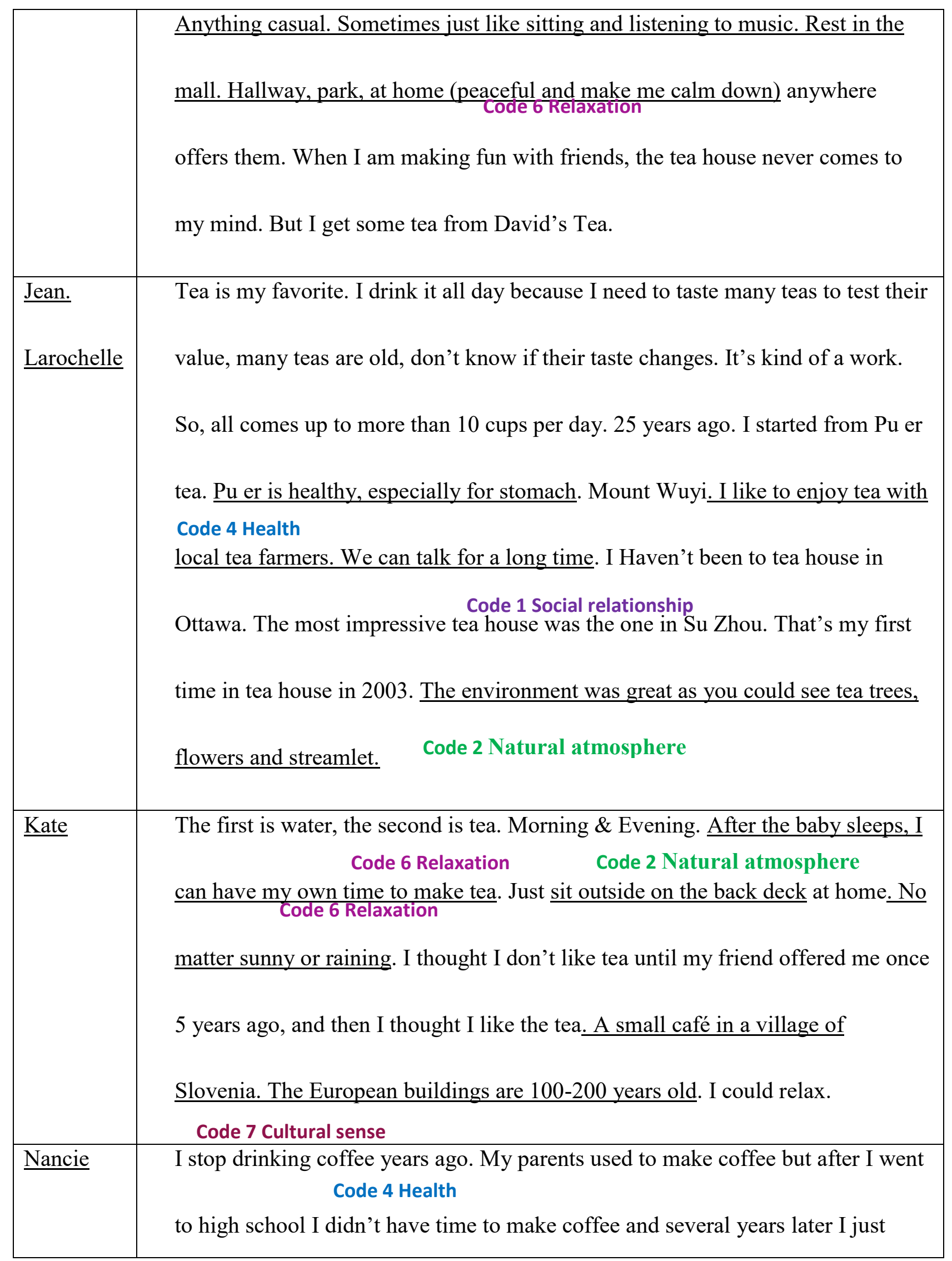




\begin{tabular}{|c|c|}
\hline & $\begin{array}{l}\text { forgot about coffee. I never drink tea only if I feel sick or I get cold, I would } \\
\text { think about drinking tea. Because tea is warm. I don't choose coffee because I am } \\
\text { afraid to depend on it. }\end{array}$ \\
\hline$\underline{\text { Peter }}$ & $\begin{array}{l}\text { Usually at lunch and after supper. Just habit. I find tea relaxing. I don't like } \\
\text { Code } 6 \text { Relaxation } \\
\text { coffee. I like the taste of tea. And I prefer warm tea. When I was a child (8 years } \\
\text { old) My parents and my grandparents drink tea. } \\
\text { Code } 3 \text { Personal memory } \\
\text { Drinking tea is a tradition. Home. Because I like drinking tea after meals so } \\
\text { usually at home. }\end{array}$ \\
\hline Phillip & $\begin{array}{l}\text { Morning, around 10pm, after dinner. I like to be drinking something and tea lasts } \\
\text { long time. I drink coffee for caffeine, but I drink tea for tastes. My mom drinks } \\
\text { tea as well. My mom makes tea for older guests and I make my mother tea. I } \\
\text { started } 2 \text { years ago. I was drinking too much soda which is tasty but not healthy, } \\
\text { Code } 4 \text { Health } \\
\text { so I change for tea. I started from fruit tea and then regular tea. }\end{array}$ \\
\hline$\underline{\text { Zi xuan }}$ & 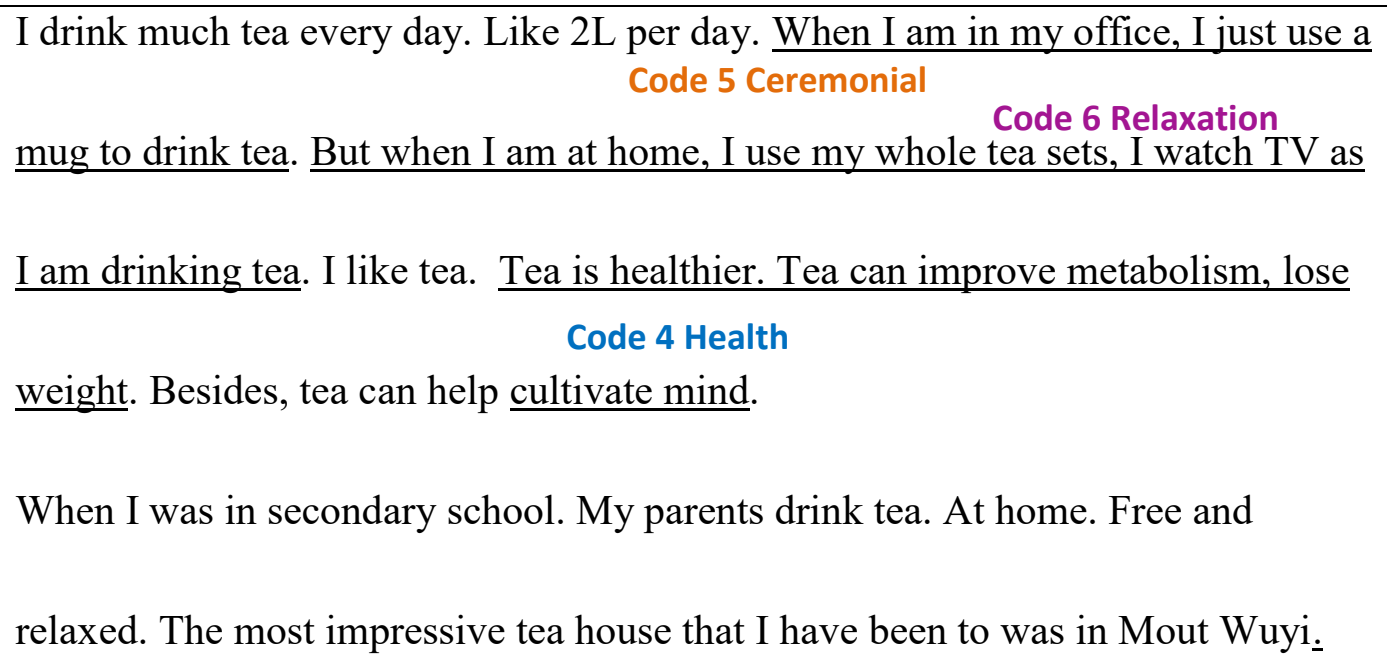 \\
\hline
\end{tabular}




\begin{tabular}{|c|c|}
\hline & $\begin{array}{l}\text { On the hillside of Wuyi mountain, there was an outdoor tea house. There is a } \\
\text { waterfall beside it. It's kind of like a stall. But the landscape like mountain and } \\
\text { Code } 2 \text { Natural atmosphere } \\
\text { river (waterfall) is so beautiful, the tea was brewed by the spring water, the } \\
\text { experience was very good. }\end{array}$ \\
\hline Bei Bei & $\begin{array}{l}\text { I drink tea all day. After adding water for 5-6 times. I will brew another tea. No } \\
\text { matter relaxing or working I drink tea. My mom love tea. I think tea is healthier } \\
\text { Code } 4 \text { Health } \\
\text { than coffee and has flavor, compared with water. } \\
\text { Besides, I love hot drinks. In addition, tea makes people look tasteful. Chinese } \\
\text { may prefer drink tea at home. }\end{array}$ \\
\hline Guan shan & $\begin{array}{l}\text { Morning. If drinking tea in the afternoon, I wouldn't sleep then. } \\
\text { Code } 6 \text { Relaxation } \\
\text { When I am relaxing. Or I feel peaceful. Tea (Chinese traditional tea) is health } \\
\text { Code } 4 \text { Health } \\
\text { which has theophylline, helping lose weight. When I was a kid. I went to my } \\
\text { friend' home and her mom made tea. That's my first time to drink tea and it } \\
\text { tasted good. Later, my dad got a tea set home, the frequency of drinking tea got } \\
\text { higher. But now, I also use tea bag because brewing tea leaves is troublesome. } \\
\text { The black tea bag with milk can stimulate my appetite. But if I have time in the } \\
\text { morning I will brew tea leaves. } \\
\text { Home. I can enjoy talking with close persons when I drink tea at home, which is } \\
\text { relaxing. }\end{array}$ \\
\hline
\end{tabular}




\begin{tabular}{|c|c|}
\hline & $\begin{array}{l}\text { I have been to Blue Ribbon. There is a place to have tea. It's enjoyable and relaxing } \\
\text { Code } 7 \text { Cultural sense } \\
\text { to drink tea there. The service was good. Waiters are polite and wouldn't disturb } \\
\text { you. The environment is quiet, vintage, and simple. }\end{array}$ \\
\hline Joyce chiu & $\begin{array}{l}\text { Tea is familiar to me, I drank tea since I was a child. } \\
\text { Coffee can make people awake for } 1 \text { hour but tea makes people awake for like } 10 \\
\text { hours, so be careful with tea. Home, I would use tea sets to brew tea at home. But } \\
\text { when I am working, I just make one cup informally. } \\
\text { There are many tea houses in Montreal. They are elegant and many of them are } \\
\text { Asian style like Chinese culture or Zen. They are quiet, you cannot bring kids as } \\
\text { children are noisy, if the environment becomes noisy, the server would strike a } \\
\text { gong to remind people of peace. } \\
\text { I have been to a tea house in Boston, the style is like Europe in } 17 \text { century, the } \\
\text { servers were in servant uniforms, and customers can take part in performance } \\
\text { code } 7 \text { Cultural sense } \\
\text { which tells the story about tea. It held tea party there. People can go through the } \\
\text { sion penally. }\end{array}$ \\
\hline Will Su & $\begin{array}{l}\text { Yes, I drink tea especially when people are playing Mahjong. That's why I } \\
\text { seldom drink tea in Canada. Every time I go back to Chengdu, I would drink tea } \\
\text { when I play mahjong, twice a week. }\end{array}$ \\
\hline Claudie & $\mathrm{ng}, \mathrm{Wc}$ \\
\hline
\end{tabular}




\begin{tabular}{|c|c|}
\hline & $\begin{array}{l}\text { drinking herbal tea is warm and cozy. } \\
\text { Code } 6 \text { Relaxation } \\
\text { I drink tea at home (tea shop to meet friends). } \\
\text { I think a traditional tea house should: } \\
\text { 1. Offer different tea. 2. Offer service, it's not like I go to the counter but the } \\
\text { servers come to me. 3. Have traditional elements } \\
\text { Code } 7 \text { Cultural sense } \\
\text { 4. Educate more traditions }\end{array}$ \\
\hline Ellis & $\begin{array}{l}\text { I drink matcha mostly no matter cold or hot as matcha has more caffeine which is } \\
\text { Code } 8 \text { Availability \& Convenience } \\
\text { healthier. I drink tea when I am working at Tea Store. }\end{array}$ \\
\hline$\underline{\text { Kelly }}$ & $\begin{array}{l}\text { I like both. I enjoy the flavor of coffee but I don't like high caffeine. } \\
\text { Herbal tea is health as it has low caffeine and different types have different } \\
\text { Code } 4 \text { Health } \\
\text { functions. I drink one coffee in the morning and have herbal tea or matcha } \\
\text { sometimes. } \\
\text { I started from } 9 \text { years old, my family drinks tea. }\end{array}$ \\
\hline Kinahan & $\begin{array}{l}\text { I drink coffee at home (all the time). } \\
\text { I drink tea in Tea Store in the afternoon. } \\
\text { When I was a child, everybody drank tea. Nobody drinks tea more than British, they } \\
\text { play for tea. In my home, its tea all day long. } \\
\text { Tea Store. It's decorated, offer different kinds of tea, there are nice people here, }\end{array}$ \\
\hline
\end{tabular}


Cultural Product Design

\begin{tabular}{|c|c|}
\hline & and I am well treated. \\
\hline Mulin & $\begin{array}{l}\text { When I feel stressful in my work, I would prefer drinking tea since tea can make } \\
\text { Code } 6 \text { Relaxation } \\
\text { people calm down. When I drink tea, I do nothing but focus on my tea and enjoy } \\
\text { it quietly. I would buy tea in Tim Hortons. I seldom brew tea myself because it's } \\
\text { Code } 8 \text { Availability \& Convenience } \\
\text { troublesome. } \\
\text { Coffee in the morning can refresh me. Coffee is easy and convenient to buy and } \\
\text { coffee is a habit. When I was } 11 \text { or } 12 \text { years old. My parents drink tea. I think tea } \\
\text { Code } 7 \text { Cultural sense } \\
\text { house in Japan is impressive. They have private rooms. Besides, the Japanese tea } \\
\text { Code2 Natural atmosphere } \\
\text { house is close to nature, there is bamboo nearby and artificial stream and bamboo } \\
\text { Code } 7 \text { Cultural sense } \\
\underline{\text { timer. }}\end{array}$ \\
\hline Hee chan & $\begin{array}{l}\text { I always have a cup of drink of whatever it is beside me when I work or study. I feel } \\
\text { Code } 4 \text { Health } \\
\text { like drinking tea is healthier. Water doesn't have taste. When I was a kid. It's a } \\
\text { cultural thing. We always have a bottle containing tea. When I feel active, I would } \\
\text { prefer the sour sweet tea. But when I feel cold, I would like barley tea, common tea. }\end{array}$ \\
\hline$\underline{\text { Tian } x i}$ & $\begin{array}{l}\text { I like coffee for the caffeine. Tea doesn't give much caffeine which cannot } \\
\text { support the entire day. After dinner, for relaxing. I like coffee for it has caffeine. } \\
\text { Code } 6 \text { Relaxation } \\
\text { I drink tea at night to relax. Relax on the sofa at home. } \\
\frac{4-5 \text { years old. At the beginning, my dad taught me how to drink tea, then I started }}{\text { Code } 3 \text { Personal memory }} \\
\text { to tea with friends on my own. }\end{array}$ \\
\hline
\end{tabular}




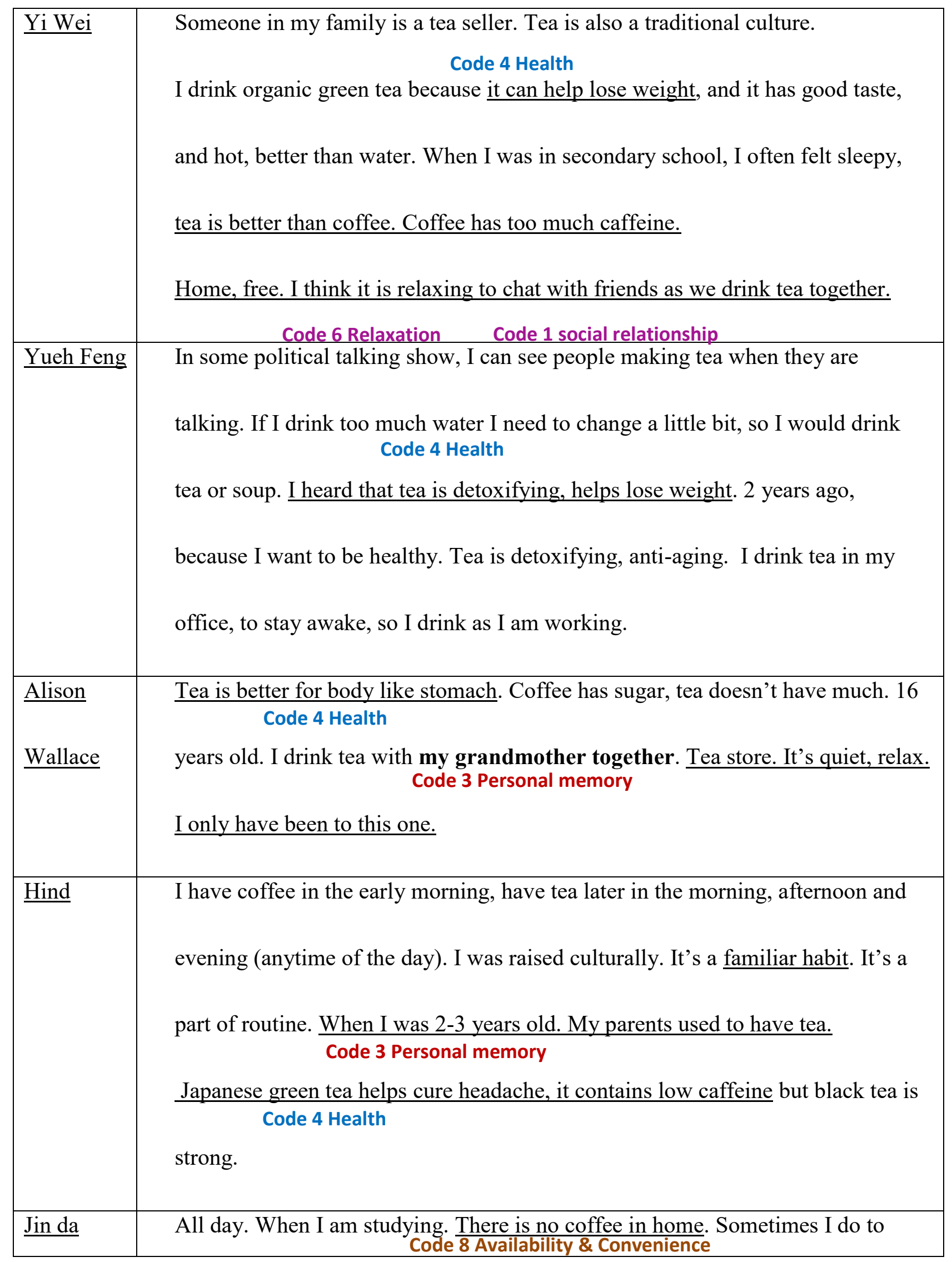




\begin{tabular}{|c|c|}
\hline & $\begin{array}{l}\text { library I would get coffee. Mostly I study at home. When I was young, I like soft } \\
\text { drinks, but in recent } 5 \text { years, I seldom have soft beverage, I think it's not good to } \\
\text { Code } 4 \text { Health } \\
\underline{\text { heath. Home. I drink tea just for being awake to study. So I don't go to tea house. }}\end{array}$ \\
\hline Josh & $\begin{array}{l}\text { Morning because I am sensitive to caffeine. Tea is part of my morning fast. } \\
\text { Coffee makes me feel nervous, and makes my body shaking. I drink tea for } \\
\text { Code } 4 \text { Health } \\
\text { health. Only have green tea, herbal tea, sometimes oolong. Black tea is too } \\
\text { strong. } \\
\text { When I was a child. My grandmother always made tea and we drink tea. I have } \\
\text { Code } 3 \text { Personal memory } \\
\text { also been to chayi and the world of tea. I like ChaYi. It serves high quality tea } \\
\text { and it's clean. Lots of wood, it's natural looking. It has natural elements like } \\
\text { Code } 2 \text { Natural atmosphere } \\
\text { wood, stone. }\end{array}$ \\
\hline Nicholas & $\begin{array}{l}\text { Before my performance (audition show), to calm down. } \\
\text { Code } 6 \text { Relaxation } \\
\text { Tea party: not busy, quiet environment, good atmosphere, relaxing, customized } \\
\text { flavors. I feel the culture, mental psychological thing, special, fancy. } \\
\text { Code } 7 \text { Cultural sense }\end{array}$ \\
\hline Roberte & $\begin{array}{l}\text { When I was } 13 \text { years old. My mom only drinks tea. } \\
\text { Mostly in the morning, Ahmad tea in the evening since it doesn't have caffeine } \\
\text { Code } 4 \text { Health } \\
\text { and it helps sleep and good to stomach. I drink tea when I am doing my hobby. } \\
\text { Code } 6 \text { Relaxation } \\
\text { At home. I also go to tea house with friends have tea with dessert. Tea house is } \\
\text { Code } 1 \text { Social relationship } \\
\text { for socializing, I meet people there. I go to tea house everywhere I travel. The }\end{array}$ \\
\hline
\end{tabular}




\begin{tabular}{|c|c|}
\hline & $\begin{array}{l}\text { most impressive one is in Dominican Republic, it's outside on the beach, serves } \\
\text { home-made pastries. } \quad \text { Code } 2 \text { Atmosphere-nature }\end{array}$ \\
\hline$\underline{\text { Adam }}$ & $\begin{array}{l}\text { It depends on the type of tea and coffee. If they both taste not good, I prefer } \\
\text { water. I buy coffee in the morning but I brew tea myself in the afternoon. Long } \\
\text { time ago. Tea is a tradition, my families drink tea. But if I drink much tea I will } \\
\text { try coffee. In China, I don't go to tea houses. My friend has an art Gallery in } \\
\text { Code } 1 \text { Social relationship } \\
\text { GuangZhou, we sometimes have tea while we are talking in his art Gallery. } \\
\text { Otherwise, my friends and I will drink tea at home. }\end{array}$ \\
\hline Ma minjie & $\begin{array}{l}\text { About twice a week if I am free at home. When I have a rest at home. There's no } \\
\text { Code } 6 \text { Relaxation } \\
\text { tea in my office. I don't use tea bag. The tea in tea bag is old and inferior. } \\
\text { Chinese mostly like fresh tea like the tea which is picked one month ago. } \\
\text { Code } 1 \text { Social relationship } \\
\text { When I meet clients at home, we would drink Kongfu Tea. } \\
\text { When I am with my good friends, we also drink kongfu tea, but after that, we } \\
\text { Code } 5 \text { Ceremonial } \\
\text { would also have other tea which is steeped in a mug which is convenient to drink. } \\
\text { I usually drink water because I don't have time to drink tea. Because I think tea is } \\
\text { not like the water. Tea has to be hot and not for thirsty, I only have tea when I am } \\
\text { free. It's like a habit like smoking. } \\
\text { Code } 6 \text { Relaxation } \\
\text { I don't like coffee. It tastes bad and the caffeine is strong if I drink much coffee I } \\
\text { Code } 4 \text { Health } \\
\text { get dizzy. But if I drink tea all day, it's fine. Home (living room). I like to drink }\end{array}$ \\
\hline
\end{tabular}




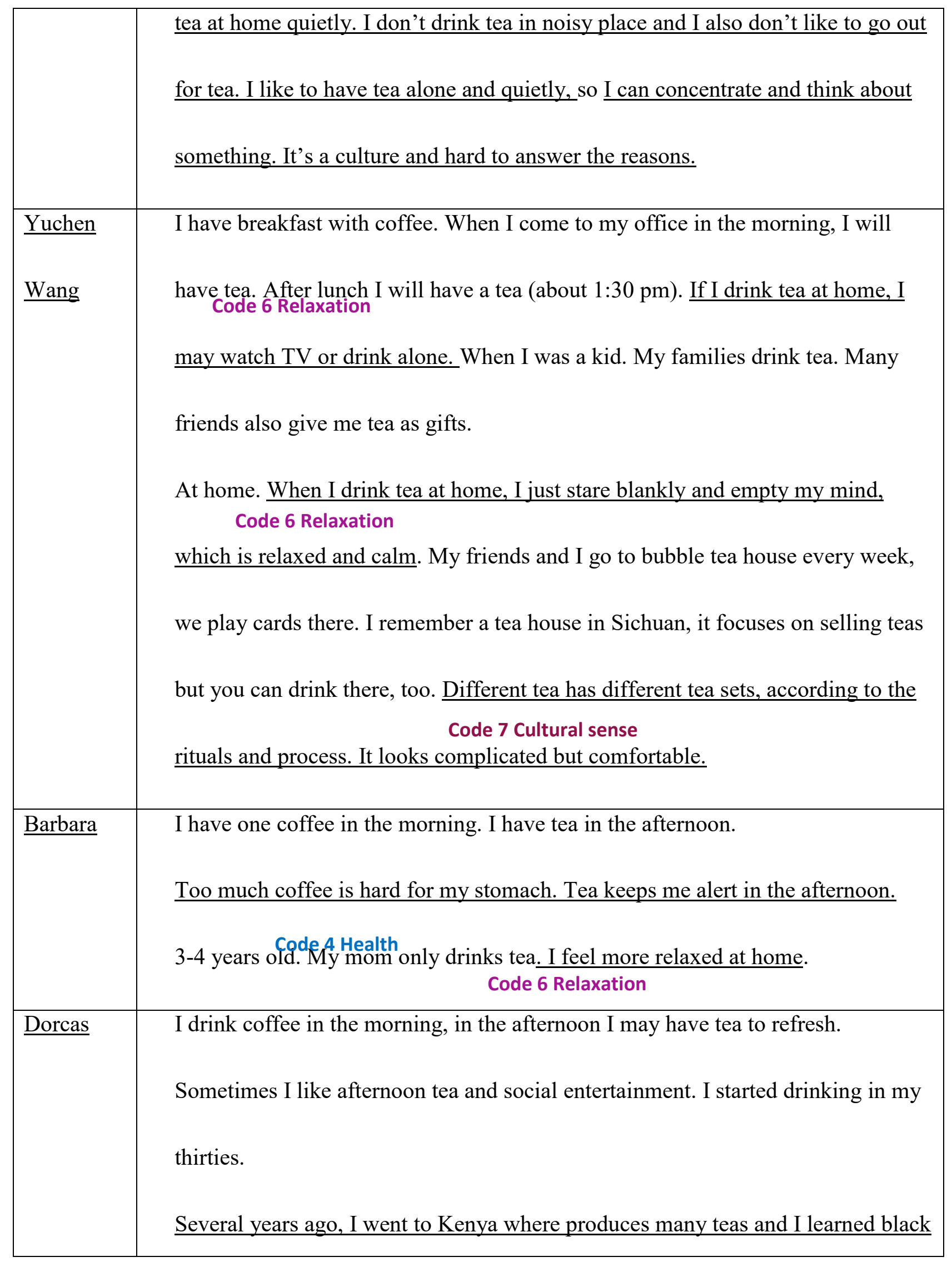




\begin{tabular}{|c|c|}
\hline & $\begin{array}{l}\text { tea there. In Morocco, I learned to drink mint tea and in Egypt, I learned sweet } \\
\text { Code } 3 \text { Personal memory } \\
\text { tea. In Hong Kong and Taiwan, they drink bubble tea. } \\
\text { It is the best to have tea in desert such as Africa, Morocco, and Egypt. Especially } \\
\frac{\text { after hiking, you drink a cup of tea at the top of mountain. In winter have hot tea }}{\text { Code } 2 \text { Natural atmosphere }} \\
\text { and in summer have ice tea. That will be wonderful. } \\
\text { I seldom go to tea house. Drinking in tea house it's not enjoyable for one person } \\
\text { alone, but is ok for social. For one person, I can drink at home, in desert, on the } \\
\text { mountain but not in tea house. }\end{array}$ \\
\hline$\underline{\text { Fincham }}$ & $\begin{array}{l}\text { I only drink Tea. I don't like coffee, I grow up drinking tea. Tea is good for you } \\
\text { without much sugar, different tea has different benefits. My family doesn't drink } \\
\text { Code } 4 \text { Health } \\
\text { coffee. Home. It's comfortable. I have my tea, my cups and can read at the same } \\
\text { Code } 6 \text { Relaxation } \\
\text { time. I have my sister make blend tea for me. }\end{array}$ \\
\hline
\end{tabular}

\begin{tabular}{|l|l|}
\hline$\underline{\text { Jason }}$ & $\begin{array}{l}\text { I never drink coffee. For tea, if it's provided I will drink. } \\
\text { I don't have favorite places. If friends around me drink tea I will have some with }\end{array}$ \\
$\begin{array}{l}\text { them. } \\
\text { Jeanne }\end{array}$ & $\begin{array}{l}\text { I am usually a tea drinker now, but I used to drink coffee. When I was in } \\
\text { university, I drank coffee because it's a faster caffeinating. And then I realized } \\
\text { Code 4 Health }\end{array}$ \\
\hline
\end{tabular}




\begin{tabular}{|c|c|}
\hline & $\begin{array}{l}\text { coffee is not good for poor bodies so I switched back to teas. } \\
\text { Tea is kind of part of my life when I grow up. My families drink tea. Tea tastes } \\
\text { Code } 3 \text { Personal memory } \\
\text { better and cause less damage to teeth. Coffee could turn teeth more brown. } \\
\text { CHA YI is really impressive but not very personalized. } \\
\text { Personalized means sitting in personal space, not just about the decoration, and } \\
\text { having cool stories. }\end{array}$ \\
\hline$\underline{\text { Leilla }}$ & $\begin{array}{l}\text { Right now (summer) I would like ice tea. In winter I always drink hot tea. I don't } \\
\text { normally have it in the evening because of caffeine. I prefer the taste of tea. } \\
\text { Code } 4 \text { Health } \\
\text { Coffee makes me hyper but tea is less strong. } \\
\text { Tea is my habit. I don't eat much when I am drinking tea. Besides, tea helps me } \\
\text { concentrate on the computer. } \\
\text { My couch (at home). }\end{array}$ \\
\hline$\underline{\text { Pinar }}$ & $\begin{array}{l}\text { I prefer tea. I have breakfast with British tea. And have tea with something sweet } \\
\text { Code } 4 \text { Health } \\
\text { after lunch and dinner. I like the taste of tea. Tea is healthier. Tea is the tradition } \\
\text { for Turkey, and tea has more types of flavor. } \\
\text { Code } 6 \text { Relaxation } \\
\text { At home or Tea Store which is casual. I have many decaf types of tea at home. }\end{array}$ \\
\hline$\underline{\text { Serdar }}$ & $\begin{array}{l}\text { I drink Kombucha. } 2 \text { cups with breakfast. And one after lunch and two after } \\
\text { dinner. I eat nuts or chocolate when I drink tea. Tea is better than coffee and it's }\end{array}$ \\
\hline
\end{tabular}




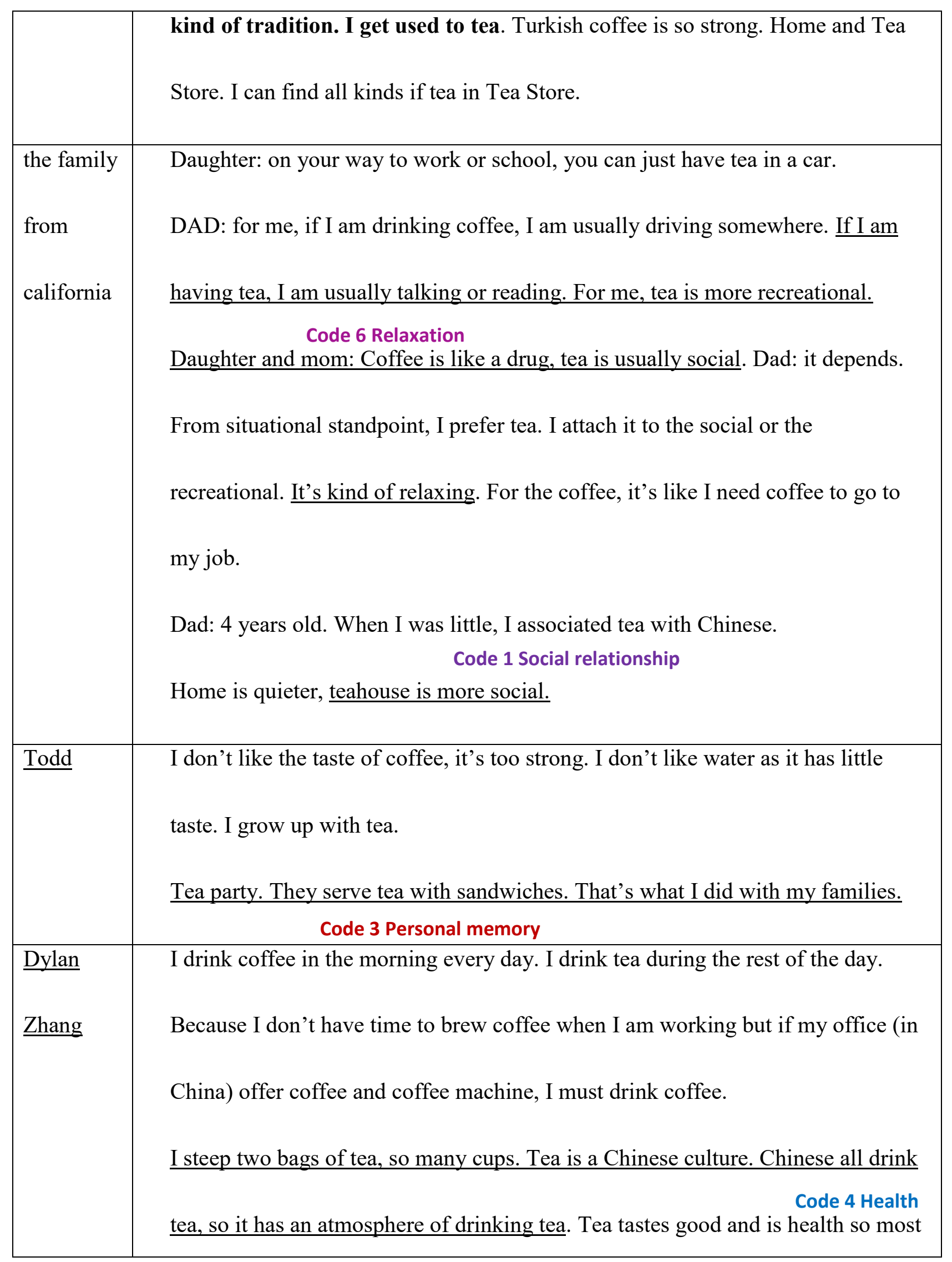




\begin{tabular}{|c|c|}
\hline & $\begin{array}{l}\text { people can accept tea. Coffee is just an adjustment for taste. I drank tea } 30 \text { years } \\
\text { ago. My father drinks tea. } \\
\text { Code } 6 \text { Relaxation } \\
\text { No requirements on place as long as there are people talking with each other. } \\
\text { Code } 1 \text { Social relationship }\end{array}$ \\
\hline$\underline{\text { Edward }}$ & $\begin{array}{l}\text { When I was in China, I drink instant coffee. After coming to Canada, I drink } \\
\text { more coffee. Because China doesn't have an environment for drinking coffee. I } \\
\text { don't believe the Chinese tea in Canada and I am not used to herbal tea. }\end{array}$ \\
\hline Hong ling & $\begin{array}{l}\text { I drink tea when I am free. Tea is healthier, anti-cancer. Tea is Chinese tradition. } \\
\text { Code } 6 \text { Relaxation Code } 4 \text { Health } \\
\text { Tea promotes losing weight. Coffee makes stomachache. When I was in my } \\
\text { twenties, I started to be particular about tea because I used to run a tea house in } \\
\text { Code } 1 \text { Social relationship } \\
\text { Xinjiang. After work, my colleagues and I will have tea together and talk about } \\
\text { the work. }\end{array}$ \\
\hline Qiaomei & $\begin{array}{l}\text { I don't drink coffee, I drink tea and mostly are flower tea. } \\
\text { When I take the English class in the morning. Water is tasteless. } \\
\text { Coffee is bitter so it goes with sugar but I don't like sugar and I cannot sleep after } \\
\text { drinking coffee as well. I have tea because I don't want water. When I was young, } \\
\text { my grandma drank tea. I like home. I like reading in the couch with mu tea is } \\
\text { Code } 1 \text { Social relationship } \\
\text { enjoyable. I meet friends in tea houses. }\end{array}$ \\
\hline$\underline{\text { Sujun }}$ & $\begin{array}{l}\text { I drink coffee in the morning and have tea in the afternoon. Tea in the afternoon } \\
\text { won't affect my sleep. Tea is the tradition and my families drink tea. I have no }\end{array}$ \\
\hline
\end{tabular}




\begin{tabular}{|l|l|}
\hline & $\begin{array}{l}\text { requirements on the place, I just drink tea when talk and chat. Office, home, } \\
\text { Code } 1 \text { Social relationship }\end{array}$ \\
restaurants are all okay. But I don't like tea bag, I think the material of tea bag is \\
not good. I like tea leaves. \\
(Every time my families visit her, she makes tea for us).
\end{tabular}

\begin{tabular}{|c|c|}
\hline Yu Wang & $\begin{array}{l}\text { Afternoon } 2.00-3.00 \mathrm{pm} \text {. I am working at this time (in a bubble tea store), so I } \\
\text { would drink tea at this time, normally, I wouldn't make tea at other time unless } \\
\text { before exams I will have black tea or green tea to refresh. I drink tea before } \\
\text { exams. Flower tea is good to skin. It won't male me uncomfortable. Coffee can } \\
\text { cause palpitation, making me feel unwell. } \\
\text { The tea sets in the store are more professional and convenient. But in home, } \\
\text { drinking tea is not as convenient as in store. } \\
\text { Code } 8 \text { Availability \& Convenience }\end{array}$ \\
\hline Anessa & $\begin{array}{l}\text { I drink a lot of water, I drink tea more than coffee. I like green tea. Usually in } \\
\text { the evening. Usually I go out during the day and it's nice to go back home to } \\
\text { Code } 6 \text { Relaxation } \\
\text { have some tea. Water and tea is healthy. I like water, tea is a good way to drink } \\
\text { Code } 4 \text { Health } \\
\text { lots of water, it tastes better. } \\
\text { When I was } 9-10 \text { years old. My family goes out to eat with tea. }\end{array}$ \\
\hline Monty & I drink tea more on weekends, not even one usually per day. Sometimes when I \\
\hline
\end{tabular}




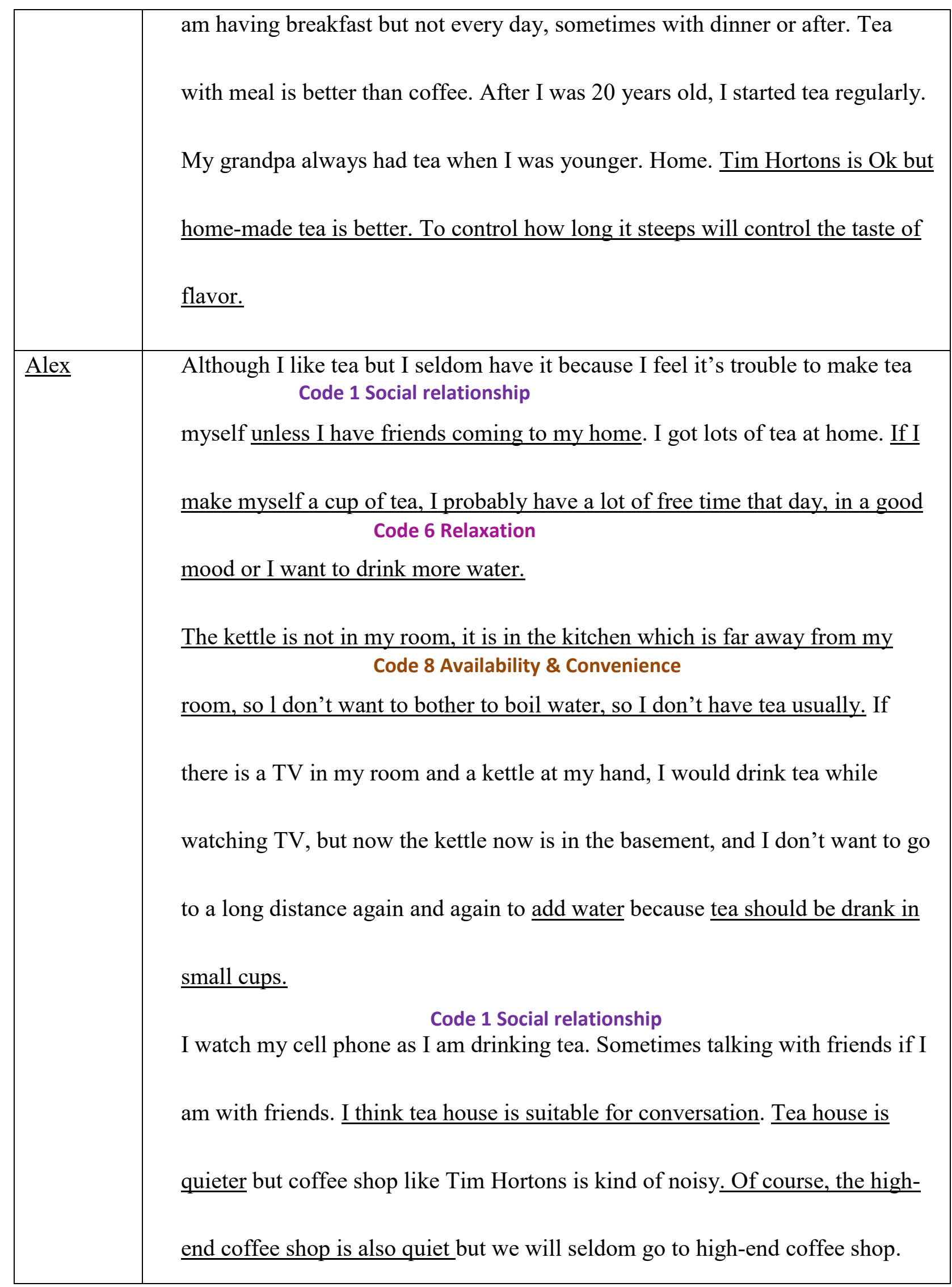




\begin{tabular}{|c|c|}
\hline Hui Zhang & $\begin{array}{l}\text { I drank coffee before but now I drink both tea and coffee. But when I was in } \\
\text { China, I drank tea more often. After coming to Canada, I drank more coffee } \\
\text { since I think coffee is more popular in Canada. } \\
\text { Code } 8 \text { Availability \& Convenience } \\
\text { I would choose coffee because coffee is easy to get here, while tea needs to be } \\
\text { brewed on my own. Although Tim Hortons and Starbucks sell tea, they use tea } \\
\text { bag. I don't think that is tea that cannot be compared with Chinese tea. } \\
\text { In this month. My parents came here to visit me and my dad brought me lots of } \\
\text { tea. My dad is particular about tea so once the tea is opened, I should finish it as } \\
\text { soon as possible. } \\
\text { I drink tea at home. Usually, I will make tea in my vacuum bottle and go out } \\
\text { with it. }\end{array}$ \\
\hline$\underline{\mathrm{Yi} \mathrm{Li}}$ & $\begin{array}{l}\text { In the winter, I drink more tea, summer is too hot and I don't want to make tea. } \\
\text { Actually I don't like coffee very much. I prefer coffee just because Tims are } \\
\text { everywhere so coffee is easy to buy and it's cheap. I drink tea at home and have } \\
\text { coffee in Tim Hortons. }\end{array}$ \\
\hline $\begin{array}{l}\text { Chao } \\
\text { Liang }\end{array}$ & $\begin{array}{l}\text { Early in the morning, for the caffeine. I would put the tea in my bottle and go } \\
\text { out with it. When I was in elementary school, my parents drink tea. }\end{array}$ \\
\hline$\underline{\mathrm{MiMi}}$ & If I am at home, I may have 2 cups of tea for I have tea at home. But if I go out \\
\hline
\end{tabular}




\begin{tabular}{|c|c|}
\hline & $\begin{array}{l}\text { I would buy coffee. I prefer tea at home. But I like to drink coffee at library. I } \\
\text { won't go to tea house, I don't go for tea specially. }\end{array}$ \\
\hline Shirmen & $\begin{array}{l}\text { Before working, a cup of tea can keep me awake. When I work on my } \\
\text { computer. Sometimes at home, I read and have a cup of tea beside me. I prefer } \\
\text { tea. I cannot drink coffee. It's too strong for me. } \\
\text { I prefer the place that closes to nature, like a park, Rideau canal, or the balcony } \\
\frac{\text { of the house, which would make me quiet. I enjoy watching the sky quietly. }}{\text { Code } 2 \text { Natural atmosphere }}\end{array}$ \\
\hline Catherine & $\begin{array}{l}\text { I drink coffee only in the morning (I won't sleep if drink coffee at night.) } \\
\text { Code } 6 \text { Relaxation } \\
\text { I drink tea any other time of the day. I prefer tea. Coffee is for waking me up in } \\
\text { Code } 6 \text { Relaxation } \\
\text { the morning. Tea is relaxing for its variety. } \\
\text { My mother drinks tea. } \\
\text { When I am down in the market (Byward market), I like come here (Tea } \\
\text { Store).Tea Store has different types of tea and home-made stuff, I like to sit } \\
\text { here and I can watch people. (she was sitting outside the Tea Store) } \\
\text { Code } 6 \text { Relaxation } \\
\text { I have been to one in Turkey. It had nice setting, it was outside, and you can see } \\
\text { nice views. }\end{array}$ \\
\hline
\end{tabular}

\begin{tabular}{|l|l|}
\hline Charlotte & I have 2 black tea in the morning with breakfast and 2 herbal tea in the \\
\hline
\end{tabular}




\begin{tabular}{|c|c|}
\hline & $\begin{array}{l}\text { afternoon. Morning with breakfast and talking with friends in the afternoon. } \\
\text { I prefer tea. Tea's flavor is better. Tea has lots of varieties. Tea is a nice social } \\
\text { Code } 1 \text { Social relationship } \\
\text { activity especially the afternoon tea. } \\
\text { When I was a teenager, my parents drink tea. } \\
\text { Home. I don't go out to drink tea. My friends and I drink tea together at my } \\
\text { home or their home. }\end{array}$ \\
\hline Christy & $\begin{array}{l}\text { It depends on how I am feeling. I would more prefer tea in winter than } \\
\text { summer. I choose tea as my everyday drink because it tastes good and it's } \\
\text { warm in cold days, it's soothing. } \\
10 \text { years old. My mom would give me tea at home. } \\
\quad \text { Code } 3 \text { Personal memory } \\
\text { Home. High tea. And when I travel somewhere in cultures (I took some tea } \\
\text { from China when I travel there.) }\end{array}$ \\
\hline KENDRA & $\begin{array}{l}\text { Between coffee and tea, I choose tea. With the meal or studying. When I was } \\
\text { in elementary school, like } 10 \text { years old. My mom drinks tea every day. When I } \\
\text { Code } 3 \text { Personal memory } \\
\text { was younger, we had played tea party. } \\
\text { [It's like playing house, kids have the cut tea cups like toys and pretend to } \\
\text { drink tea but there may not be tea in the cup but other drinks, when they grow } \\
\text { older, the tea party becomes a real tea party]. I drink tea mainly Home. }\end{array}$ \\
\hline Sarah & I prefer tea. $\frac{\text { You can't drink too much coffee but tea is ok. In my graduation, I }}{\text { Code } 4 \text { Health }}$ \\
\hline
\end{tabular}




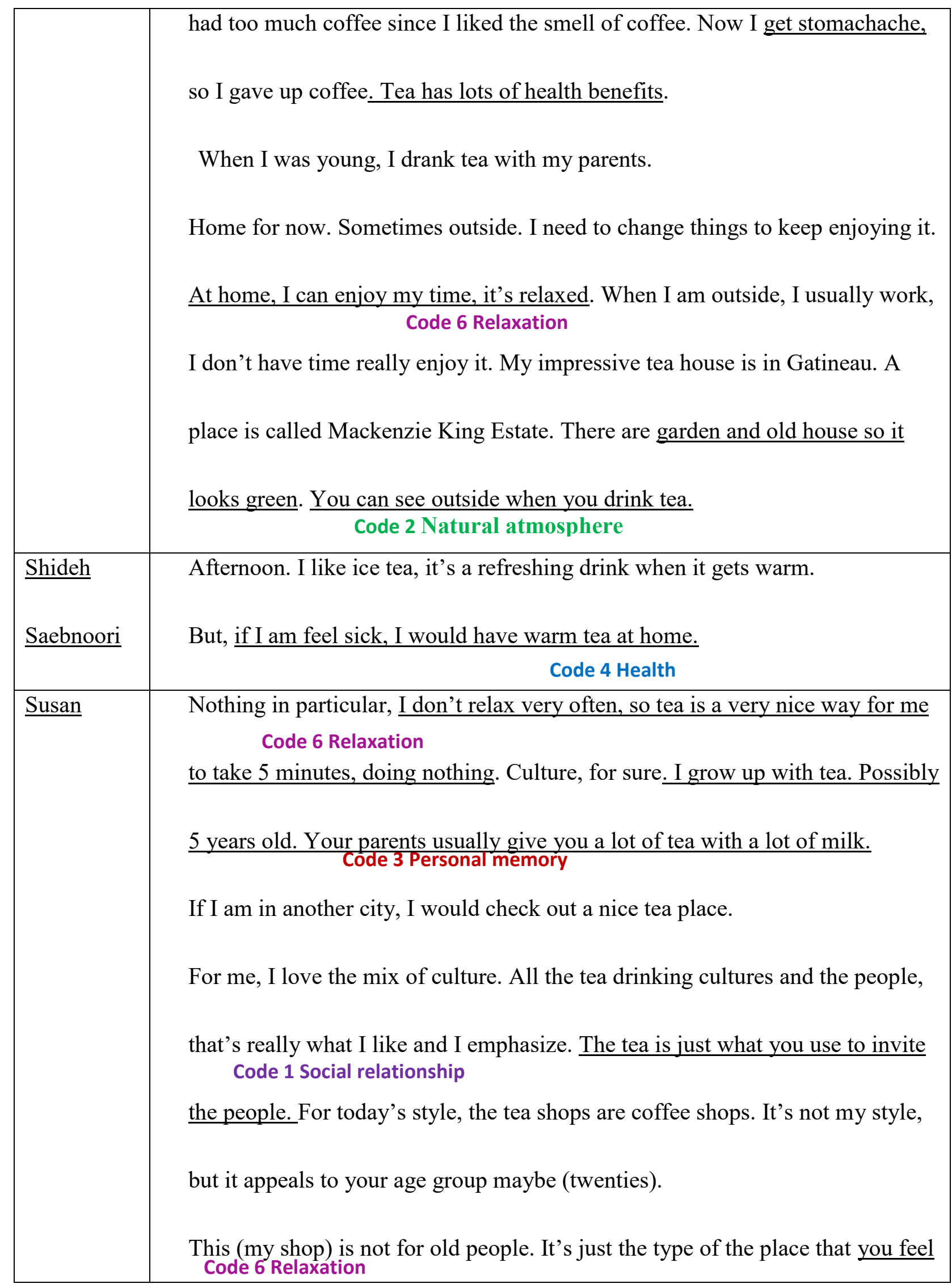




\begin{tabular}{|c|c|}
\hline & $\begin{array}{l}\text { comfortable in and it depends on culture, age. } \\
\text { I don't know why but there is also heath reports on the benefits of tea. This } \\
\text { promotes drinking tea as well. And the more it's available, the more people are } \\
\text { curious. Certainly, the typical tea drinking cultures, like Chinese, Japanese, } \\
\text { Indian, Russian, British, these are all tea drinking nations, whether you grow it } \\
\text { or import it, for generations and generations have drunk tea. Now it's visibly } \\
\text { available for everybody, so North American saying, hey, what's this? }\end{array}$ \\
\hline$\underline{\text { nicole }}$ & $\begin{array}{l}\text { Tea is healthier and doesn't taste strong. When I was over } 10 \text { years old. } \\
\text { Parents drink tea. Home is cozy, for you drink tea, you need to keep adding } \\
\text { Code } 8 \text { Availability \& Convenience } \\
\text { water, it's convenient to boil water at home and you can read when you drink } \\
\text { Code } 6 \text { Relaxation } \\
\text { tea at home. }\end{array}$ \\
\hline Zhiya & $\begin{array}{l}\text { I must use a whole tea set for drinking tea. In the morning, I have coffee with } \\
\text { Code } 5 \text { Ceremonial } \\
\text { breakfast, and have tea during the day. I drink tea like water, but if there has to } \\
\text { be an activity with tea, I would say copying Buddha scriptures sometimes. I } \\
\text { Code } 7 \text { Cultural sense } \\
\text { like coffee and tea both. But tea is a habit to me. Besides, tea has more flavors } \\
\text { than coffee, and tea is more unique. Different tea has different healthy benefits. } \\
\text { I was } 3-4 \text { years old. My parents drink tea. So it's kind of a family reason. In } \\
\text { addition, tea is a way how you live, like I said, copying scriptures can make } \\
\text { Code } 6 \text { Relaxation } \\
\text { you calm down. Tea also needs time to ferment, if you want good tea, you }\end{array}$ \\
\hline
\end{tabular}




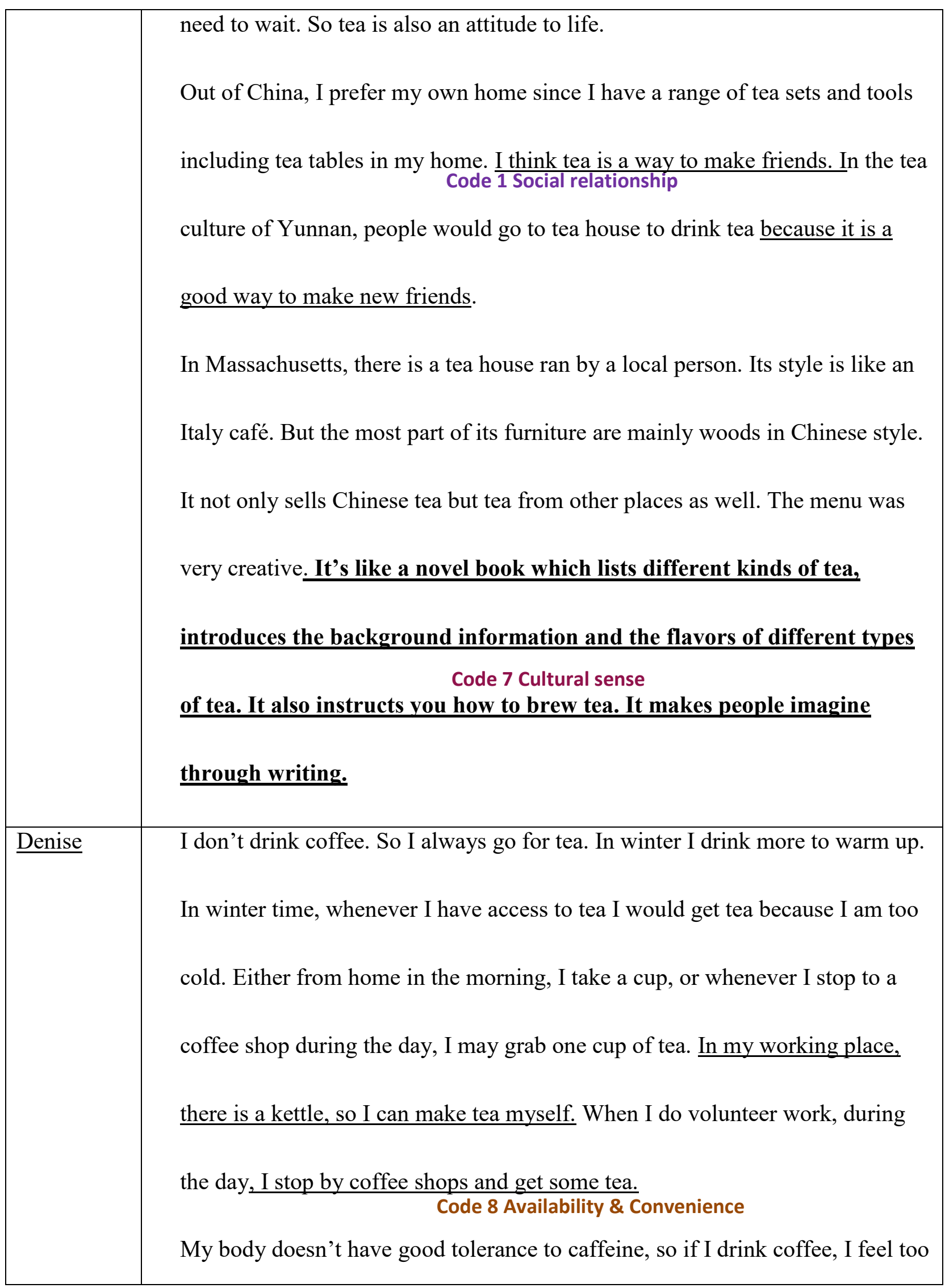




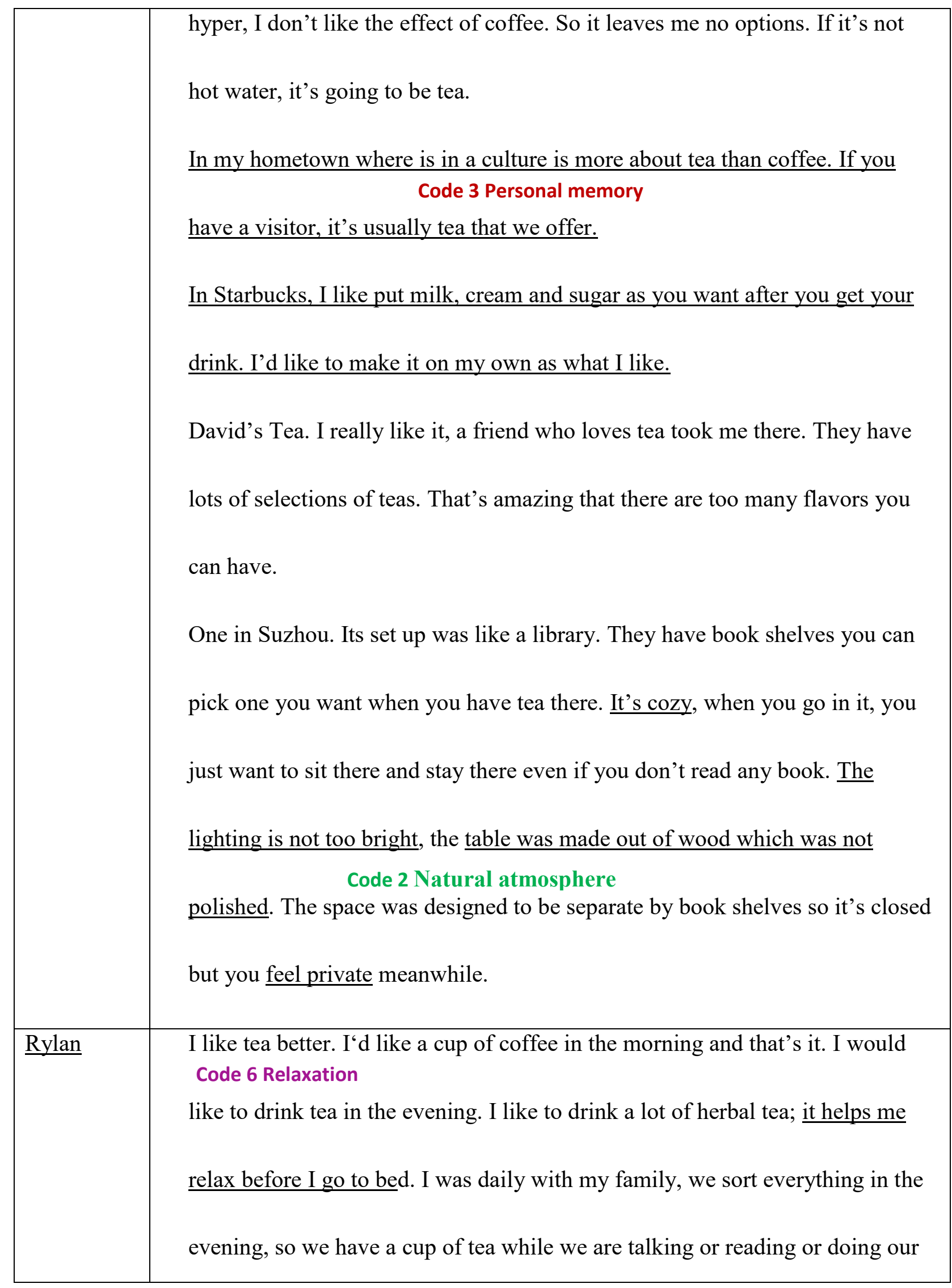


Cultural Product Design

\begin{tabular}{|c|c|}
\hline & own something separately. \\
\hline $\begin{array}{l}\text { Song } \\
\text { zheheng }\end{array}$ & $\begin{array}{l}\text { I mostly drink water. Sometimes I drink tea but I hardly have coffee. After I } \\
\text { get up I feel kind of cold (the weather in North America) and then I would } \\
\text { make a tea. It's comfortable to have something hot. } \\
\text { Code } 8 \text { Availability \& Convenience } \\
\text { I use tea bag, I don't make tea from tea leaves even though I brought tea } \\
\text { leaves from China because I think it's trouble and it seems I am an elder. But } \\
\text { tea bags may be the way of drinking tea among the young. After dinner, I used } \\
\text { to go to study room which is near a kitchen room. So I would make a tea in the } \\
\text { kitchen room and chatted for a while with friends there, and then went to study } \\
\text { room with my tea. } \\
\text { friends. }\end{array}$ \\
\hline $\begin{array}{l}\text { Christine } \\
\text { (the owner }\end{array}$ & $\begin{array}{l}\text { I drink coffee in the morning and like to have tea in the afternoon. } \\
\text { In the afternoon, tea is a comfort thing. Sometimes I feel stressful in my day, }\end{array}$ \\
\hline
\end{tabular}




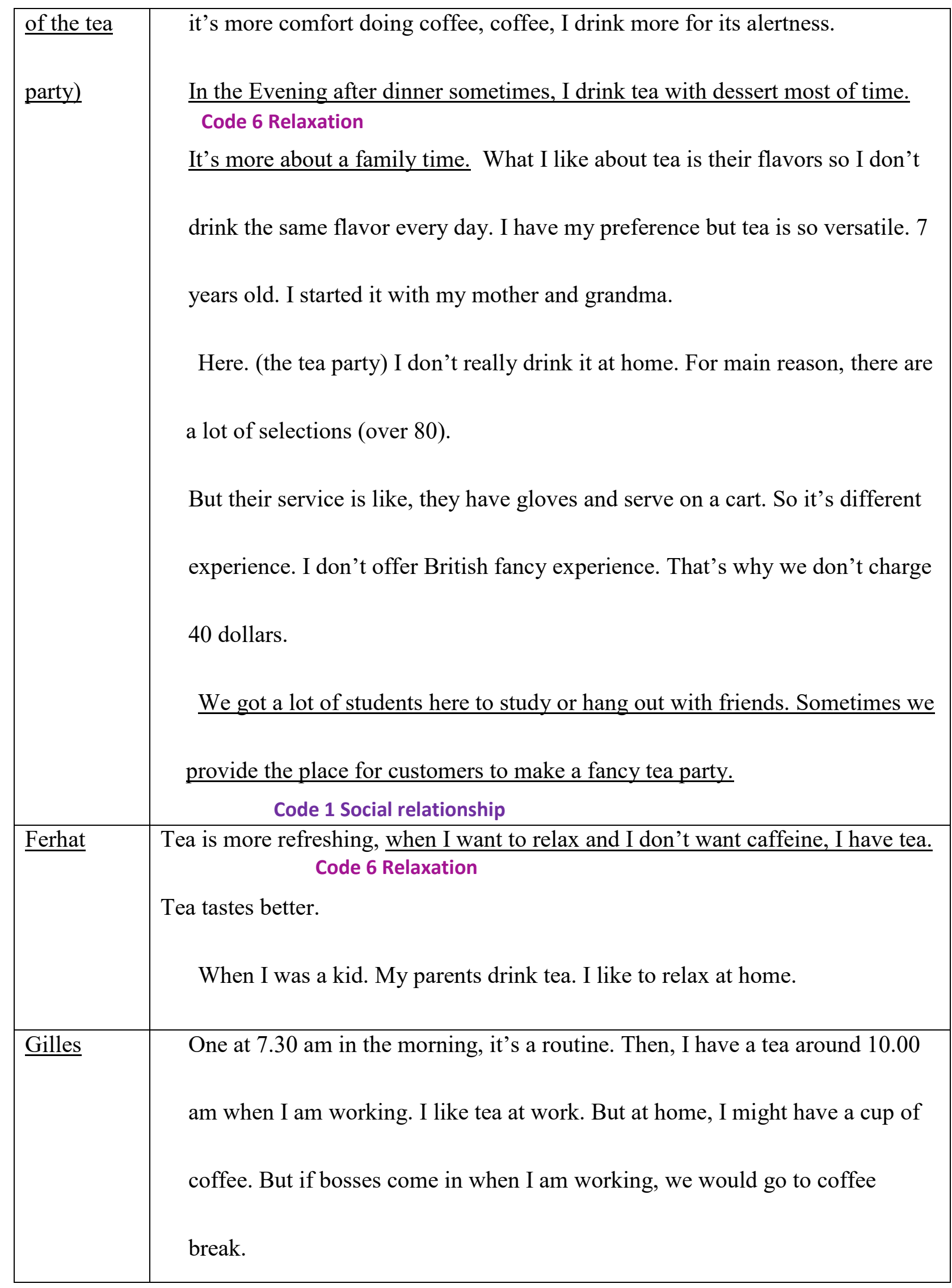




\begin{tabular}{|c|c|}
\hline & $\begin{array}{l}\text { It depends on my stomach. I prefer tea in the morning. } \\
\text { Code } 4 \text { Health } \\
\text { It also depends on how much work we have, if work is heavy, I go for tea. It it's } \\
\text { not, I go for coffee since I have time to go downstairs to the coffee shop and talk } \\
\text { with colleagues. } \\
\text { I usually drink tea on my desk when I am working. It's for my stomach. }\end{array}$ \\
\hline Greg Harris & $\begin{array}{l}\text { I mean as far as the family environment that I grew up, tea has been part of our } \\
\text { diet. I drink coffee in the morning; I drink tea in the evening. In summer, I } \\
\text { have ice tea once a week. But in winter, I will have more tea; I may go up to } 2 \\
\text { Code } 1 \text { Social relationship } \\
\text { cups a day. Sometimes in social setting, you want warm drinking, I would go } \\
\text { for tea. I drink both, but too much coffee cause stomachache. Tea is easier. I } \\
\text { Code } 4 \text { Health } \\
\text { don't want too much coffee so tea is my second choice. } 40 \text { years ago. It started } \\
\text { in a family meal setting. My families serve tea but when I was a child they } \\
\text { didn't give me tea. So it was introduced by my families. I don't go out for tea. } \\
\text { Culturally for me, going out for a drink usually involves alcohol like beer. We } \\
\text { always have tea at home. Or occasionally have tea at the restaurant after } \\
\text { dinner. }\end{array}$ \\
\hline Jimmy & $\begin{array}{l}\text { In the morning. I almost have one coffee every morning during weekdays, so } \\
\text { on the weekends, I don't drink coffee, I choose tea instead since I don't want } \\
\text { too much caffeine. }\end{array}$ \\
\hline
\end{tabular}




\begin{tabular}{|c|c|}
\hline & $\begin{array}{l}\text { Watching TV or stay in the back yard if it's nice outside. } 5 \text { years ago. My } \\
\text { Code } 6 \text { Relaxation } \\
\text { parents told me that tea can help digest. } \\
\text { Code } 4 \text { Health } \\
\text { HOME IS accessible. It's relaxing. } \\
\text { Code } 8 \text { Availability \& Convenience }\end{array}$ \\
\hline Linda & $\begin{array}{l}1 \text { at lunch, } 1 \text { in the afternoon and } 1 \text { at the supper. At noon and evening, it's just } \\
\text { Code } 6 \text { Relaxation } \\
\text { with meal, in the afternoon, it's a break. } \\
\text { The first time I drank tea I remembered I tried the Oreo cookies dip in the tea } \\
\text { as my friends suggested, that's good. No favorite place. Sometimes in my } \\
\text { house, sometimes in my friend's house, but most of time we go to Tims. } \\
\text { Code } 1 \text { Social relationship }\end{array}$ \\
\hline Sahil & $\begin{array}{l}\text { I drink coffee on weekdays in the morning. On weekends, I don't drink coffee } \\
\text { sometimes. It depends on moods. I drink between tea and hot water. I drink a lot } \\
\text { of hot water, if I get bored to one, I change another one. } \\
20 \text { years old. I took a nutrition class in } 2013 \text { and it encouraged me to diversify my } \\
\text { Code } 4 \text { Health } \\
\text { beverages. Then I stop sugar juice and started to drink coffee and tea more. } \\
\text { HOME. When I drink tea at home, I do nothing. } \\
\text { A tea house in Istanbul in Turkey. Their service was friendly. The quality of } \\
\text { beverages was good. They gave samples, talked about history. The ambience } \\
\text { there was Turkish traditional with Turkish music. } \\
\text { Code } 7 \text { Cultural sense }\end{array}$ \\
\hline Charles & $\begin{array}{l}\text { At night. I usually drink it when I am watching TV or something. } \\
\text { Code } 6 \text { Relaxation } \\
\text { I want something hot or I just don't want water and juice, so I drink tea. }\end{array}$ \\
\hline
\end{tabular}




\begin{tabular}{|c|c|}
\hline & $\begin{array}{l}\text { I use both tea bag and leaves. It depends on what the tea is. I bought tea bag in } \\
\text { grocery stores. I got tea leaves from special stores like Chinese stores or } \\
\text { Korean stores. } \\
\text { Only HOME for tea. }\end{array}$ \\
\hline Daniel & $\begin{array}{l}\text { I drink tea more in the evening after dinner to Relax. } \\
\text { Code } 6 \text { Relaxation } \\
\text { I like tea's flavors, it has not much caffeine and doesn't give me stomachache. } \\
\text { Tea is not every da } 4 \text { drink, if I have time at home with my friends or girlfriend, } \\
\qquad \text { Code } 1 \text { Social relationship } \\
\text { we would have tea. It's a social drink. } \\
\text { 10-11 years old. It was my grandmother who gave me some tea. } \\
\text { Code } 3 \text { Personal memory }\end{array}$ \\
\hline Joelle & $\begin{array}{l}\text { At work in the morning, } 10.00-10.30 \text {. And when I go back to home I need a } \\
\text { Code } 6 \text { Relaxation } \\
\text { drink so I drink tea ( } 5.30 \mathrm{pm}) \text {. It's a break time for relaxing. } \\
\text { In the winter I would have more tea, it's comforting. Tea is comforting and } \\
\text { relaxing. In Montreal, where I live was near some Chinese stores, I tried ginger } \\
\text { Code } 8 \text { Availability \& Convenience } \\
\text { tea and I found it so good. } \\
\text { My home. I feel security at home. } \\
\text { Going to tea house to kill time with friends, it's social time. } \\
\text { Code } 1 \text { Social relationship }\end{array}$ \\
\hline Marie & $\begin{array}{l}\text { Afternoon. Maybe sometimes in the evening I have herbal tea as I prefer the } \\
\text { drinks without caffeine. Since I have coffee in the morning so I have tea in the } \\
\text { afternoon to make a change. }\end{array}$ \\
\hline
\end{tabular}




\begin{tabular}{|c|c|}
\hline & $\begin{array}{l}\text { My friends introduced tea to me. Sometimes at home. At fancy restaurant, I } \\
\text { would like tea after a meal. } \\
\text { Code } 6 \text { Relaxation } \\
\text { I meant that for me, it's not only about the tea but the whole experience so } \\
\text { the place should be nice and cozy. The furniture should be beautiful and the } \\
\text { colors chosen for the décor be appealing } \\
\qquad \text { Code } 2 \text { Natural atmosphere }\end{array}$ \\
\hline$\underline{\text { Sylvain }}$ & $\begin{array}{l}\text { In the evening, after supper, with dessert. I need something hot before going } \\
\text { Code } 6 \text { Relaxation } \\
\text { to bed. Mostly on weekends. } \\
10 \text { years ago. In chronological order I lived in Tunisia, Singapore and then } \\
\text { Kenya. I started to drink more tea in Africa (Tunisia) where it was very } \\
\text { Code } 3 \text { Personal memory } \\
\text { common. In Africa, I also drank tea more, but not as often as Asia. } \\
\text { I guess restaurant is a better setting to relax and get tea with deserts than at } \\
\text { Code } 1 \text { Social relationship } \\
\text { home where I don't take as much time to sit down and relax... with a young } \\
\text { family. }\end{array}$ \\
\hline Warren & $\begin{array}{l}\text { In the evening with dinner. My wife drinks tea. Generally I have tea unless } \\
\text { she has made it for me. I never buy it or make it myself. } \\
\text { Probably when I was in the university. I just tried it. Sometimes it was cold, I } \\
\text { Code } 6 \text { Relaxation } \\
\text { wanted something hot like tea or hot chocolate. }\end{array}$ \\
\hline Kathleen & Normally before supper, because I am getting old, dark tea doesn't help fall \\
\hline
\end{tabular}




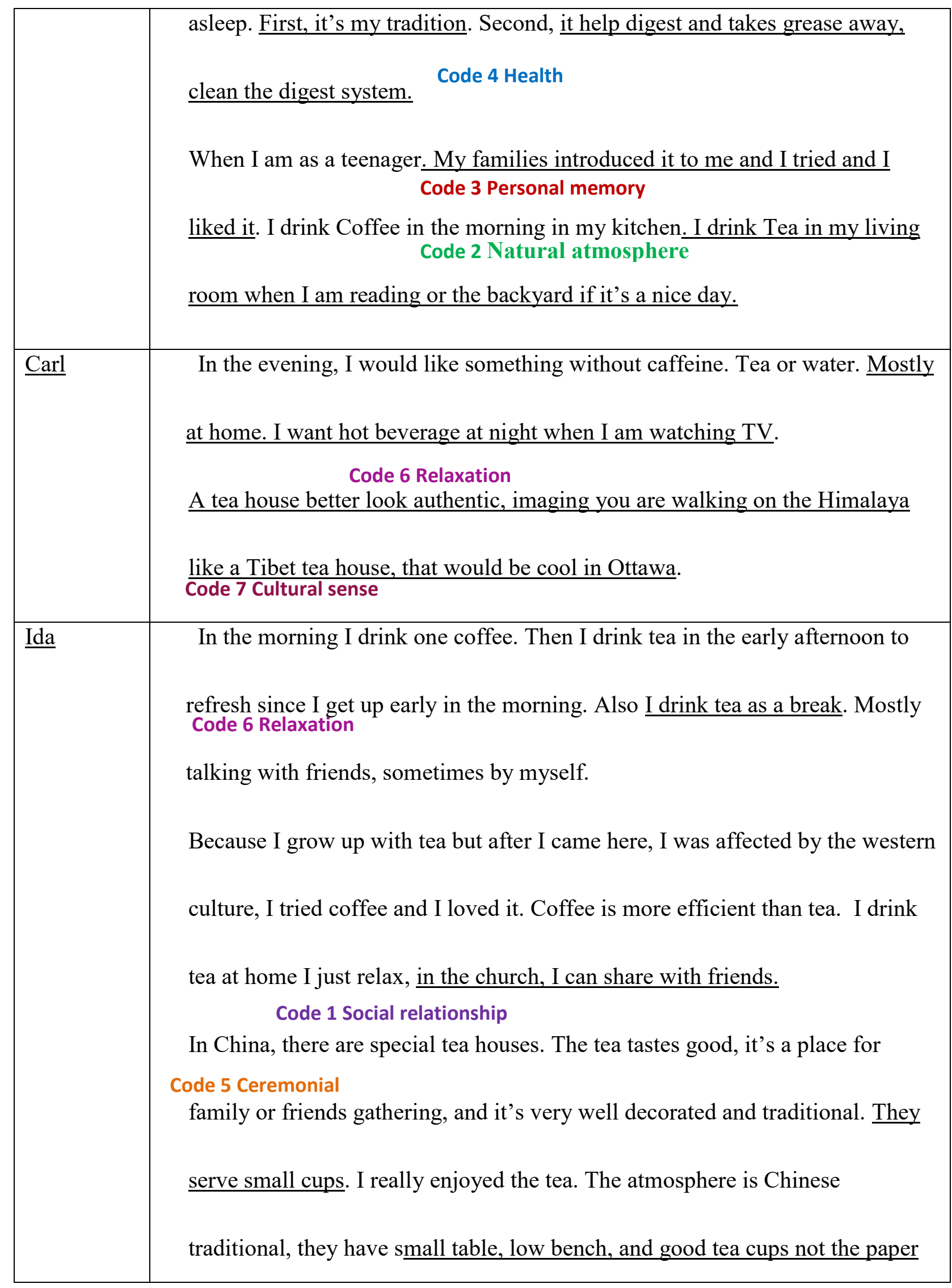




\begin{tabular}{|c|c|}
\hline & $\begin{array}{l}\text { cup. It looks old. Every teapot and tea has a story, people introduced you the } \\
\text { stories about how the tea were planted and why the teapot looked like this. Tea } \\
\underline{\text { has a lot of stories to tell. }}\end{array}$ \\
\hline Richard & $\begin{array}{l}\text { After a meal. It's refreshing and clearing my throat. It's also a relax time for } \\
\text { me. Tea's caffeine is not much. } \\
\text { code } 6 \text { Relaxation } \\
\text { Tea is for relaxing, coffee doesn't relax me. My father took me to tea house for } \\
\text { dim sum in HK. AT HOME, I brew my own tea. It's relaxing and quiet. I don't } \\
\text { like have tea in the public, it's too noisy. Like in tea house of dim sum. } \\
\text { I prefer a quiet place at home and I enjoy looking people passing by through } \\
\underline{\text { the window. }}\end{array}$ \\
\hline$\underline{\text { Shen Wei }}$ & $\begin{array}{l}\text { I never drink coffee. Tea is alkaline, coffee is acid. Tea is anti-cancer and } \\
\text { healthy. In the morning after I get up or early afternoon, but I never drink tea } \\
\text { in the evening because green tea has caffeine. } \\
\text { If I have friends visiting me, we will have tea using tea sets. When I am alone, } \\
\text { Code } 1 \text { Social relationship } \\
\text { I just use a mug. I don't use tea bags. Tea bags are inferior. } \\
\text { When I was young. Tea is a part of Chinese culture. The place is not important } \\
\text { but the quality of tea is vital. But I hang out with friends in tea house, we chat } \\
\text { together. }\end{array}$ \\
\hline Adrien & rink tea is a special group, I don't think there is much culture of tea. It \\
\hline
\end{tabular}




\begin{tabular}{|c|c|}
\hline & $\begin{array}{l}\text { depends on who you are. Maybe tea is an alternative to coffee. } \\
\text { I have more tea in cold seasons. In the summer, I don't often drink tea. I just } \\
\text { do anything at home with a hot drink. Sometimes after a meal, I have tea with } \\
\text { Code } 6 \text { Relaxation } \\
\text { desserts with families. But tea is not mainly for social events, it's just the hot } \\
\text { beverage with caffeine. I drink more coffee for the caffeine. But I drink tea } \\
\text { later in the afternoon or evening. }\end{array}$ \\
\hline Cloris & $\begin{array}{l}\text { I drink green tea, black tea and bubble tea. In the summer time I like ice } \\
\text { tea/fruity tea. For the breakfast, I make English tea with milk and sugar, or } \\
\text { sometimes at night. Usually after dinner, talking with friends. } \\
\text { Code } 1 \text { Social relationship } \\
\text { Before I was pregnant, I would make one pot when I worked at home. But if I } \\
\text { don't have time, I don't drink it. } \\
\text { I grow up with dim sum. In the winter, I like warm nice tea. } \\
\text { In the summer, I like cold drink. Tea is a nice alternative to water. } \\
\text { Code } 3 \text { Personal memory } \\
\text { As a kid, I went dim sum with mum. } \\
\text { Home. I buy a lot of tea at home and I have a big variety to choose, it's } \\
\text { Code } 8 \text { Availability \& Convenience } \\
\underline{\text { convenience. }}\end{array}$ \\
\hline Joyce & $\begin{array}{l}\text { I drink hot water, American ginseng tea (ginseng powder). I like leaf tea, } \\
\text { there is a whole variety, but I use tea bags for English tea. All day. I would use } \\
\text { a glass bottle if I am doing leaf, but I put tea bags in a mug. Every time I add }\end{array}$ \\
\hline
\end{tabular}




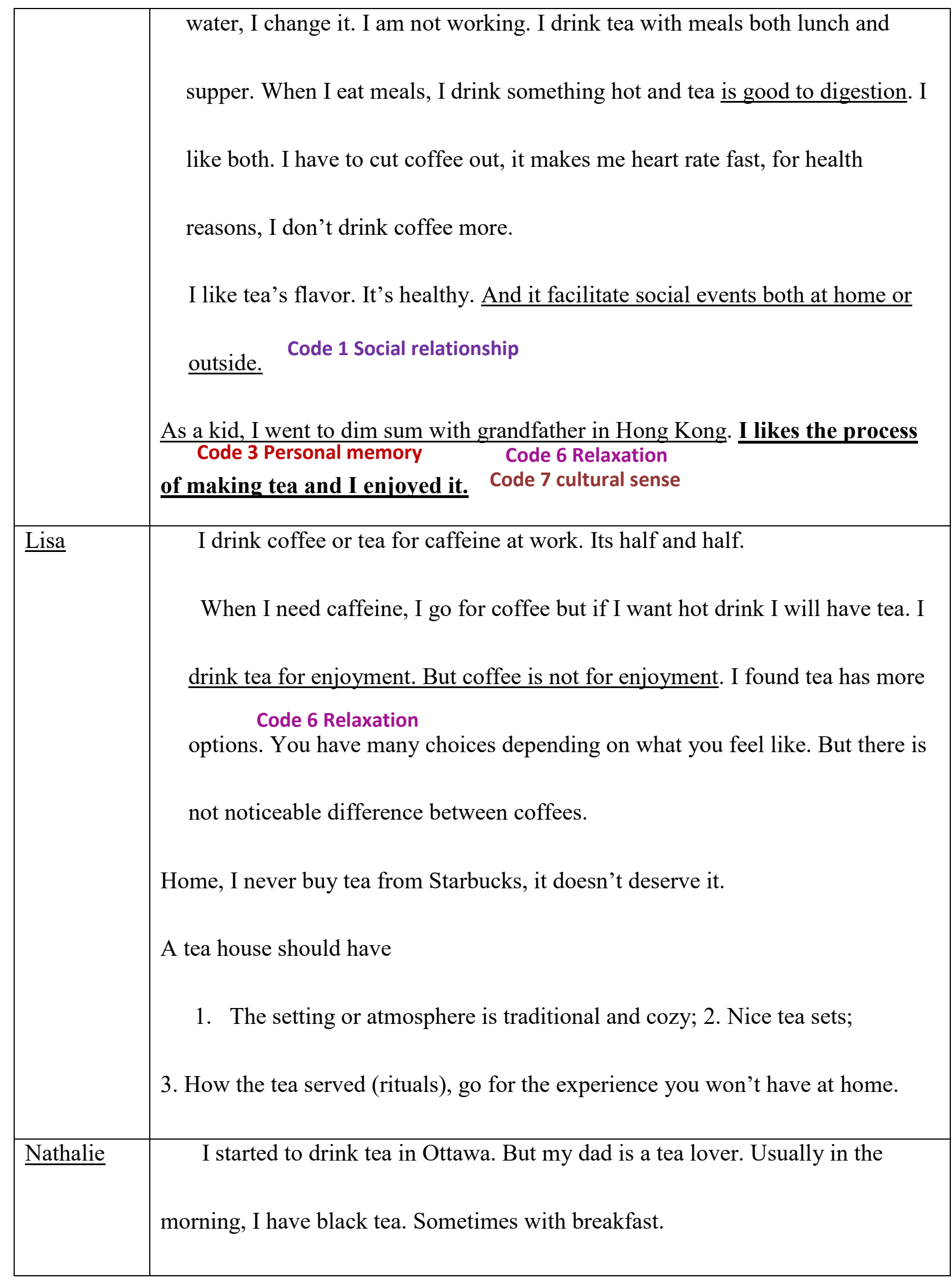


Cultural Product Design

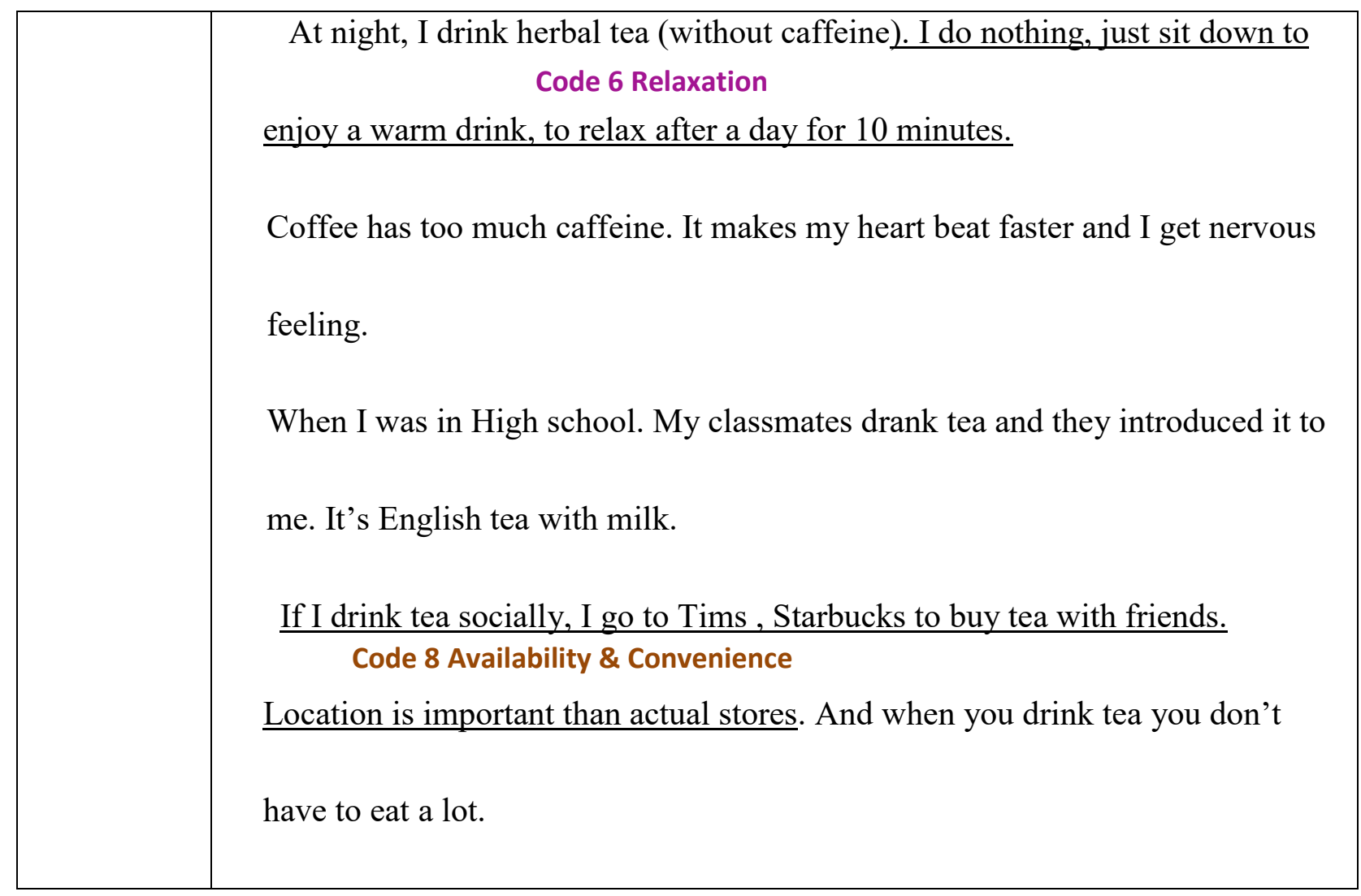

\section{Code 1 Social relationship}

Code 2 nature atmosphere

Code 3 Personal memory

Code 4 Health

Code 5 Ceremonial

Code 6 Relaxation

Code 7 Cultural sense

Code 8 Availability \& Convenience 


\section{References}

Batcho, \& Irene, K. (1995). Nostalgia: A Psychological Perspective. Perceptual and Motor Skills, pp. 131-143.

Benet-Martinez, V., \& Haritatos, J. (2005). Bicultural identity integration (BII): Components and psychosocial antecedents. ournal of Personality, pp. 1015-1050.

Bhaba, H. (2005). A Humanist Who Knows Corn Flakes. Harvard Magazine, pp. 64-65.

Bricki, N., \& Green, J. (2007). A guide to using qualitative research methodology. MSF Field Research.

Çakmakçığlu, B. A. (2017). Effect of Digital Age on the Transmission of Cultural Values in Product Design. The Design Journal, pp. S3824-S3836.

Celikoglu, O. M. (n.d.). lobal locality: A study on redesigned examples of Turkish traditional tea/coffee tray and tea glass. Design and semantics of form and movement, p. 154.

Chavan, Lahiri, A., Gorney, D., Prabhu, B., \& Arora, S. (2009). COVER STORY The washing machine that ate my sari---mistakes in cross-cultural design. interactions, pp. 26-31.

Chen, H. B., Yeh, S. S., \& Huan, T. C. (2014). Nostalgic emotion, experiential value, brand image, and consumption intentions of customers of nostalgic-themed restaurants. Journal of Business Research, pp. 354-360.

chindler, R. M., \& Holbrook, M. B. (2003). Nostalgia for early experience as a determinant of consumer preferences. Psychology and Marketing, pp. 275-302.

Cila, N., \& Hekkert, P. (2009). Product metaphors: A framework for metaphor generation and experience in products. Proceeding of International Association of Societies of Design Research (IASDR) 2009 Conference, (pp. 316-320).

Corbett, S. (2008). Can the Cellphone Help End Global Poverty? New York Times Magazine.

Craik, J. (1992). Resorting to tourism. Sydney: Routledge.

D, N. (2012, January 09). Does Culture Matter for Product Design? Retrieved 2018, from core77: www.core77.com/posts/21455/Does-Culture-Matter-for-Product-Design

Davis, F. (1979). Yearning for Yesterday: A Sociology of Nostalgia. New York: Free Press.

Dayton-Johnson, J. (2000). Determinants of collective action on the local commons: a model with evidence from Mexico. Journal of Development Economics, pp. 181-208.

Faber, R. J., O'Guinn, T. C., \& McCarty, J. A. (1987). Ethnicity, Acculturation and the Importance of Product Attributes. Psychology \& Marketing, pp. 121-134. 
Feng, W. D. (2017). Metonymy and visual representation: towards a social semiotic framework of visual metonymy. Visual Communication, pp. 441-466.

Forceville, C. (1996). Pictorial Metaphor in Advertising. London: Routledge.

G, C. (2004). Wondrous innocence. Printing advertising and the origins of permissive child rearing in the US. Journal of Consumer Culture, pp. 183-201.

Gorman, C. R. (2009). Religion on demand: Faith-based design. Design and Culture, pp. 9-22.

Granot, E., Alejandro, T. B., \& Russell, L. T. (n.d.). A socio-marketing analysis of the concept of cute and its consumer culture implications. Journal of Consumer Culture, pp. 66-87.

Hall, C. M., Mitchell, I., \& Keelan, N. (1991). Maori culture and heritage tourism in New Zealand. Journal of Cultural Geography, pp. 155-158.

Hekkert, P., \& Cila, N. (2009). Metaphorical communication and appreciation in product design. Manuscript in preparation.

Hey, J. L., Agogino, A. M., \& Wood, K. L. (2008). Analogies and metaphors in creative design. International Journal of Engineering Education, p. 283.

Immigration and Ethnocultural Diversity Highlight Tables. (2017, 11 01). Retrieved 8 22, 2018, from Statistics Canada: https://www12.statcan.gc.ca/census-recensement/2016/dp-pd/hltfst $/ \mathrm{imm} /$ Table.cfm?Lang $=\mathrm{E} \& \mathrm{~T}=21 \& \mathrm{Geo}=01 \& \mathrm{SP}=1 \& \mathrm{view}=2 \&$ age $=1 \& \mathrm{sex}=1$

Irimia, M. (2011). BEYOND CULTURAL BORDERS OF CLASSIC MODERN BRITISH CULTURE: THE CULTURAL INSTITUTIONS OF TEA, COFFEE AND CHOCOLATE AND THE LITERATURE. Yearbook of the'Gheorghe Sincai'Institute for Social Sciences \& the Humanities of the Romanian Academy.

Janke, T. (1997). Our culture, our future: Proposals for the recognition. Canberra: Australian Institute of Aboriginal and Torres Strait Islander.

Kesebir, S., \& Kesebir, P. (2017). A growing disconnection from nature is evident in cultural products. Perspectives on Psychological Science, pp. 258-269.

Kessous, A. (2015). Nostalgia and brands: a sweet rather than a bitter cultural evocation of the past. Journal of marketing management, pp. 1899-1923.

Ko, E., \& Lee, S. (2011). Cultural heritage fashion branding in Asia. Advances in Culture, Tourism and Hospitality Research, pp. 89-109.

Kotler, P. (1986). Global standardization - courting danger. Journal of Consumer Marketing, pp. 13-15.

Kumphai, P. (2006). Cultural products: Definition and website evaluation. Doctoral dissertation.

Lakoff, G., \& Johnson, M. (1980). Metaphors We Live By. Chicago: University of Chicago Press. 


\section{Cultural Product Design}

Lieber, R. J., \& Weisberg, R. E. (2002). Globalization, culture, and identities in crisis. Globalization, culture, and identities in crisis, pp. 273-296.

Lutgendorf, P. (2012). Making tea in India: Chai, capitalism, culture. Thesis Eleven, pp. 11-31.

Masuda, T., Gonzalez, R., Kwan, L., \& Nisbett, R. E. (2008). Culture and aesthetic preference: Comparing the attention to context of East Asians and Americans. Personality and Social Psychology Bulletin, pp. 1260-1275.

Mossakowski, K. N. (2003). Coping with perceived discrimination: Does ethnic identity protect mental health? Journal of health and social behavior, pp. 318-331.

Newitz, A. (n.d.). Why is everything so damn cute? The fluffy-bunny regime is getting ugly. San Francisco Bay Guardian, pp. 20-21.

Norman, D. (2005). Emotional Design: Why We Love (or Hate) Everyday Things. New York : Baker \& Taylor.

Phinney, J. S. (1991). Ethnic identity and self-esteem: A review and integration. Hispanic journal of behavioral sciences, pp. 193-208.

Rowan, Y., Baram, U., \& eds. (2004). Marketing heritage: Archaeology and the consumption of the past. Maryland: Rowman Altamira.

Scott, A. J. (2004). Cultural-products industries and urban economic development: prospects for growth and market contestation in global context. Urban affairs review, pp. 461-490.

Skjerven, A. (2012). Cultural traditions for the sake of innovation: The concept of Scandinavian design as a potential tool in the development of a sustainable China. Sustainable Development, pp. 230-238.

Swidler, A. (1986, April). Culture in Action: Symbo1s and Strategies. American Sociological Review, pp. 273-286.

Tea Association of the USA Inc. (2018-2019). Tea Fact Sheet. Retrieved from Tea Association of the USA Inc: http://www.teausa.com/14655/tea-fact-sheet

Tseng, Y. S., \& Ho, M. C. (2011, July). Designing the personalized nostalgic emotion value of a product. International Conference of Design, User Experience, and Usability (pp. 664672). Berlin, Heidelberg: Springer.

Urde, M. (2007). Corporate brands with a heritage. Brand Management, pp. 4-19.

V., B. V. (2006). Using thematic analysis in psychology. Qualitative research in psychology, pp. $77-101$.

Varley, H. P. (1989). ea in Japan: Essays on the history of Chanoyu. University of Hawaii Press. 


\section{Cultural Product Design}

Xue, H. (2017). On design and nostalgia: from the perspectives of culture, experience and design strategy. Aalto University.

Zeppel, H., \& Hall, C. M. (1991). Selling art and history: cultural heritage and tourism. Journal of Tourism Studies, pp. 29-45.

黄蔚. (2016). 对北京故宫艺术衍生品热卖的思考. 艺术科技, p. 139.

李和畅. (2006). 现代视觉传达设计中的中国传统意境创构. 艺术探索, pp. 81-82.

林楠, \& 张晓娜. (2015). 北京故宫博物院: 文创产品半年卖出 7 亿元. 支点, pp. 88-91.

张菁雅. (2016). 浅析文创产品的新媒体营销模式一以故宫淘宝为例. 新闻研究导刊, pp. 66-67.

张抒. (2007). 视觉传达设计意境论. 艺术百家, pp. 102-103. 
Cultural Product Design 